University of Nebraska - Lincoln

DigitalCommons@University of Nebraska - Lincoln

Papers from the University Studies series (The University of Nebraska)

3-1951

\title{
A CRITIQUE OF JEAN-PAUL SARTRE'S ONTOLOGY
}

Maurice Natanson

Follow this and additional works at: https://digitalcommons.unl.edu/univstudiespapers

Part of the Arts and Humanities Commons

This Article is brought to you for free and open access by the University Studies of the University of Nebraska at DigitalCommons@University of Nebraska - Lincoln. It has been accepted for inclusion in Papers from the University Studies series (The University of Nebraska) by an authorized administrator of DigitalCommons@University of Nebraska - Lincoln. 


\section{University of Nebraska Studies March 1951}

\section{A CRITIQUE OF \\ JEAN-PAUL SARTRE'S ONTOLOGY}

$\star \quad \star \quad \star$

MAURICE NATANSON

N E W S E R I E S N $\mathbf{N}$. 6

PUBLISHED BY THE UNIVERSITY AT LINGOLN, NEBRASKA 


\section{THE UNIVERSITY OF NEBRASKA}

\section{SENATE COMMITTEE \\ ON PUBLICATIONS OF UNIVERSITY STUDIES}

R. W. Goss, Chairman
E. N. ANDERSON
H. T. BATES
K. H. FREEMAN
R. W. Frantz
W. G. LEAVITT
F. A. LUNDY
H. L. WEAVER

\section{BOARD OF UNIVERSITY PUBLICATIONS}

R. V. Shumate, Chairman
K. O. BRoAdy
F. A. LuNDY
H. F. RHOADES
G. W. ROSENLOF
G. S. Round
L. C. WIMBERLY
Emily Schossberger, Secretary 


\section{O N T E N T S}

\section{PART I \\ EXPOSITION}

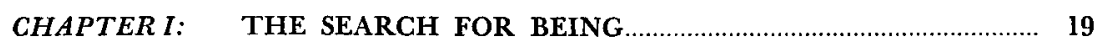

1. What is Being?

2. What is the Relation of Consciousness to Being?........................ 21

3. What is the Relation of Temporality to Being?........................... 23

4. What is the Relation of Nothingness to Being? ......................... 26

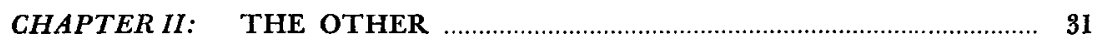

1. Three Theories of the Other..................................................... 31

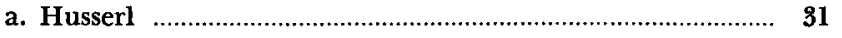

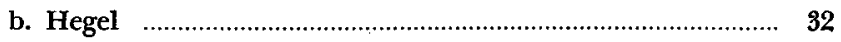

c. Heidegger …................................................................. 33

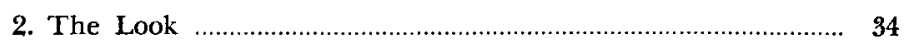

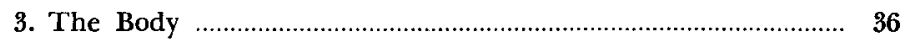

4. Attitudes Toward the Other:........................................................ 42

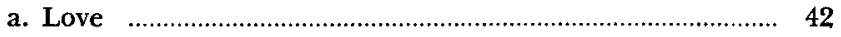

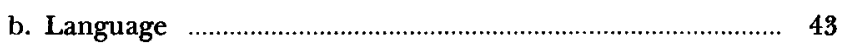

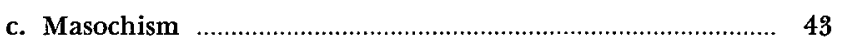

d. Indifference

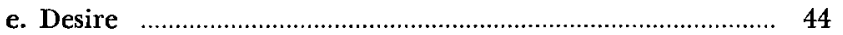

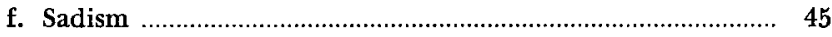

g. Hate ............................................................................ 46

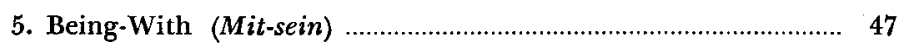

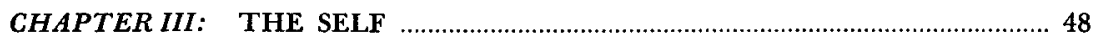

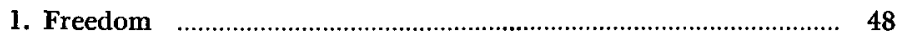

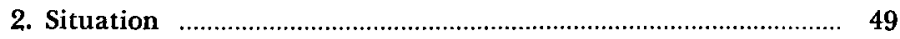

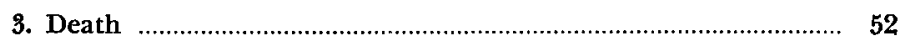


CHAPTER IV： EXISTENTIAL PSYCHOANALYSIS ….................................. 53

1. Existential Versus Freudian Psychoanalysis.................................... 53

2. Existential Psychoanalysis and Ontology.................................... 54

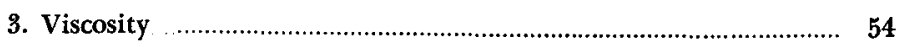

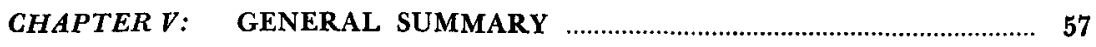

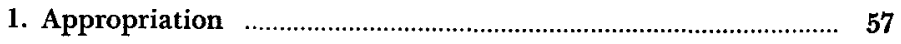

2. The Dualism of en-soi and pour-soi............................................. 60

3. Metaphysical Questions ……………................................................ $\quad 61$

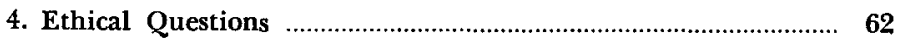

\section{PART II \\ EVALUATION}

CHAPTER VI: SARTRE'S PHENOMENOLOGICAL METHOD...................... 65

CHAPTER VII: THREE THESES OF L'ETRE ET LE NEANT CRITICIZED 75

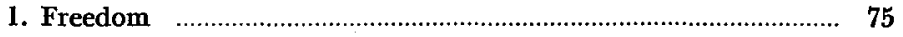

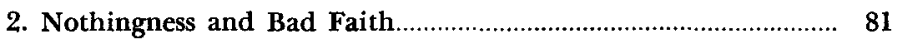

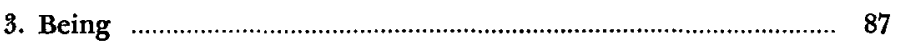

CHAPTER VIII: SARTRE'S "COPERNICAN REVOLUTION": AN INTERPRETATION …….......................................... 93

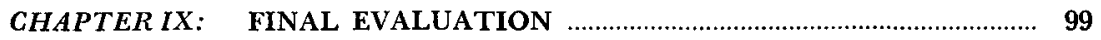

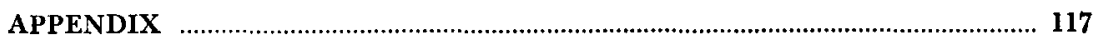

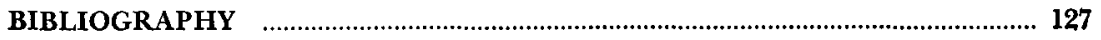


FOR

CHARLES AND KATE

LOIS AND CHARLES 


\section{ACKNOWLEDGMENT}

A number of persons have directly or indirectly aided me in achieving a greater degree of philosophic comprehension as well as in completing this work. The expression of my thanks to them is more than a formality.

I am indebted to Drs. Bouwsma, Patterson, Storer, and Waters-members of the Department of Philosophy of the University of Nebraska, 1948-1950.

Mr. John Chapman of the University Library has skillfully assuaged my bibliographical pains.

Dr. Boyd G. Carter of the University Department of Modern Languages has helped me with my numerous language problems.

Miss Emily Schossberger, Editor of the University of Nebraska Press, has aided me considerably in preparing my manuscript for publication.

Any note of thanks for the aid my wife, Lois Natanson, has given me would be inadequate for the expression of my appreciation.

I am happy, finally, to state my thanks and gratitude to Professor W. H. Werkmeister, who has devoted a great deal of his time to bringing this work to its most successful form, and whose persistent interest in my philosophic advancement and welfare has meant much to me. 


\title{
INTRODUCTION ${ }^{1}$
}

\author{
"Why is my pain perpetual, \\ and my wound incurable, \\ which refuseth to be healed?" \\ -Jeremiah
}

\begin{abstract}
"Existentialism" today refers to faddism, decadentism, morbidity, the "philosophy of the graveyard"; to words like fear, dread, anxiety, anguish, suffering, aloneness, death; to novelists such as Jean-Paul Sartre, Dostoievski, Camus, Kafka; to philosophers like Kierkegaard, Heidegger, Marcel, Jaspers, and Sartre-and because it refers to, and is concerned with, all of these ideas and persons, existentialism has lost any clearer meaning it may have originally possessed. Because it has so many definitions, it can no longer be defined. As Sartre writes:
\end{abstract}

"Most people who use the word existentialism would be embarrased if they had to explain it, since, now that the word is all the rage, even the work of a musician or painter is being called existentialist. A gossip columnist ... signs himself The Existentialist, so that by this time the word has been so stretched and has taken on so broad a meaning, that it no longer means anything at all." 2

This state of definitional confusion is not an accidental or negligible matter. An attempt will be made in this introduction to account for the confustion and to show why any definition of existentialism involves us in a tangle. First, however, it is necessary to state in a tentative and very general manner what points of view are here intended when reference is made to existentialism.

Sartre means by existentialism the doctrine "that existence precedes essence, or, if you prefer, that subjectivity must be the starting point." 3 We must begin with subjectivity, not simply because it is

${ }^{1}$ With minor changes this introduction appeared in the Winter, 1950, issue of The University of Kansas City Review.

2 Sartre, J-P., Existentialism, 14-15.

Ibid., 15. 
some sort of convenient starting point but because man has become problematic to himself, and self-consciously so. His problem is his own existence. The traditional categories of cognition are not only insufficient for a solution but are utterly inapplicable, for the problem is not one of cognition, certainly not one of cognition in the ordinary sense of the term.

Nietzsche exclaimed: "God is dead," and men are faced with the profound responsibility of deciding for themselves, choosing for themselves, acting for themselves, and being themselves; i.e., choosing authentic existence rather than "losing" themselves in the crowd, becoming a "non-entity," escaping reality. In this transvaluation of all values more is at stake than traditional Christianity. According to tradition a man could not only be saved but he could depend upon the state, count on his family, and similar institutions. The crisis of our age, however, of which the existentialist writers speak is the loss of faith in the absoluteness of Reason, of Science, and of Logic. Ours is the time of a-logicality. Man is burning between chance and despair, between hope and nothingness, between salvation and guilt.

Existentialism emerges as deeply felt concern with and for the concrete reality of the individual: it is his existence that is vital, and it is he who must define himself. It is no longer possible to lose oneself in the System or hope to reveal existence by analytic procedures used in the investigation of "life" or the "cosmos." The individual as such, in his unique subjectivity, in his personal existence, is at stake; and existentialism holds that the essence of a person may not be revealed by reference to an $a$ priori theory of man or any religious interpretation that speaks of man prior to and apart from his actual existence.

In view of this tentative definition of our subject matter, it is reasonable to ask about the history of this idea or complex of ideas referred to as existentialism; whether it represents a movement which has deep roots in the history of philosophy, or whether it began as a literary interest. It is possible to speak, if we wish, of an existential "attitude" and trace the origins of this attitude in past cultures. However, since the purpose of this work is not historical, the "tracings" that will be done will be rather casual and incomplete. We shall review the history and background of existentialism merely in an attempt to find a more adequate definition and to assign to it more properly its place in the general history of ideas. 
However, we are faced at once with a specific difficulty; for it is obvious that in some sense every philosopher, every man who has ever "philosophized," has been concerned with the problem of man's existence. It soon becomes meaningless, therefore, to search for historical antecedents of existentialism unless we restrict the meaning of the term "existentialist" to those philosophers or thinkers whose specific concern is the concrete subjectivity of man as it defines his actual and concrete existence. And even with this restriction of the term some names will have to be considered whose bearers are at best but doubtful "existentialists." 4

The reaction of Socrates against the Sophists was more than a rejection of rhetoric and fee-taking; it was the turning to a deeper respect for the problems of men. These problems concerning the Good Life, Justice, and so on were not simply artificial debates in which the victor was the "cleverer" who might take the opposite side the next day to exhibit his verbal dexterity. For Socrates, philosophy was a communion with persons, in the act of conversation recognizing their right to bring forth their ideas-to give birth to their potential ideachildren. These ideas, again, are not the issues of mathematics or physics, but rather the great ethical and social problems. There is an ambiguous attitude toward reason and its products: an acceptance of the validity of the rational process and a denial of purely rational problems. It is thus possible through dialectic to reason our way to an understanding of the human situation, but it is at the same time more vital to discuss that human situation than work out equations or puzzles in geometry. Socrates, the life of Socrates, is an affirmation of the untechnical and human in philosophy, and we shall see a little later that it is largely for this reason that Kierkegaard is so "taken" by Socrates. He is the antithesis of the "professor" that Kierkegaard railed against. But to summarize: Socrates asks, what would you rather have, a geometer's argument or a myth? He gives us myths that have as their orientation-point man's place in the market-square, the language of "shoemakers" and "shepherds," the specificity of the human condition.

We face in subsequent philosophy the fluctuations in valuation of the worth, importance, and primacy of the individual. From Descartes

\footnotetext{
- For a historical study of existentialism see Kurt Hoffman, Existential Philoso-
} phy: A Study of its Past and Present Forms. 
to Hegel we witness the decline of the centrality of the individual. If modern philosophy is roughly dated with the Cartesian philosophy, we may assert that until the period of the reactions against Descartes and Hegel which came with Pascal and Kierkegaard, the story of modern philosophy is the story of the loss of individuality, the languishing of existential subjectivity.

Descartes in his search for "clear and distinct" ideas ignored the immediate fact of human existence. The dualism of res extensa and res cogitens is founded essentially on a separation of man's essence from his existence, and Descartes never succeeded in welding the two together again, or in synthesizing them. The reaction of Pascal was to expose man as a feeling creature, a finite creature caught in the paradox of his search for the infinite, a creature that must believe his heart because his reason is inadequate. Consider some of Pascal's Pensées:

"Let us then take our compass; we are something, and we are not everything. The nature of our existence hides from us the knowledge of first beginnings which are born of the Nothing; and the littleness of our being conceals from us the sight of the Infinite." 5

"This is our true state; this is what makes us incapable of certain knowledge and of absolute ignorance. We sail within a vast sphere, ever drifting in uncertainty, driven from end to end. When we think to attach ourselves to any point and to fasten to it, it wavers and leaves us; and if we follow it, it eludes our grasp, slips past us, and vanishes for ever. Nothing stays for us. This is our natural condition, and yet most contrary to our inclination; we burn with desire to find solid ground and an ultimate sure foundation whereon to build a tower reaching to the Infinite. But our whole groundwork cracks, and the earth opens to abysses." 6

And, of course:

"The heart has its reasons, which reason does not know." 7

The brief protest of Pascal is swept up in the Hegelian Surge. The Hegelian System which promises everything, the All-inclusive System,

\footnotetext{
${ }^{5}$ Pascal, B., Pensées, 24-25.

- Ibid., 25.

'Ibid., 95.
} 
makes of the Pascalian heart a determined point in the process. A dialectical mechanism is constructed by Hegel. The unfolding of the Absolute promises to reveal the slightest incident, but in revealing a particle, a tiny happening, a single heart, it collapses the blown uniqueness of the person. Inwardness of the personality, the felt life is ruptured by a plan that engulfs the past, present, and future of man. Kierkegaard is Hegel's punishment.

The positing of "the self against the System" 8 rests on the belief that speculation (by which Kierkegaard meant the Hegelian philosophy) never reaches the Self but falls short of it. The exploration of the Self is the burden of Kierkegaardian existentialism. By the Self Kierkegaard means the "inwardness" of the individual, that unique aspect of each of us which seeks to synthesize infinity and finitude, temporality and eternity, freedom and necessity. The Self faces the problem of salvation, of its "fear and trembling" and its despair. As a theistic existentialist, Kierkegaard is concerned "to find out where the misunderstanding lies between speculation and Christianity." 9 The traditional and orthodox Christianity of his time is unacceptable to him. The ritual and pomp of the church have led away from the essential Christian problem: the individual Self. But the issue is clear for Kierkegaard: how is the Self to discover itself, to define itself, to found itself? Kierkegaard speaks of stages in life's way which lead from the undiscovered to the founded Self.

The first stage he calls the Aesthetic. At this level the individual leads the life of the crowd. He loses himself in a bundle of activities. $\mathrm{He}$ investigates the sensuous and sensual life. He faces everyone but himself. The road from outwardness to inwardness crosses next the Ethical Stage. Shocked from the aesthetic life, the individual finds himself suddenly without props, and he reels from the knowledge that what he has hitherto experienced is vain and illusory. He feels his loneliness and recognizes his life as "sickness unto death." The third or Religious Stage involves man directly with the issue of his relation to God. He recognizes in his fear and trembling that it is only a blind "leap to faith" through which he can reach God. There is no rational guidance in this dialectic toward God. An incomprehensible divine grace is active in its operation.

\footnotetext{
${ }^{8}$ Grene, M., Dreadful Freedom. "The Self Against the System" is the partial title of Ch. 2.

'Ibid., 15.
} 
The dualisms of Kierkegaard are those of finite man seeking an infinite God, yielding the strange paradox of the God-man; the attempt of a finite and imperfect reason striving to comprehend the infinite and incomprehensible, giving rise to the paradox of thought trying to think the unthinkable; and man seeking to synthesize the incompatible elements of his own ethic and God's law, which is the paradox of faith. The Bible story of Abraham and Isaac is to Kierkegaard the desperate essence of man's condition. The story is described in Kierkegaard's Fear and Trembling. Abraham is desirous of following the law of the community, the law of his people. He loves his son, yet he is requested by God to sacrifice his son. He must transcend man's law and obey God's. Also, in Isaac alone exists Abraham's promise of the future. If he kills Isaac, he slays as well the possibility of new generations. Isaac is his delight and he must yet choose God. Kierkegaard asks:

"Who gave strength to Abraham's arm? Who held his right hand up so that it did not fall limp at his side? He who gazes at this becomes paralyzed. Who gave strength to Abraham's soul, so that his eyes did not grow dim, so that he saw neither Isaac nor the ram? He who gazes at this becomes blind.-And yet rare enough perhaps is the man who becomes paralyzed and blind, still more one who worthily recounts what happened. We all know it-it was only a trial." 10

The necessity of God is the reflection of man's guilt, of his finitude. Marjorie Grene writes:

"Subjectivity can be truly subjective only in the confrontation
of the individual with God, since only the absolute is completely
indescribable beyond the inroads of abstraction and objectivity.
Only before God is a man really himself, because it is only before
God that he is finally and irretrievably alone. But before God
the finite individual is as nothing; and it is the bitter realization
of that nothingness that marks the religious stage of existence."11

The dialectic of Kierkegaard is integral to his philosophy. Here is the Self, but the Self in its contradictions and in its confusions and humors. Paradox is the booby-trap into which we plunge immediately upon reading Kierkegaard, just as Alice went down the rabbit hole. In

${ }^{10}$ Kierkegaard, S., Fear and Trembling, 28-29.

${ }^{11}$ Grene, M., op. cit., 37-38. 
Either/Or Kierkegaard contrasts the aesthetic with the ethical standpoint. In developing the description of the aesthetic life, he writes of the Seducer. The latter keeps an amazing diary recording the total history of a seduction: the most subtle shadings of emotion and interest and the torturous psychologies involved. The ethicist in the second part of Either/Or writes edifying letters to the aesthetician. The fantastic irony and humor of Kierkegaard lies in the very composition of such works. They are published under pseudonyms which are not seriously meant to fool anyone; they contain odd inner ironies, such as aestheticist-ethicist, but it is never certain that the letters are being written to whom it appears they are intended. One does not know for sure at any point whose side the laugh is on.

It is easily seen that in Kierkegaard we find the first authentic existentialist. His philosophy is directed toward a comprehension of individuality. It faces the human condition but is religiously founded and seeks to locate authentic existence for the Self by facing God and attempting to reach him. The dialectical quality, the irony of Kierkegaard are the strong irrationalism of the thinker. His writing is the testimony to the exhausted categories of Hegelian rationalism; and so it is to be expected that Kierkegaard understands man as a creature who cannot "prove" the existence of God via ontological arguments but leaps to him in an act of ultimate faith.

The strange combination of irrationalism, poetry, irony, and faith constitutes Kierkegaard's passionate paradox. It is a new kind of philosophizing, and yet it is as old as Socrates. We have thus come back to our starting point. It is now possible to determine what Kierkegaard found sympathetic in Socrates. The Socratic dialogue is really astounding: persons talk to persons, they don't rattle categories at each other; there is a simplification of attitude: the dialogue hopes to establish the meaning of Truth, Justice, and the Good. Imagine that these values could derive from a conversation! The astrologer Hegel would have to consult the Absolute!

Swenson once remarked that Kierkegaard never found his poet; but, surely, Kierkegaard found his novelist in Kafka. The piercing works of Kafka are a stubborn testimony to the effort of a writer to deal with the problem of man's guilt. The basic situation Kafka writes about may be seen in his novel, The Trial. The story begins: 
"Someone must have been telling lies about Joseph K., for without having done anything wrong he was arrested one fine morning." 12

K. has been accused. That morning two representatives of the law presented him formally with the accusation. The next step is to learn the details of the charge: of what exactly has he been accused? But to this question the reader finds no answer in the novel.

K. must of necessity find a lawyer to represent him in the courts, yet again the startling fact is that he is making preparations to defend himself against unrevealed charges. And this state of accusation is man's guilt: he must prepare his case before God, take it to the courts, appeal his case to higher authorities, make "deals" with advocates, appeal to hangers-on who pick up bits of information around the courts regarding his case; and he can never penetrate to the highest court, he can never know God, and he is to be condemned and destroyed!

Before his case began, $\mathrm{K}$. was an ordinary citizen, a bank worker, a person who rented quarters, a person who said "hello" to acquaintances, who went about his business. With the accusation K., in being summoned to defend himself in court, is stunned into awareness of himself and the pressing anxiety that accompanies his situation. Quickly he becomes the defendant. He realizes soon that his acquaintances are aware of his "case"-aware that he has been accused. Soon K. is isolated. He shuttles to and from his advocate's home. He engages in conversations only with those connected with his case. Another defendant with whom he speaks recalls the large number of people waiting perpetually in the anterooms and outer chambers of the courts.

" 'I saw all the people in the lobby,' remarked K., 'and thought how pointless it was for them to be hanging about.' 'It's not pointless at all,' said the traveller, 'the only pointless thing is to try taking independent action." "13

There is no "way" for the accused man. He must spend his existence in momentary conversations, blind alleys, fragments of dreams, desperate arguments with advocates and clerks, notes from the lower courts, summonses, and trivial adjudications; there is no withdrawal from one's case-it cannot be dropped. But if independent action is

${ }^{13}$ Ibid., 220-221. 
impossible, then K. faces the paradox and the absurdity of being forced to await an unforseeable decision while defending himself on an unknowable charge.

The conclusion of K.'s case is his assassination. There is no other possibility. If a man should stand face to face with an omnipotent diety, is it possible that he should observe anything but his finitude and, therefore, his guilt? The description of K.'s death is the magnificent synthesis of the issues of The Trial. At the death-place and moment K.'s

"glance fell on the top story of the house adjoining the quarry. With a flicker as of a light going up, the casements of a window there suddenly flew open; a human figure, faint and insubstantial at that distance and that height, leaned abruptly far forward and stretched both arms still farther. Who was it? A friend? A good man? Someone who sympathized? Someone who wanted to help? Was it one person only? Or were they all there? Was help at hand? Were there some arguments in his favour that had been overlooked? Of course there must be. Logic is doubtless unshakable, but it cannot withstand a man who wants to go on living. Where was the Judge whom he had never seen? Where was the High Court, to which he had never penetrated? He raised his hands and spread out all his fingers.

"But the hands of one of the partners were already at K.'s throat, while the other thrust the knife into his heart and turned it there twice. With failing eyes $K$. could still see the two of them, cheek leaning against cheek, immediately before his face, watching the final act. 'Like a dog!' he said; it was as if he meant the shame of it to outlive him." 14

Kafka's work is one expression of the existentialism of the literary genius; Dostoievski's writings are another. For in them we find equally powerful expression of the issues of salvation and human existence. In the novels of Sartre, however, we have the clearest case of a philosophic existentialist writing existentialist novels. In the literary work of all three writers the chain of thought started by Socrates, emphasized by Pascal, and stated with agonizing force by Kierkegaard, comes to artistic fruition. But at this point we shall turn to the more theoretical formulations of existentialism as they may be found in Sartre's popular lectures and articles.

${ }^{14}$ Ibid., 287-288. 
Sartre writes:

"When we say that man chooses his own self, we mean that every one of us does likewise; but we also mean by that that in making this choice he also chooses all men." 15

But if in each of our actions we choose an image of man, we are faced with the profound responsibility of accounting for that image; and anguish is the accompaniment of this responsibility.

"Every man ought to say to himself, "Am I really the kind of man who has the right to act in such a way that humanity might guide itself by my actions?' And if he does not say that to himself, he is masking his anguish." 16

If there is no a priori essence of man, then all human values are created in the acts of choice. It is no longer meaningful to speak of what we might have done in our lifetime if our dreams had come true. Our potentiality was precisely defined in the acts we performed.

"For the existentialist there is really no love other than one which manifests itself in a person's being in love. There is no genius other than one which is expressed in works of art; the genius of Proust is the sum of Proust's works; the genuis of Racine is his series of tragedies. Outside of that, there is nothing. Why say that Racine could have written another tragedy, when he didn't write it. A man is involved in life, leaves his impress on it, and outside of that there is nothing." 17

By the same criterion we cannot speak of a living person as a "coward" or a "failure" or a "hero" in the sense that this person has some inner quality that determines his cowardice or heroism. Cowards and heroes are cowardly or heroic simply in so far as they commit acts of cowardice or heroism. A man who has acted as a beast may definie himself as a human being of dignity if he acts with dignity. We are not condemned to being a failure, but also our past success is continually in the balance, for we must redefine that success as we go along.

\footnotetext{
${ }^{15}$ Sartre, J-P., Existentialism, 20.

${ }^{10}$ Ibid., 24.

${ }^{17}$ Ibid., 38-39.
} 
Existential choice is self-conscious choice. In any case, a choice occurs. If we actively determine it, so much the better; but if we remain passive, then we have chosen passivity-so much the worse! There is no escape from the responsibility of our choice: no one can choose for us.

But one might ask at this point why this philosophy has been termed decadent and morbid.

"The picture of the world drawn from Existentialist literature is not a rosy one. Some themes recur with a revealing insistence in their novels: nausea (physical and metaphysical), inordinate absorption of hard drinks 'à l'américaine,' homosexuality, abortion, even occasional scatology." 18

The themes dealt with are the themes of the crisis of our age. Men are bitterly aware of death-an horrific war has been fought. The sudden crises and challenges and betrayals of life during the occupation, the fantastic existence of the underground resistance movement; torture, capture, escape, starvation, the death of love-these were all as immediate as the daily newspaper and the cinema. Moreover, there is on the part of authors like Céline and Henry Miller an awareness which Sartre and the existentialists share-the awareness of a vast ennui, the stifling mud of pretense and bureaucracy that stuffs the streets, the crafty doings of the merchants, the disordered, running social cancer of lives that are groping toward a litle freedom. Within this struggle Sartre, in his novels, addresses the actors and points to a kind of freedom which carries with it the awfulness and trembling of uncertainity when everything is at stake. The actors cannot turn to God and they cannot turn to the psychologists; they must choose themselves and construct from the tissue of their own actions the structure of their existence.

It seems that we have reached the logical point for a reconsideration of the tentative definition of existentialism given at the outset of this study. That early definition was derived from Sartre; and it is now clear, I believe, in what sense Sartre intended it. We must now ask: Is this what existentialism is? Have we cut to the heart of the doctrine? Let us proceed cautiously in the investigation at this point.

${ }^{18}$ Peyre, H., "Existentialism-A Literature of Despair?", Yale French Studies, Spring: Summer (1948), 23. 
It is not difficult to observe that there are definite levels of interest and attitude in the literary and philosophic works we have thus far considered. At the literary level we have existentialism discussed or used to explicate the condition of man, to examine his suffering and aloneness and guilt. Writers such as Kafka, Dostoievski, to some extent even Sartre, are shrewd and revealing psychologists as well as literary masters. If we are concerned with descriptions of people, of characters, in specific situations, then few descriptions surpass those of Dostoievski. But such descriptions are literature and not philosophy. They do not concern us here. We turn instead to the philosophical level of existentialism.

Let us leave Kierkegaard in a class by himself. Kierkegaard's problems are those of man's guilt, of his position before God, and of his "fear and trembling" in his finitude. The definition of existentialism as the doctrine of "existence being prior to essence" seems hardly adequate for such a position. To speak of existence and essence in such a stilted style is almost anti-Kierkegaardian in spirit. It smacks of the systematizers, the professors and Privatdozenten. If we omit further consideration of Kierkegaard, we are left at the philosophical level with thinkers such as Heidegger, Jaspers, Marcel, and Sartre. Of these men we select Sartre for further study.

It is imperative to recognize several levels of existentialist thought even in Sartre. His novels and popular lectures comprise one level; his technical ontology occupies a different one. The basic confusions and misinterpretations of Sartre's thought are largely due to the confounding of these levels. The novels and lectures are concerned with employing and expositing certain highly technical theories of man's Being: of his human situation and his problems of choice. But the philosophic meaning of such concepts as "situation," "choice," "responsibility," and "anguish" cannot be understood unless they are examined in their proper technical context-as they are developed in Sartre's L'Être et le Néant. To comprehend fully the meaning and import of Sartrean existentialism, therefore, we must turn to the background, development, and structure of his ontology, his philosophy of man's Being.

Sartre's philosophy is indebted to the projected ontology of Martin Heidegger. Sartre is Heidegger's best-known follower, and much may be learned about Sartre's existential philosophy by turning briefly to Heidegger's problem. 
Heidegger returned in philosophy to the old Aristotelian problem of Being. He is concerned with knowing the nature of Being as Being. The point is clearly stated by Wahl:

"Heidegger has declared that he is not a philosopher of existence, but a philosopher of Being, and that his eventual aim is ontological. Heidegger considers the problem of existence solely to introduce us to ontology, because the only form of Being with which we are truly in contact (according to Heidegger) is the being of man." 19

Sartre, too, commences with the problem of Being. His main philosophic work, Being and Nothingness, is subtitled "Essay in Phenomenological Ontology." However, the problem of Being for Sartre is not simply a continuation of Heidegger's Sein und Zeit, but the attempt to develop an original ontology. For Sartre, the approach to Being turns as much for help to the phenomenology of Husserl and Hegel as to Heidegger. These thinkers have had a profound influence upon Sartre. As Wahl points out, the influence of Husserl in particular leads Sartre "into a kind of idealism which may not be completely consonant with the elements he may have derived from Heidegger." 20 Sartre's interpretation of Being as en-soi (in-itself) and as the pour-soi (for-itself) betrays the dual tendencies in his thinking; for the en-soi corresponds to the realistic element whereas the pour-soi corresponds to the idealistic aspect. ${ }^{21}$

For Husserl phenomenology had as its prime purpose the attempt to describe and clarify the content of experience by way of the acts of experiencing. In Heidegger the totality of the acts of the individual determine the individual, and by knowing the former we may know reality. It may be seen, then, that Sartre is in this tradition and is attempting to cut across the traditional positions of idealism and realism in founding a radically new ontology. He is attempting to determine if phenomenology is competent to resolve the problems of ontology.

${ }^{19}$ Wahl, J., A Short History of Existentialism, 11; also see W. H. Werkmeister, "An Introduction to Heidegger's Existential Philosophy," Philosophy and Phenomenological Research, II (1941-2).

${ }^{20}$ Wahl, J., op. cit., 28.

${ }^{21}$ Throughout this work the terms "pour-soi" and "en-soi" will be used, rather than their English equivalents "for-itself" and "in-itself." 
Historically, the Kantian philosophy is the starting point in investigating the phenomenological-existential problem. Varet writes:

"The failure of the Kantian critique begins with the idea that the theory of the understanding can be developed independently, without an ontology." 22

For Sartre the question is: Does phenomenology have the inner capacity to expand into an ontology? Sartre's task, therefore, is to determine whether phenomenology can be developed into what Husserl never made of it, namely, a general philosophy. Sartre may then be placed in the Kantian tradition in this sense:

"In the critical idea, every question about being calls forth the examination of the conditions for knowing it. ... Thus in Heidegger and in Sartre every philosophic question has the property-it is the very essence of a philosophic question- of going back to the possibles of that question. In this precise sense every conscious existentialist, phenomenologist or not, Sartre in particular, is largely a tributary of the Kantian 'revolution,' which is indeed one of the fundamental acquisitions of modern philosophy. This must be henceforth the distinctive character of every philosophy, to include in its own problem the philosophic enterprise in its totality, and therefore the philosopher himself." 23

But Sartre faces an even deeper problem in respect to Kant: the issue, namely, of the phenomenon-noumenon dualism. Sartre's two aspects of Being are not parallels to the Kantian dualism, but they nevertheless have been derived only by facing the same issues. Phenomenology goes beyond the Kantian dualism, but it is still possible to ask whether phenomenology is a generalized Kantianism.

If one were now to ask, What is existentialism for Sartre?, the answer would have to be: An ontology which seeks to determine the nature of Being via an investigation of man's Being, thus indebting itself to Heidegger, and which also seeks to determine the complete expression of phenomenology, thus indebting itself to Husserl and Hegel. Ultimately questions of man's choice-situation and his anguish, etc., will come into the picture-but only as derivatives of an

\footnotetext{
${ }^{22}$ Varet, G., L'Ontologie de Sartre, 17.

${ }^{23}$ Ibid., 15.
} 
ontology, involving only peripheral issues. Varet, therefore, is right when he says that "for Sartre the point of departure is not human reality, or existence, or bad faith, or atheism." 24

Sartre's problem is one of technical philosophy and not of literature or quasi-philosophy. One may talk or write as much as one pleases about Sartre's plays and novels and popular lectures-about human responsibility and the choosing of oneself-and not even come close to the real core of his existentialism. This, of course, is disappointing news for those who considered themselves experts on "existentialism." But did not Sartre himself warn us when he wrote of existentialism:

"Actually, it is the least scandalous, the most austere of doctrines. It is intended strictly for specialists and philosophers." 25

In the preceding pages several levels of "existentialism" have been indicated, and only one of these, existentialism as ontology, is the genuine philosophical meaning of the term. A sustained, comprehensive, and critical investigation of Sartre's ontology is the raison d'être of this work, which is intended to unquote "existentialism" by considering it as technical ontology.

24 Varet, op. cit., 2.

${ }^{25}$ Sartre, op.cit., 15. 


\section{PART I \\ Exposition}




\section{Chapter I}

\section{THE SEARCH FOR BEING}

"The concept of 'Being' is the' most universal one, as was also realized by Aristotle, Thomas and Hegel; and its universality goes beyond that of any 'genus.' At the same time it is obscure and indefinable; 'Being' cannot be comprehended as anything that is. ... It cannot be deduced from any higher concepts and it cannot be represented by any lower ones; 'Being' is not something like a being, a stone, a plant, a table, a man. Yet 'Being' seems somehow an evident concept. We make use of it in all knowledge, in all our statements, in all our behavior towards anything that ' $i s$,' in our attitude towards ourselves. We are used to living in an 'understanding of Being' . . . but hand in hand with it goes the incomprehensibility of what is meant by 'Be. ing." "'

-Werner Brock

Before beginning our exposition of Sartre's L'Être et le Néant, it is necessary to forewarn the reader that both the style and the content of Sartre's main work offer a serious problem in any attempt to present lucidly his ideas and intentions or to translate his language into intelligible English. It is impossible to convey to anyone who has not read L'Être et le Néant the involved and often tangled line of Sartre's argument and the horrifying quality of the prose which is intended to convey the author's ideas. In addition to seemingly endless sentences and ambiguous repetitions, the author uses words that do not appear in any dictionary. Sartre invents a new terminology to meet the requirements of the radical ontology he presents. Thus, nouns are used as verbs, and new grammatical constructions are invented to meet the author's needs. What emerges from this strange new language is an ontological structure of Gargantuan length and complexity. We must beg the reader's indulgence in the following pages and hope that he will realize that much of the difficulty of the exposi- 
tion is necessitated by the nature of the material presented. In many cases it is simply impossible to render the argument in simpler language without danger of doing violence to the meaning Sartre intends to convey to his reader. There has not been a single critic who has written on Sartre's ontology, to our knowledge, who has not commented on the obscurity and complexity of L'Être et le Néant. ${ }^{1}$ The reader of this work, therefore, who may be only slightly acquainted with Sartre's philosophy, should realize that he is not alone in despairing over these involved arguments and this sometimes fantastic terminology. We hope that our pains in attempting to make this exposition as clear as possible will result in confining the reader's despair to an unavoidable minimum.

To commence our exposition, we may say that "The Search for Being" is a clue to the essential problem with which Sartre is concerned in his attempt to formulate a new ontology. In some sense, the problem of Being has engaged every philosopher and philosophic system under various titles: phenomenon-noumenon, permanence-change, appearance-reality are a few examples. The "Search for Being" may be characterized by a series of questions which Sartre raises throughout L'Être et le Néant-such questions as these:

\section{What is Being?}

2. What is the relation of consciousness to Being?

3. What is the relation of temporality to Being?

4. What is the relation of Nothingness to Being?

The answers to these questions involve, in turn, still further questions which we shall ask as we go along. We are here concerned with a clarification of the questions stated.

\footnotetext{
${ }^{1}$ For example: "It is practically certain that one could count on the fingers of one hand those who have had the patience to read every line of L'Etre et le Néant, and fewer still is the number of those who can in all honesty claim that they have always understood it,"-Foulquié, P., Existentialism, 41. Also, L'Étre et le Néant is described as "exceedingly long, over 700 large and closely printed pages, always difficult and often obscure."-Ayer, A. J., "Novelist-Philosophers: V-Jean-Paul Sartre," Horizon, Vol. XII, No. 67 (1945), 12.
} 


\section{WHAT IS BEING?}

In the attempt to penetrate to the "heart" of Being, Sartre first considers the answers modern thought has given to the problem of Being. He examines and discards a series of historical dualisms. Sartre throws out as inadequate the dualisms of interior-exterior, appearance-being, potency-act, appearance-essence, and, finally, phenomenon-noumenon.

For Sartre, a preliminary definition of Being is, in a sense, impossible; at least, its possibility would involve us either in paradoxes or in an infinite regress. If we mean by 'definition,' in part, a listing of predicates which describe the object, then such a listing cannot be attempted so far as Being is concerned; for, as we shall show later, the ascription of any predicate involves us in the problem of the being of the predicate ascribed. We should thus have to define the being of the being of the predicate, and the being of the being of that being, ad infinitum. For Sartre, the phenomenological method provides an approach to the nature of Being.

Taken in its most fundamental sense, phenomenology is a direct "looking upon" or inspection of the givens of sensory experience. Such inspection confronts us, first of all, with "appearances." These appearances are-in the sense, namely, that we are presented with them. They would not be appearances unless they appeared. But if these appearances are, then, according to Sartre, we have located Being; for appearance is Being. Thus, if appearance is, "Being is." The object in appearance is; and "that is the sole manner of defining its way of Being." 2

\section{WHAT IS THE RELATION OF CONSCIOUSNESS TO BEING?}

It is essential to the understanding of Sartre's doctrine of Being that we distinguish between two realms of Being, the en-soi and the pour-soi. In the introduction we said that the pour-soi corresponds to the idealistic element in Being, and the en-soi to the realistic element. This statement requires clarification.

The pour-soi, in its most simple sense, is consciousness. For Sartre, speculation begins in subjectivity; more specifically, it begins with the Cartesian cogito, which is taken to be the root of all judgments and all cognition. It is "an absolute truth founded upon the immediate

\footnotetext{
'Sartre, L'Étre et le Néant, 15. (Hereafter the abbreviation "EN" will be used).
} 
grasp which consciousness has of itself, and as such is the basis for all other certain truths."3 Sartre recognizes, however, that there is a prereflective as well as a reflective cogito, and that through the examination of the pre-reflective cogito, we may come to a general understanding of the other pole of Being, the en-soi.

Moreover, the pre-reflective cogito is the basis for the reality of consciousness; for there can be no consciousness where there is no reference to an object. ${ }^{4}$ Consciousness cannot exist apart from its active unfolding in the acts of consciousness. 5 Consciousness is thus the cause of its own manner of Being and is the identity of appearance and existence. Consciousness exists to the extent to which it "appears"; and the absoluteness of consciousness consists in the identity of its appearance and existence. Sartre's recourse to the pre-reflective cogito, therefore, enables him to escape from the infinite regress of "knowingknown"; for the "coincidence of existence and appearance indicates that the pre-reflective cogito is an absolute in the order of existence and a condition of all knowledge." 6

Consciousness is more than self-reflection; all consciousness is consciousness of something. Consciousness intends some object in the world. What is intended, Sartre asserts, is some "trans-phenomenal" Being beyond consciousness. The realm of transphenomenal Being is the realm of the en-soi. For Sartre, the $e n$-soi is the rough is-ness of Being, the brute confrontation of Being, the "stuff" of the world. Thus, the Being of consciousness faces the Being of the phenomenon: the pour-soi faces the $e n$-soi, and although both may be identified by an analysis of subjectivity, they remain alien and severed realms. If we tentatively defined the pour-soi as consciousness, we may tentatively define the en-soi as the transphenomenal Being of the object. Whether contact between these realms is possible is one of the profound problems Sartre faces in his analysis.

By constructing an "ontological argument in reverse," Sartre tries to demonstrate the existence of the transphenomenal Being of the object from the pre-reflective cogito; for consciousness, he argues, implies in its very Being a non-conscious, transphenomenal Being. Conscious-

\footnotetext{
${ }^{3}$ Collins, J., "The Existentialism of J-P. Sartre," Thought, Vol. XXIII, No. 88, (March, 1948), 69.

- EN, 19.

${ }^{5}$ Ibid., 19-21.

${ }^{8}$ Collins, op. cit., 69.
} 
ness, Sartre holds, is a Being which, because it is in question in its own Being, implies a Being other than itself. 7 The definition of consciousness which Sartre ultimately establishes is the following: the pour-soi (consciousness) is that which it is not, and is not that which it is. We intend to explicate fully the nature and meaning of this paradoxical conception of consciousness.

\section{WHAT IS THE RELATION OF TEMPORALITY TO BEING?}

The consciousness with which we are concerned, the pour-soi, is not static; it is "passionately involved in temporality." In fact, the pour-soi exists only because it has a future. Sartre's discussion of temporality reveals the deeper relation between consciousness and Being. He says that the Being of the pour-soi will be elucidated only when we have defined and described the signification of the temporal. "It is only then that we shall be able to arrive at the study of the problem which occupies us: that of the original relation of consciousness with Being." 8

What, then, is the relation of temporality to Being? For Sartre, temporality is an original synthesis containing structured moments. ${ }^{9}$ To understand temporality it is necessary to pursue a phenomenological analysis of the dimensions of temporality: past, present, and future.

Let us consider a few sentences: I am the person you now see; I am the person you saw last Monday; I was the man who owned that white bulldog. The difflculty is: in what sense is it possible to speak of one's present self as the self that was at place $P$ at time $T$ ? Is it the same self? Was it the same self? This tie between the present self and the past self must be explained. In what sense do I remain the same self, able to be both "was" and "is"?

Sartre holds that temporality cannot be artificially split up into past and present. There must be an ontological connection between them. "The term 'was' designates ... the ontological leap from the present into the past and represents an original synthesis of these two modes of temporality." 10 "Was" is the ontological liaison of the pour-

${ }^{7}$ EN, 29.

s Ibid., 149.

Ibid., 150.

${ }^{10}$ Ibid., 158. 
soi; what Sartre terms the "facticity" of the pour-soi is it pastness."11 The facticity of the pour-soi is threatened and encroached upon by the en-soi; the latter attempts to "swallow" it up. The "was" characterizes the type of Being of the pour-soi: "The relation of the pour-soi to its Being. The past is the en-soi which I am, considered as passed beyond." 12

In the present-past relationship a dialectic is involved: "I was the man who owned that white bulldog." This means that $I$ am the man who "was the man." But in the same sense in which I am the man who was, I certainly am not the man who was; for I am the man I am. The internal connection in this dialectic of "am," "was," and "am not" is the relation "not to be." It follows, then, that if "I am not my own past, it cannot be in the original mode of becoming, but in so far as $I$ have to be it in order not to be it and $I$ have not to be it in order to be it." 13 Sartre concludes that, in regard to my Being, "I am in the mode of internal liaison with the not to be." 14

The dialectic of present-past reveals the relation between the two realms of Being: the pour-soi, when it becomes pastness, is seized by the en-soi and rendered pastness or "facticity," as Sartre puts it. But since the present is pour-soi, a paradox is involved: although we must define the present in terms of Being, whenever we attempt to specify the present, we are left with only an infinitesimal instant, a Nothingness. Here is the fundamental contradiction of existence: we always find the indissoluble pair, Being and Nothingness.

The problem of the present forces us to expand our understanding of the pour-soi. The pour-soi, as present, cannot be seized as such; it is in a state of flight. Sartre says that the present is a perpetual flight in the face of Being and that whenever we experience the present it is under the form of flight. We cannot truly seize the present in any of its instants, for these instants themselves are in flight. ${ }^{15}$

The present, however, is as yet imperfectly understood, for we have considered only one half of its dialectical relation. In addition to flight from, there must be flight to. The pour-soi has a facticity, but

\footnotetext{
${ }^{11} \mathrm{EN}, 162$.

${ }^{12}$ Ibid.

${ }^{23}$ Ibid., 161.

${ }^{14}$ Ibid.

${ }^{15}$ Ibid., 168.
} 
it also has a future. ${ }^{16}$ Sartre's theory of the nature of futurity is complex. The Sartrean future is the pour-soi's unavoidable though indeterminate Being-to-be. This future is not some chronologically ordered or homogeneous succession of instants to come.17 Futurity is the paradoxical mixture of what I shall be and yet what that shall-be is not. Just as the dialectic of past-present entails an ontological liaison of "was-ness," so the dialectic of present-future depends upon the ontological connective of "flight." Flight from present Being toward future Being outlines the skeleton of the shall-be, although it does not cause or mold that shall-be.

Since "the future is that which $I$ have to be in so far as I am able not to be it," 18 and since "the future is myself in so far as I await myself as presence at a being beyond being," 19 Sartre asserts that the pour-soi of the present reveals the pour-soi yet to be. The latter is held before the pour-soi as its image-to-be. In this sense the not-yet has Being, and its Being is that of futurity. The future world "has meaning as future only in so far as I am present in it as an other which I shall be, in another physical, affective, social, and so on, position." 20 Sartre concludes that "I must . . . 'become what I was', but it is in a world itself become that I must become it, and in a world become from what it is." 21

From the total unity of past, present, and future, with the ontological liaisons of "was-ness" and "flight" which bind them together dialectically, arises the Self. The Self holds within it the problem of its freedom, for the flight of the pour-soi toward its future is its measure of freedom to become what it will be. But this freedom is unique: the pour-soi does not accept or reject its freedom in a purely conceptual fashion. The pour-soi faces its own "problematicity." 22 "The future constitutes the meaning of my present pour-soi, as the project of its possibility, but it does not predetermine in any way my pour-soi to come, since the pour-soi is always abandoned in this 'nihilating' (néantisante) obligation to be the foundation of its nothingness." 23

\footnotetext{
${ }^{10} \mathrm{EN}, 168$.

${ }^{17}$ Ibid., 174.

${ }^{18}$ Ibid., 170.

${ }^{19}$ Ibid., 172.

${ }^{20}$ Ibid., 171.

${ }^{21}$ Ibid., 172.

22 Ibid., 174.

${ }^{23}$ Ibid., 173.
} 
Sartre concludes that the pour-soi cannot avoid its "problematicity," since the pour-soi itself is problematic in the sense of continually being faced by an uncertain future. This is what Sartre means when he asserts that Man is a Being whose meaning is always problematic. Thus, "the pour-soi can never be anything but problematically its future, for it is separated from that future by a nothingness which it itself is: in a word, the pour-soi is free and its freedom is to itself its own limit." ${ }^{24}$ To be free, Sartre says, is to be condemned to be free. ${ }^{25}$

\section{WHAT IS THE RELATION OF NOTHINGNESS TO BEING?}

We have thus far attempted to answer the question, "What is Being?" If we now ask, "What is non-Being?", we have hinted at the nature of Nothingness; for to each question we ask there exists the possibility of a negative answer. ${ }^{26}$ Sartre considers several varieties of non-Being.

The non-Being of knowing is of a conceptual order. If I say "the dog is not the cat," I am, according to Sartre, formulating a purely conceptual negation. However, if I say "Pierre is not here" after I have expected to find him here and have looked for him here, then I am uttering a negation which is not purely conceptual. The difference between these two types of non-Being is that the "non-Being" of Pierre has a Being, it is a Nothingness.

Sartre explains the Being of Nothingness in the following example: Let us say that Pierre has not waited for me at an appointment. I came to the place where we were supposed to have met, and "I immediately saw that he was not there." Was there, then, an intuition of Pierre's absence? When I looked at the scene where I was supposed to meet Pierre, everything I saw underwent a "nihilation" (néantisation).

I am at this moment looking for Pierre; as I look about me at the scene where he is supposed to be, there is, for me, a successive disappearance of objects, Sartre says,-of those objects which are not Pierre. The "nihilated" form of Pierre rises between my look and the objects upon which my look is directed. The Nothingness of Pierre is in opposition to the Nothingness of the crumbled objects, because the Nothingness of Pierre "haunts" the scene.27

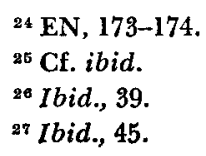


This non-conceptual Nothingness has a certain structure which the purely conceptual Nothingness does not have. If, after I have determined that Pierre is absent, I say to myself, "Well, George Washington isn't here either," there arises no constitution of the Nothingness of George Washington. Such a negation is simply a thought and does not produce non-Being. ${ }^{28}$

Being has priority over Nothingness in the sense that there can be Being without Nothingness, but there can be no Nothingness unless there has been Being. Whereas Hegel says that Being and Nothingness are equally empty abstractions, Sartre holds that although Being is empty of every determination other than identity with itself, non-Being is empty of Being. "In a word, what is necessary here to recall against Hegel is that being is and that nothingness is not." ${ }^{29}$

We may now ask, "Where does Nothingness come from?" Sartre also raises the associated question, "What must man be in his being in order that through him Nothingness comes to Being?" Sartre reveals the "secret" of Nothingness. He says that "it is necessary to find the foundation of all negation in a 'nihilation' which would be exercised at the very core of immanence; it is in absolute immanence, in the pure subjectivity of the instantaneous cogito, that we must discover the original act by which man is to himself his own nothingness." 30

In what sense is the instantaneous or pre-reflective cogito the basis of all negation? We said earlier that the pre-reflective cogito is the basis for the reality of consciousness and that the reality of consciousness depends on its being presented with a known object. Original negation or Nothingness arises from the pre-reflective cogito because the cogito is not before it meets its known object. To put it in another way: when Sartre says ${ }^{31}$ that, in rising from the heart of Being, consciousness creates and sustains its essence-the synthetic arrangement of its possibilities-he implies that the pre-reflective consciousness $i s$ only in so far as it does realize its possibilities. But if the possibilities are "possibles," (i.e., if they lie in the future), then the possibility of their not being realized exists; this is negation in its root form.

${ }^{28}$ EN, $46-47$.

${ }^{29}$ Ibid., 51.

${ }^{\text {so }}$ Ibid., 83.

${ }^{31}$ Ibid., 21. 
Sartre distinguishes between two types of nihilation. There is the nihilating structure of the pre-reflective cogito. Consciousness "is not its own motive in so far as it is empty of all content." 32 This emptiness of content is what has been described above as the root-negation of as yet unrealized "possibles."

Although the original negation which arises from the pre-reflective cogito is the basis of all negation, there is a second type of nihilation which is the nihilating structure of temporality. Of this second type Sartre says that "the consciousness is confronted with its past and its future as confronted with a self which it is in the mode of not-being." 33 This is the area of negation which circumscribes the core of the poursoi. It is the Nothingness of that which separates the pour-soi from its past and from its future. The Nothingness of the pour-soi is, for Sartre, the possibility of freedom. Freedom is the "possibility for the human reality to secrete a nothingness which isolates it" ${ }^{34}$ and "freedom is the human being putting its past outside of the game in secreting its own nothingness." 35

Nothingness reveals freedom and also reveals our anguish. "It is in anguish that man becomes conscious of his freedom or, if one prefers, anguish is the mode of being of freedom as consciousness of being; it is in anguish that freedom is in its being in question for itself." 36

Anguish must be distinguished from fear. The latter is of things of the world, but anguish is anguish before oneself, fear of having fear, consciousness of freedom. Sartre gives the example of a person walking along a narrow, dangerous path, who considers the various possibilities of catastrophe: the earth giving way, a landslide, slipping on a rock, and so on. These imagined catastrophies are general; they might happen to anyone walking along such a path. But as soon as our protagonist on the path considers these possibilities as his possibilities -that he might slip and fall to his death-then he experiences fear. The distinction between fear and anguish is that fear has a specific object, but anguish is anguish before one's "possibles"-no specific one having been selected. Fear of having fear is anguish because it is fear

\footnotetext{
${ }^{32}$ EN, 72.

${ }^{33}$ Ibid.

${ }^{84}$ Ibid., 61 .

${ }^{35}$ Ibid., 65.

${ }^{86}$ Ibid., 66.
} 
of the non-specific. Anxiety has no ascertained object, and that is the piercing hurt of the anguish.

When Sartre says that anguish is the self-awareness of "possibles" as $m y$ "possibles," he does not mean that the awareness of these "possibles" is a conceptual act which occurs prior to some involvement with those situations of which the "possibles" are a part. Rather, we act in situations which reveal "possibles" in the process of being realized. We are referred back to the meaning of the "possibles," but we do not experience the awareness of "possibles" in a purely beforehand, or abstract sense. Man is a creature involved in his reality. He does not gaze upon it as a Martian might coolly consider earthman's works-he is inextricably a part of reality. We are engaged in our reality, hurled into the world and involved in it. "This means that we act before positing our "possibles" "37 We discover ourselves, then, in a world peopled with exigencies, and we are at the core of projects in the course of realization. Thus, man turns up in the world-he appears on the scene. 38

Sartre, in concerning himself with the profound problem of Being qua Being, has found it necessary to investigate man's being in order to penetrate to the heart of Being. He has considered temporality, consciousness, and Nothingness as dimensions of the dialectic of Being. The problem has been to resolve the basic dualism of the two realms of Being, the pour-soi and the en-soi.

It may be seen that the pour-soi is in flight both toward the future and from the past, and, further, that it is separated from both by the Nothingness which establishes its freedom and, at the same time, its anguish. The pour-soi, as consciousness, is man's possibility of freedom, for in self-reflection and self-awareness lie the roads of freedom. But the en-soi is quite the opposite of the pour-soi; it is unreflective, stolid, and gross-brute packed-togetherness. ${ }^{39}$

In Sartre's novel Nausea, the protagonist, Roquentin, suddenly grasps the reality of existence in its brute $e n$-so $i$ as he is seated on a park

${ }^{37} \mathrm{EN}, 75$.

${ }^{38}$ Existentialism, op. cit., 18.

${ }^{89}$ Collins, op. cit., 77-78. Sartre "describes the en-soi as a massive, crammed-down bulk of being which quite brutally is. It allows for no self-acquaintance with its own reality because of its opacity and thickness. Only in a loose sense can the In-self be called a self, for it supports no relations with others and allows for no presence to itself and self-development of its own solid plenitude." 
bench one day. In an almost perverse Husserlian fashion the normal world is bracketed off, and he perceives the park and its objects as a swollen blob of jelly-like consistency, which presses in on him like quicksand about a sinking man.40 The experience of the $e n$-soi in its unexpurgated immediacy is "nausea." The flight of the pour-soi, then, is the flight from this nauseous en-soi toward futurity. But futurity itself has en-soi as part of its Being. Thus, man is in flight from en-soi toward en-soi; this is the tragedy of his condition. Man in his flight is haunted by Being, yet he cannot absorb that Being under pain of the engulfment of his pour-soi. "The human reality in its being is suffering because it arises to being as perpetually haunted by a totality which it is without power to be, since precisely it could not reach the en-soi without losing itself as pour-soi." 41

The pour-soi is in a vicious paradox: since it is lack, it is hurled toward the future; yet if it fills itself with $e n$-soi, it nauseates itself. In like fashion, we can retreat into the past only at the risk of absorbing the $e n$-soi of facticity: we slip away into the en-soi and so yield our freedom, our authenticity. The dilemma of the pour-soi is the urgent condition of human existence. If freedom of the pour-soi is freedom only within the confines of this condition, and if man is condemned to this strange and awful freedom, then Sartre's great burden in the remainder of his research on Being and Nothingness must be the explanation of how man operates in his Being and how he may both choose and realize his "possibles."

40 Sartre, J-P., "The Root of the Chestnut Tree," Partisan Review, (Winter, 1946), 32-33. "Was it a dream, that enormous presence? It was there, poised over the park, tumbling from the trees, all soft, gluing up everything, a thick gelatinous mass. And was $I$ in it, I, and the entire park? I was afraid, but above all I was furious, it seemed so stupid, so inappropriate. I despised that ignoble jelly. It was everywherel It reached to the sky, it spread out in all directions, it filled everything with its sprawling mass, and I could see layer upon layer of it, extending much farther than the limits of the park and the houses and Bouville. I was no longer in Bouville, nor anywhere, I was floating. I was not surprised; I was very well aware that it was the World, the naked World which had suddenly shown itself, and I was choking with rage against this huge absurd being. . . I I cried out: "What a filthy mess, what a messl' and I shook myself to throw off the sticky slime but it clung to me and there was so much of it, tons and tons of existence, endless tons: I was suffocating under the weight of a tremendous ennui."

${ }^{42}$ EN, 134. 


\section{Chapter II}

\section{THE OTHER}

In the first part of L'Être et le Néant Sartre described mainly the Being of the pour-soi and its relation to the en-soi. This study, however, has left him with the necessity of rescuing his ontology from the charge of solipsism, for he has explicated only the Being of one's consciousness with no bridge established to the consciousness of Others. The danger is that "Sartre has followed so closely the idealistic conception of Self-consciousness (cogito) as the transcendental origin and 'creator' of all Being that he constantly faces the danger of transcendental solipsism." 1 In facing the problem of solipsism in EN, Sartre analyzes the existence of the Other and the relations between my Being and the Being of the Other. ${ }^{2}$

\section{THREE THEORIES OF THE OTHER}

In his analysis of the "Reef of Solipsism" Sartre takes into consideration the theories of the Other held by Husserl, Hegel, and Heidegger before presenting his own views.

a) Husserl.-"Husserl's main argument-as Sartre sees it-consists in the thesis that the reference to the Other is a necessary condition for the existence of the world." 3 Husserl, according to Sartre, has defined the Other as an "absence." How, Sartre asks, is it possible to have an intuition of an absence? Unless I arbitrarily presuppose that the Other is identical with me, true knowledge of the Other escapes me. ${ }^{4}$

\footnotetext{
${ }^{1}$ Marcuse, H., "Existentialism: Remarks on Jean-Paul Sartre's L'Etre et le Néant," Philosophy and Phenomenological Research, Vol. VIII (1947-1948), 316.

2 EN, 277.

${ }^{3}$ Schuetz, A., "Sartre's Theory of the Alter Ego," Philosophy and Phenomeno. logical Research, Vol. IX, No. 2, (1948), 183.

${ }^{\star}$ Ibid., 184.
} 
The inadequacy of the Husserlian theory of the Other is that phenomenological method operates only through reducing the object via the self's analysis and through intending the object via the self's acts of intending. But since we cannot penetrate beyond the core of the self, the Other escapes us. "The only liaison which Husserl has been able to establish between my being and that of the other is that of the understanding; he could not then ... escape from solipsism." 5

b) Hegel.-For Hegel the problem of the Other is the problem of consciousness of self. Sartre quotes Hegel: "The consciousness of self is real only in so far as it knows its echo (and its reflection) in another." 6 For Hegel, Sartre claims, the existence of my consciousness as consciousness of self depends on the appearance of the Other. Selfconsciousness appears with the excluding of the Other." "Such exclusion takes a double form: By the very fact of being myself, I exclude the Other; by the very fact of being himself, the Other, whom I exclude, excludes me." 8

Sartre accuses Hegel on two counts: first, of "epistemological optimism" and, second, of "ontological optimism." According to Sartre, it appears to Hegel "that the truth of the consciousness of self can appear, that is, that an objective accord can be realized between the consciousness under the name of recognition of me by the Other and of the Other by me." 9 The "ontological optimism" is an even more fundamental element in Hegelian philosophy. The essence of this optimism, according to Sartre, is the Hegelian assertion that the truth of the All already exists, permitting, therefore, the claim that the truth regarding the Other is possible to obtain.10

${ }^{5} \mathrm{EN}, 291$.

Ibid., 293.

"Ibid., 291.

${ }^{8}$ Schuetz, op. cit., 185.

${ }^{8} \mathrm{EN}, 296$.

10 Ibid., 299. "Truth is truth of the All. And he places himself at the point of the truth, that is, of the All, in order to envisage the problem of the other. Thus, when the Hegelian monism considers the relation of the consciousnesses, it is not to be placed in any particular consciousness. Although the All is to be realized, it is already there as the truth of all that is true; also, when Hegel writes that every consciousness being identical with itself is other than the other, he has established himself in the All, outside of consciousness and considers consciousnesses from the point of view of the Absolute." 
The failure of Hegel's optimism is the failure to produce the basis of intersubjective knowledge (knowledge of the Other). Hegel is left with a mere plurality of consciousnesses which cannot be properly connected. Hegel's optimism is the illusion that such a connection has been established in his arguments concerning the Other. ${ }^{11}$

c) Heidegger.-It is also necessary to point out that the question of the Other arises for a person, according to Sartre's exposition of Heidegger's thought, only when that person has achieved authentic existence. Authenticity is achieved in the resolute decision the individual makes regarding his possibility of death. At the moment that the individual chooses his authenticity, he is disclosed to himself in authenticity, and the Others around him are at the same moment elevated toward the authentic. ${ }^{12}$

Sartre charges that Heidegger's description of the Other is an ontic and psychologistic description and not a true ontological explanation, since he claims there is no warranty for passing from the idea of beingwith to the ontological structure of being-in-the-world. ${ }^{13}$ Sartre holds that Heidegger, like Husserl and Hegel, has failed to produce an acceptable theory of the Other and that Heidegger's philosophy leaves the problem unsolved: it leaves the self isolated in the dungeon of solipsism-in "solitary."

In general, Sartre is dissatisfied with the positions of both realism and idealism in so far as they have taken stands on the problem of intersubjectivity. Through a dialectical examination of the problem in both idealist and realist camps, ${ }^{14}$ he concludes that both positions lead to paradox and internal contradiction; for the realist position, when followed through, leads necesarily to idealism, whereas idealism, when it abandons the solipsist hypothesis, leads to a dogmatic and

${ }^{11} \mathrm{EN}, 299$, "The optimism of Hegel results in a defeat: between the object-other and me-subject, there is no common measure, no more than between the consciousness (of) self and the consciousness of the other. I cannot know myself in the other if the other is first object for me and I can no more seize the other in its true being, that is, in its subjectivity. No universal consciousness can be derived from the relation of the consciousnesses. It is what we shall call their ontological separation."

${ }^{12}$ Ibid., 303.

${ }^{13}$ Ibid., 304.

${ }^{14}$ Ibid., 277-288. 
totally unjustified realism. ${ }^{15}$ The problem of the Other, according to Sartre, can, therefore, be solved by neither idealism nor realism.

\section{THE LOOK}

Any attempt to explore intersubjectivity, Sartre asserts, must commence with the cogito. We cannot prove the existence of the Other in the sense of logical proof. The Other is immediately known, or, as Sartre puts it, "encountered." "The existence of the Other has the nature of a contingent and irreductible fact." 16 We, therefore, cannot ontologically derive the existence of the Other. ${ }^{17}$ Such is the general outline of Sartre's theory of the Other's existence. ${ }^{18}$

If the cogito is to be the starting point, then Sartre commits himself to the position that any consideration of the Other must begin wih the Being of the self. ${ }^{19}$ Also, he holds that the rapport with the Other will be a relationship of Being to Being and not one of understanding to understanding. ${ }^{20}$ Husserl failed by measuring Being by the understanding, Hegel failed in identifying understanding with Being. ${ }^{21}$ Sartre, to the contrary, proposes to give an explanation of the relationship between my Being and the Being of the Other. ${ }^{22}$

In the affirmation of the existence and presence of the Other, taken now as a relation of Being to Being, the question which initiates the Sartrean inquiry into the specific problem of the Other arises: "Is there in the everyday reality an original relation to the Other which

${ }^{15} \mathrm{EN}, 285$.

16 lbid., 307.

${ }^{17}$ Marcuse, op. cit., 316.

${ }^{18}$ Schuetz, op. cit., 187. "Sartre formulates the following criteria for a valid theory of the Other's existence. 1. Such a theory need not prove the Other's existence, the affirmation of which is rooted in a 'pre-ontological' understanding. 2. The Cartesian cogito is the only possible point of departure in order to find (not reasons for my belief in the Other's existence, but) the Other himself as being-not-me. 3. The Other does not have to be grasped as an object of our cogitations, but in his existence 'for us' as affecting our actual concrete being. 4 . The Other has to be conceived as being 'not me,' but this negation is not an external spatial one; it is an internal negation, defined by Sartre as a synthetic and active connection between two terms, either of which constitutes itself by negating the other."

${ }^{10}$ EN, 300.

${ }^{20}$ Ibid., $300-301$.

${ }^{21}$ Ibid.

${ }^{22}$ Ibid., 311 . 
can be constantly sought and which, consequently, can be disclosed to me, outside of all reference to a religious or mystical unknowable?" 23

The basis of the original relation to the Other is the very appearance of the Other in my world: he appears to me. A shock accompanies the presentation of the Other to my world. "The appearance among the objects of $m y$ universe of an element of disintegration of this universe is what I call the appearance of $a$ man in my universe." 24 The Other shocks my world in an original, unique, and irreducible manner: he looks at me. ${ }^{25}$ "At each instant the Other looks at me." ${ }^{26}$ The basis of the solution to the problem of the Other will be the Look. But "what does it mean for me: to be seen?" 27

Sartre asserts that shame reveals to the self the Look of the Other. ${ }^{28}$ The Other looks at me and, in the Look, shocks or "haemorrhages" my inner unity, my inner world, my subjectivity. The recovery of this inner world of the self is possible by a retaliation against the Other; i.e., by making the Other the object of $m y$ Look and destroying his inner unity. By the Look of the Other I have been made an object for his subjectivity, and he knows me only as object, never as subject. In the same manner, $I$ know the Other as object, never as subject. ${ }^{29}$

Consciousness of being object exists when the Other looks at me, but does it also exist when the Other is absent? Absence is defined by Sartre as a mode of Being of the human-reality that was originally determined by presence. ${ }^{30}$ That is, I look for somebody because he is generally there. But what is important in consciousness of being object, or of being the one who looks for the Other in his absence, is that in these cases we are being-for-other. Thus, "the look has placed us on the track of our being-for-other and it has revealed to us the indubitable existence of this otherself for which we are." 31

I "cannot be object for an object"; 32 I must be object for a subject. But if my being-for-other has revealed the necessity for the Other, the

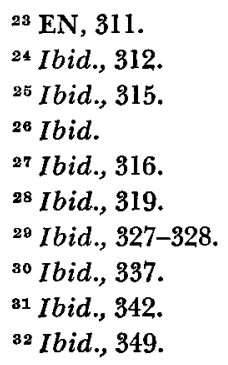


question remains: What is the Being of the being-for-other? ${ }^{33}$ Sartre asserts that the being-for-other is not an ontological structure of the pour-soi. ${ }^{34}$ "We cannot even think of deriving, as a consequence of a principle, the being-for-other from the being-for-self, nor, reciprocally, the being-for-self from the being-for-other." 35 Sartre's answer to our question will be given later, when the ground for such an answer has been prepared.

We may return now to the concept of shame and its relation to the problem of the Other. Pure shame, Sartre tells us, is the feeling of being an object, not some particular object. Shame exists when I recognize myself as degraded by and dependent upon the Other. "Shame is the feeling of original fall, not from the fact that I would have committed such and such a fault, but simply from the fact that I am 'fallen' into the world, in the midst of things, and that I need the mediation of the other in order to be what I am." 36

Partly, then, through the experience of shame, I seek the overthrow of the Other by appropriating him as object for my subjectivity. But in this appropriation I hope to achieve more than simply the objectification of the Other. What I seek is no less than the discovery in the Other of an aspect of myself: my objectivity.

But the explication of the being-for-Other has been carried as far as possible within the limits of the structures of Being examined. A dilemma has resulted: the Other "seizes" me in my facticity as object, and I can never "seize" the Other in his subjectivity. If I attempt to prove the latter, my proof founders on the reefs of the limits of my knowledge; and if I accept the facticity of the Other as object, I fail to penetrate to his core.

\section{THE BODY}

Sartre's argument regarding the Other can be carried no further in its present framework; it is necessary to investigate a series of new levels of the structure of Being.

If we return to the very first knowledge of the Other, it will be recalled that the Other appears to us. The appearance of the Other is possible only in so far as he originally appears manifested as a body.

\footnotetext{
${ }^{33} \mathrm{EN}, 342$.

${ }^{34}$ Ibid.

${ }^{35}$ Ibid.

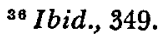


If "this object that the Other is for me and this object that I am for the Other are manifested as bodies," 37 then Sartre asks, What is my body? and What is the body of the Other? 38

My body has a dualistic aspect: it is "either a thing among things, or else it is that by which the things are disclosed to me." 39 My body cannot be both of these two aspects at the same time. ${ }^{40}$ Because of this double relation, I may be present to a part of my body without its being $m e$ or my being it. This double relation derives from the fact that I cannot sense one of my organs sensing. I cannot see my eye seeing. When I do "seize" my eye, it is as an aspect of the world-an object for me--or else "it is that by which ... things are disclosed to me." ${ }^{41}$ There are, then, two aspects of the investigation of the body that can be delineated: the body as being-for-self and the body as being-for-Other.

Sartre asserts that the understanding itself is a self-contradictory element if it is unrelated to positional experience. The understanding must be involved; i.e., it must be understanding of something somewhere. 42

"To be for the human reality is to-be-there; that is, 'there, on that chair,' 'there, at that table,' 'there, at the top of that mountain, with those dimensions, that orientation, etc.' " 43 The necessity of the positional element in experience (being-there) involves, however, an ambiguity: "On the one hand ... if it is necessary that I may be under the form of being-there, it is completely contingent that I am, for I am not the foundation of my being; on the other hand, if it is necessary that I may be engaged in such and such a point of view, it is contingent that it is precisely this one, to the exclusion of every other." 44 Sartre terms this double contingency the "facticity" of the pour-soi. We used the term "facticity" earlier in the exposition of Sartre's definition of the pour-soi as not being what it is and being what it is not. The pour-soi can never know itself in itself, for at the foundation of itself is its Nothingness. ${ }^{45}$

\footnotetext{
${ }^{87} \mathrm{EN}, 364$.

ss Ibid.

${ }^{30}$ Ibid., 366.

${ }^{40}$ Ibid.

11 lbid.

4 Ibid.

4 Ibid., 371.

4 Ibid.

4 Ibid.
} 
The individuation of the pour-soi is realized through its body. "The body is a necessary characteristic of the pour-soi; it ... proceeds necessarily from the nature of the pour-soi that it is body." 46 The body appears to Others. The world in which it appears is given to the pour-soi as positional to it, not simply as an experential "possible," or a cognitive expectation. In so far as I am given to the world, I am given through my body. "To say that I am entered into the world, 'come to the world,' or that there is a world or that I have a body, is one sole and selfsame thing." 47

The world, for Sartre, is given to me through its utensil quality and its resistance to my actions toward it. This means that the desk in front of me is desk-to-be-written-upon, not simply "desk," and the Others, in the same fashion, are Others-for-me. The objectivity of the world resides in the synthetic unity of the utensils which comprise it and not in creative power of a subjectivity. "Thus, the world appears to me as objectively articulated: it never refers back to a creative subjectivity but to the infinity of utensil complexes." 48

An example which Sartre gives clarifies the utensil-quality of the world. ${ }^{49}$ The statement "Carthage is to be destroyed" has the indifferentness of an unoriented, referenceless proposition. The meaning of the destruction of Carthage is one thing for the Romans, but quite another for the Carthagenians. For the Romans, Carthage is to be destroyed, but for the Carthagenians, Carthage is to be enslaved. Thus, meanings are always meanings in situo, related to persons ... involved. In their totality these utensils reveal more than objectivity: they are objects which resist us. "What I perceive when I wish to draw this glass to my mouth is not my effort, it is its heaviness, that is, its resistance toward entering into a utensil complex, which $I$ have made appear in the world." 50

The resistance of utensils to the pour-soi reveals the nature of the position of the pour-soi in the world. There is a dialectic of interaction between the objects, the Others, and the Self. This dialectic can-

46 EN, 372.

${ }^{47}$ Ibid., 381.

${ }^{48}$ Ibid., 387.

4 Ibid.

${ }^{50}$ Ibid., 389. 
not posit a body apart from the objects which are utensils for and resistants to that body. ${ }^{51}$

The body involves infinitely more than simply the flesh I inhabit. My body in its being-for-Others is the synthetic resultant of my "seizing" of the totality of utensils given to me and, in addition, my seizing of Others as they condition my experience with their attitudes, interests, and passions. The way in which objects are disclosed to me will then depend on my birth, my race, my class, my nationality, my physiological structure, etc., in so far as these elements themselves are constituted by my relationships to Others. This also is a dialectical relation, for I am not simply conditioned into class, nationality, etc., but pass beyond such conditioning and, in the passing beyond, establish the synthetic unity of my being-in-the-world.

Sartre is now able to relate the conception of body to choice and both to freedom.

Sartre holds that we choose the manner in which we "exist" 52 ourselves. The pour-soi "exists" its body and thereby chooses its meaning to the Self. If I have an infirmity, for example, I choose in which way I shall "exist" that infirmity. I may "exist" it as "intolerable," 'humiliating,' 'to be hidden,' 'to be revealed to all,' 'object of pride,' 'justification of my failures,' etc." 53 The concept of the pour-soi's "existing" itself, as we shall see later, is the key to Sartre's theory of the Self and of human freedom. In later sections we shall discuss this concept in great detail. At the present time it is not possible to define the concept any further, since we have not yet exposited those correlated ideas necessary to its comprehension.

${ }^{51} \mathrm{EN}, 389-390$. "We have surrendered all claims to endowing ourselves first with a body in order then to study the way in which we seize or modify the world through it. But, on the contrary, we have given as foundation to the disclosure of the body as such, our original relation to the world, that is, our very arising in the midst of being. Far from the body's being first for us and revealing the things to us, it is the things-utensils which, in their original appearance, indicate our body to us."

${ }^{52}$ Sartre uses the verb "to exist" as a transitive verb with a direct object. In other words, he may speak of "I exist myself" (when "I" bring into existence "myself") as distinguished from "I myself exist" (when the statement simply means that I myself do exist). It seems impossible to get away from Sartre's use of "to exist." For example, Sartre writes (EN, 418): "J'existe mon corps," which can only be translated: "I exist my body."

${ }^{53} \mathrm{EN}, 393$. 
The seizing of the Self as Self, as pure facticity, as consciousness which does not "exist" itself via pain or other such phenomena-such seizure is the taste of nausea. "A discrete and insurmountable nausea perpetually reveals my body to my consciousness." 54 Sartre's novel Nausea makes clear that what is grasped in nausea by the pour-soi is its stuffness, its en-soi. Physical nausea is only one of the manifestations of existential nausea. "Far from our having to understand this term of nausea as a metaphor derived from our physiological loathings, it is, on the contrary, on its foundation that are produced all the concrete and empirical nauseas (nausea before rotten food, fresh blood, excrements, etc.) which lead us to vomiting." 55

The appearance of my body to the Other or vice versa is not the way in which the Other is truly manifested to me or the way in which $I$ am manifested to the Other. This would be a relation of pure exteriority, whereas the real relationship is one of interiority. "My liaison to the Other is inconceivable if it is not an internal relation." 56 The internal relation needed, then, is the "signification" of the body. The signification of the body is defined through the relations which the body has to the chairs it sits on, the sidewalks it walks on, etc. "The body is totality of the significant relations to the world ... The body could not appear, in fact, without sustaining, with the totality of that which it is, significant relations." 57

The Other appears to me as related to the totality of "significations" he expresses. Thus, the body of the Other is a certain distance from that glass, in a specific relation to the chair he sits on, etc. I can understand the Being of the body of the Other only by comprehending the Other as he exists within a total situation. ${ }^{58}$ The totality referred to here may be explained as follows: an organ or part of another person appears to me in relation to his total situation. If the Other holds his fist directly before my eyes, I do not, therefore, infer that his fist is larger than his body. Here the traditional notion of perspective is translated into the signification-perspective of life. Fists are not simply

\footnotetext{
54 EN, 404.

${ }^{55}$ Ibid.

${ }^{50}$ Ibid., 405.

${ }^{57}$ Ibid., 411.

${ }^{58}$ Ibid., 412.
} 
objects; they are parts of beings who themselves are parts of situations in which their fists are related to what they are engaged in. ${ }^{59}$

Just as we cannot truly seize the organ of the body apart from the totality, we cannot speak of the emotion, or passion, or expression of a man apart from the activity through which that emotion, passion, or expression is evidenced. The form of evidencing the emotion is the emotion:

"These knittings of the brows, this redness ... which seem ... threatening do not express the anger, they are the anger. But it is very necessary to understand: in itself a clenched fist is nothing and means nothing. But also we never perceive a clenched fist: we perceive a man who, in a certain situation, clenches his fist. This significant act considered in liaison with the past and the "possibles," understood from the synthetic totality 'body-in-situation,' is the anger." 60

Within a specific situation-for example, the relation of the glass to Pierre, who happens to be sitting in that armchair-the Other has the freedom to change his situation (Pierre can move to the couch). Because the body of the Other is "seized" only in so far as we must admit the referential quality of the situation of the Other (all references of utensils are to the Other, since they are his utensils), we are compelled to admit the freedom of the Other.

Because of the freedom of the Other, we can never consider his body as mere body; it is always greater than the facticity of the body, since the Other passes beyond, transcends, that facticity in his engagement. There is an objectivity, a mere facticity of the body, but in so far as $I$ grasp the Other in his surroundings, in his engagement, in synthetic totality, I do not observe that facticity. ${ }^{61}$

Three ontological dimensions of the body have been defined in the relations between the Being of the Self and the Being of the Other:

"I exist my body; such is its first dimension. My body is utilized and known by the Other: such is its second dimension.

${ }^{59} \mathrm{EN}, 413$.

Bo Ibid.

${ }^{61}$ Ibid., 418. "The body for the Other is the magical object par excellence. Thus the body of the Other is always 'body-more-than-body,' because the Other is given to me without intermediary and totally in the perpetual passing beyond of its facticity." 
But in so far as I am for the Other, the Other is disclosed to me as the subject for which I am object. It is a question even here, as we have seen, of my fundamental relation with the Other. I exist then for myself as known by the Other by virtue of body. Such is the third ontological dimension of my body." 62

In the third ontological dimension I know my body as it is for the Other, yet I have a new knowledge of it myself. This new knowledge is gained during certain states of my body: when I perspire in fear of the Other, when I blush, etc. In such instances, I have a consciousness of my body not as it is for me, but as it is for the Other. ${ }^{63}$

The Being which we are escapes us, and we, paradoxically, get to know that Being in tangential fashion through the manner in which we experience that Being as it is for the Other. Thus, for example, we can never know our body as it is; only another sees us in totality so that he sees our body as it is; but in being aware of the fact that I am object for another who sees my body as it is, I feel timidity or shame, and in the experience of that timidity or shame my body becomes known to me as body-known-by-the-Other. "It appears to us then that the Other accomplishes for us a function of which we are incapable, which however is incumbent on us: to see us as we are." 64

\section{ATTITUDES TOWARD THE OTHER}

The introduction of the relations of timidity and shame leads Sartre to a consideration of the concrete relations the pour-soi has with the Other. The attitudes of the pour-soi toward the Other which Sartre describes are Love, Language, Masochism, Indifference, Desire, Sadism, and Hate.

a) Love.-Love presents an ambiguous and paradoxical relationship. In loving the Other, we are faced with the problem of whether such love is love of the Other as object or as subject. Do we necessarily appropriate the Other as object in the love relation? If so, then in what sense is the freedom of the Other maintained? Or is love by necessity a severing and destruction of the freedom of the loved one? Again, what effect do these possibilities have on the lover?

\footnotetext{
${ }^{02} \mathrm{EN}, 418-419$.

${ }^{63}$ Ibid., 420.

's Ibid., 421 .
} 
Since, for Sartre, the freedom of the Other is the foundation of my Being, I am in danger of losing my freedom if the freedom of the Other is lost. ${ }^{65}$ If I shatter the subjectivity of the Other whom I love by rendering him an object in my world, I am at the same time endangering my own status, my own freedom; for it is always through the Other that my freedom is determined.

Thus, there is a general paradox of love: the lover makes of his loved one an object, and, in so doing, negates the freedom of the loved one. But the freedom of the loved one was what the lover sought in his love. In loving he has destroyed the love he sought. The lover wishes for an impossible thing: "He wishes to possess a freedom as freedom." 66 Since this is in principle impossible, love is a paradoxical relation which results in frustration.

b) Language.-The problem of language is exactly parallel to the problem of the body, and the descriptions which were valid in one case are valid in the other. ${ }^{67}$ It is through the Other that we learn the true nature of our body. The Other sees us as we are. Thus, we must turn to the Other to learn what we are, and this is necessarily accomplished through language. Since it is only through the Other that we can see ourselves, we depend upon the description the Other gives us concerning ourselves. These descriptions which we receive through language, then, are the sole way in which we may hope to comprehend ourselves as we exist for the Other. ${ }^{68}$

c) Masochism.-In masochism the desire of the masochist is to be completely and purely an object for the Other. The flight of the masochist is toward en-soi. It is the masochist who refuses to be anything more than an object for the Other. In feeling himself an object for the Other, the masochist experiences the feeling of shame, and it is this feeling that he seeks in his abnormality. The masochist wants and loves his shame. ${ }^{69}$

But masochism is also the assumption of guilt. The masochist is guilty from the sole fact that he is an object. He is also guilty in so far

\footnotetext{
${ }^{65} \mathrm{EN}, 433$.

${ }^{\circ}$ Ibid., 434.

${ }^{87}$ Ibid., 442.

${ }^{\circ 8}$ Ibid., 421.

${ }^{\circ 9}$ Ibid., 446.
} 
as he willingly allows himself to be made an object for the Other ${ }^{70}$ But the guilt of the masochist is just part of his paradoxical condition, which makes of masochism a necessary failure.

Masochism carries the germ of its destruction within itself, for while the goal of the masochist is to reduce himself to an utter object for some Other's subjectivity, he must, in his masochism, treat that other person, who beats him, whips him, etc., as an object for his subjectivity. It is, then, in vain that the masochist permits himself to be mistreated or tortured, since he is mistreated or tortured by the Other, who ultimately is object for him. Thus, the more the masochist attempts to "taste his objectivity, the more he will be submerged by the consciousness of his subjectivity." 71

d) Indifference.-The attitude of indifference is induced by a "blindness" toward Others. In being indifferent, the pour-soi retreats from Others, chooses to ignore reality. The pour-soi practices, then, a sort of solipsism of attitude: the Others walking by me in the street are hardly noticed, they are simply "coefficients of adversity," like walls or buildings. ... "I do not even imagine that they can look at me." 72

Thus, "there are men who die without having suspected-except during brief and terrifying illuminations-what the Other was." 73

e) Desire.-"Desire" is always sexual desire, which is "my original attempt to possess the free subjectivity of the Other through its objectivity-for-me." ${ }^{74}$ The questions which now arise are: What is desire? Of what is there desire? and What is it that desires? ${ }^{75}$

Sartre's answer to the first question is that "desire is nothing other than one of the grand forms which the disclosure of the body of the Other can take." ${ }^{76} \mathrm{He}$ also says that "desire is an attempt to undress the body of its movements as of its clothes and to make it exist as pure flesh; it is an attempt at incarnation of the body of the Other." 77 This

\footnotetext{
${ }^{70} \mathrm{EN}, 446$.

${ }^{71}$ Ibid., 447.

72 Ibid., 449.

${ }^{73}$ Ibid.

${ }^{74}$ Ibid., 451.

${ }^{75}$ Ibid., 455.

"T Ibid.

"I Ibid., 459.
} 
"incarnation" of the body of the Other is accomplished through the "caress," which Sartre describes as a "shaping" through which I make the flesh of the Other "be born." 78

Desire, however, also leads to a paradox-an "impossible ideal": "to possess the transcendance of the Other as pure transcendance and yet as body; to reduce the Other to his simple facticity, because he is then in the midst of my world, but to make this facticity be a perpetual presentation of its 'nihilating' transcendance." 79

f) Sadism.-Sadism is the correlated reverse of masochism. Like masochism it is destined to failure. "The object of sadism is immediate appropriation. . . . Sadism is, at one and the same time, refusal to be incarnated and flight from all facticity, and effort to become master of the facticity of the Other." 80

"What the sadist seeks ... with so much tenacity, what he wants to knead with his hands and break under his fist is the freedom of the Other." 81 To accomplish this the sadist seeks the moment of decision when his victim gives in under the torture. At that moment what the sadist sought for is momentarily gained. The body of his victim "is entirely flesh, panting and obscene, it keeps the position that the torturers have given to it, not that which it would have taken by itself, the cords which bind it sustain it as an inert thing and, by that, it has ceased to be the object which moves spontaneously." 82 This tortured body is the symbol of enslaved freedom.

But there is a necessary cycle of defeat in sadism, and for several reasons. Although the sadist tries to appropriate the transcendent freedom of the Other, "this freedom remains, in principle, out of reach, and the more the sadist is intent on treating the Other as instrument, the more this freedom escapes him." 83 The sadist discovers the failure of his efforts when his victim looks at him. In the Look the sadist realizes "that he could not act on the freedom of the Other, even by compelling the Other to humiliate himself and to beg for mercy, for it is precisely in and by the absolute freedom of the Other that a world

${ }^{78} \mathrm{EN}, 459$.

${ }^{79}$ Ibid., $463-464$.

${ }^{80}$ Ibid., 469.

81 Ibid., 473.

${ }^{82}$ Ibid., 474.

${ }^{83}$ Ibid., 476. 
happens to exist in which there are a sadist and instruments of torture and a hundred pretexts for being humiliated and disowned." 84 The Look is for the sadist more unbearable than crucifixion or death, for it haunts his Being as pure guilt. "The look of the Other in the world of the sadist makes the meaning and the goal of the sadism collapse." 85

All the conducts of men toward each other are only variations, increased complexes, of the original attitudes of sadism and masochism (and a third-hate). Thus, conducts such as collaboration, obedience, maternal love, pity, and good will are fundamentally founded on masochism and sadism. In the description of such complex attitudes, it is necessary to take into consideration historical situation, concrete particulars, etc.; "but they all enclose within them as their skeleton the sexual relations." 86

g) Hate--Hatred is the attempt of the Self to avoid being an object for another by wishing the extinction or destruction of the Other. But in order to hate an Other, I must first admit the existence and the subjectivity of the Other. Thus, hate carries with it necessarily a recognition of the freedom of the Other.

"The occasion which provokes hate is simply the act of the Other by which $I$ have been placed in a state of submitting to his freedom." 87 But in hating the Other, who has appropriated me, and in recognizing his freedom, I am hating all Others as well. My hatred for the Other is symbolic, then, of my hatred for all Others. ${ }^{88}$

But this hatred is necessarily involved in a failure, for even if I succeed in overcoming the Other, the very attempt I make to triumph over him is admittance of the fact that he existed. I am unable to prevent myself from recognizing the existence of the Other, even though that existence may be part of my past. Thus, once I have been made an object for the Other, I am "contaminated" in my Being for the rest of my days, "even if the Other has been entirely overcome." 89

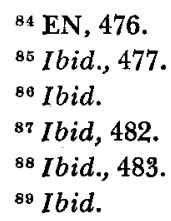




\section{BEING WITH (MIT-SEIN)}

The investigation of the Other leads to the concept of Being-With: the 'we.' The problem of Being-With is one of the communal relations of the Self with the Other and with Others. The experience of the 'we' is a true experience, according to Sartre, for "the very existence and use of this grammatical form (we) refers back necessarily to a real experience of the 'Mit-sein'." 90 However, this experience of the 'Mitsein' is a psychological, not an ontological structure.

The rejection of the Mit-sein as an ontological structure is a fundamental concept of EN. For Sartre, human reality is not originally communal but, rather, is in conflict-in necessary and perpetual conflict. Thus, "the essence of the rapports between consciousnesses is not the 'mit-sein,' it is conflict." 91

The concept of action is implicit in the philosophy of Sartre. In its dialectical flight, in its relation toward Others, the pour-soi acts. It is now necessary, Sartre says, to raise such questions as: What does it mean to act? Why does the pour-soi act? How can the pour-soi act? The foundation for the answers to these questions has been constructed already in Sartre's considerations of nihilation, facticity, the body, the Other, and, of course, the pour-soi and the en-soi. ${ }^{92}$ Through a new interrogation of these concepts, Sartre proposes to reveal the ontological nature of action and to show the relation of action to man's freedom.

\footnotetext{
${ }^{80} \mathrm{EN}, 484$.

${ }^{91}$ Ibid., 502.

${ }^{92}$ Ibid., 503.
} 


\section{Chapter III}

\section{THE SELF}

\section{FREEDOM}

According to Sartre, every action is, in principle, intentional; and true action implies a consciousness of acting on the part of the actor. Thus, if someone throws away a lighted cigarette which happens to set off a fuse, which in turn produces an explosion, he has not acted. On the other hand, true action has been taken by the worker whose job it is to follow out the steps required to set off a dynamite charge. ${ }^{1}$ Since action is necessarily intentional, no political or economic fact can cause action in the individual. Motivation is inner. ${ }^{2}$

The "indispensible and fundamental condition of all action is the freedom of the acting Being." 3 Freedom is evidenced in the pour-soi in so far as the pour-soi exists as "lack." The "lack" of the pour-soi is its Nothingness. Because the pour-soi "exists" itself through flight, it is nothing, for its existence is always non-static: the pour-soi is not that which it is and is that which it is not. ${ }^{4}$

Choice, freedom, and action are inextricably bound together in the existence of the pour-soi. There can be no freedom if there is no choice; there can be no choice if there is no freedom; there can be no action where there is no freedom. "Freedom, choice, nihilation, temporalization are but one sole and selfsame thing." 5

Sartre means something quite different by 'freedom' than is intended in common usage or in general philosophical usage. Freedom, as it is generally understood, might be defined as "the ability to satisfy needs plus the ability to develop new needs, with the understanding,

\footnotetext{
${ }^{1} \mathrm{EN}, 508$.

2 Ibid., 510-511.

I Ibid., 511 .

¿ Ibid., 558.

'Ibid., 543.
} 
of course, that abilities do not evolve unless objective conditions are favorable." 6 Sartre cannot accept such a definition.

Sartre's ontological conception of freedom is not a description of those conditions external to man which allow him to choose among alternatives but, rather, freedom is the state of Being of the pour-soi to which the pour-soi is condemned. "We are a freedom which chooses, but we do not choose to be free: we are condemned to freedom." 7 Since the pour-soi is in question in its Being, freedom is its condition: "I am ... an existant which learns of its freedom by its acts ... My freedom is perpetually in question in my being; it is not a super-added quality or a property of my nature; it is the very stuff of my being." 8

To comprehend freedom is to understand that the human reality is its own Nothingness.9 The pour-soi, in order to be, must choose itself. There is no a priori essence or God-given human nature that the pour-soi can depend upon or cling to. The pour-soi is "entirely abandoned, without aid of any sort, to the unbearable necessity of making itself be down to the slightest detail." 10

Man's freedom cannot be relative to any particular situation or occurrence; for his freedom is his Nothingness, and his Nothingness is an absolute in the sense that it is the condition of the pour-soi. Thus, "man could not be sometimes free and sometimes slave: he is entirely and always free, or he is not." 11

\section{SITUATION}

Thus far freedom has been described in terms of the "lack" of the pour-soi. However, it is necessary to understand the pour-soi not as an

${ }^{6}$ McGill, V. J., "Sartre's Doctrine of Freedom," Revue Internationale de Philosophie, (15 Juillet 1949), 341.

' EN, 565.

8 Ibid., 514.

${ }^{\theta}$ Ibid., 515. "To be, for the pour-soi, is to nihilate the en-soi which it is. In these conditions, freedom could be nothing other than this nihilation. It is through it that the pour-soi escapes its being as its essence; it is through it that the pour-soi is always something other than what one can say of it, for . . . the pour-soi is that which is already beyond the name one gives to it, the property one recognizes in it. To say that the pour-soi has to be what it is; to say that it is what it is not in notbeing what it is; to say that in it existence precedes and conditions essence or . . . that for it 'Wesen ist was gewesen ist,' is to say one sole and selfsame thing, namely, that man is free."

${ }^{10}$ Ibid., 516.

11 Ibid. 
abstraction but as engaged, as in situation. In fact, the pour-soi is only in so far as it is engaged and in situation. We must, therefore, turn to the concept of situation in order to describe the more profound implications of Sartre's theory of human freedom.

The situation of man is the totality of the limits with which the pour-soi is faced in its relation to the world. This world consists of other pour-sois and of things. Although the objective world of "brute things" "may, from the start, limit our freedom of action, it is our freedom itself which must previously constitute the framework, the technique, and the ends in regard to which they will manifest themselves as limits." 12

The situation, then, is the resultant or synthesis of two aspects of reality: the facticity of things as revealed in their coefficient of adversity, and the meanings which the pour-soi legislates for them. The relation of the pour-soi to a situation is described through what Sartre terms "being-there." "Being-there for a colonial is to be twenty days from France-better still: if he is a functionary and awaits his paid voyage, it is to be six months and seven days from Bordeaux." ${ }^{13}$ It is through being-there that the object of desire or of cognition takes on meaning for the pour-soi; and its meaning identifies the situation and defines it. The mountain I now look at has a certain "coefficient of adversity." It is difficult to climb, it is high, it is craggy, etc.; but the meaning of "difficult to climb" and of "high" and of "craggy" is determined by the pour-soi who is confronted by that mountain in a particular situation. ${ }^{14}$

The relationship between situation and freedom is one of paradox. Freedom exists only in a situation and a situation exists only if the pour-soi is free. "The human reality encounters everywhere resistances and obstacles which it has not created; but these resistances and these

${ }^{12} \mathrm{EN}, 562$.

13 Ibid., 574.

${ }^{14}$ Ibid., 569. "To an equal desire to climb, the rock will be easy to ascend for such an athletic climber, difficult for such another, a novice badly trained and with a puny body. But the body reveals itself in its turn as well or badly trained only in regard to a free choice. It is because I am there and have made of myself what I am that the rock develops in regard to my body a coefficient of adversity. For the lawyer living in town who pleads, for the body hidden under his legal robe, the rock is neither difficult nor easy to ascend: it is melted into the totality 'world' without emerging in any way from it." 
obstacles have meaning only in and through the free choice which is the human reality." 15

But situation is itself partially a function of the pour-soi which is understood under the dimensions of temporality: past, present, and future. Hence, a situation will be constituted, in part, by what I was as well as by what I am. If "Wesen ist was gewesen ist," then the past can be understod only in paradox. "I could not conceive of myself without a past; better, I could no longer think anything about myself since I think about what I $\mathrm{am}$, and I am in the past; but on the other hand, I am the being through which the past comes to itself and to the world." 16

Sartre's conception of situation and freedom as intimately associated and correlative aspects of the pour-soi defines the nature of human reality. "If the pour-soi is nothing other than its situation, it follows that the being-in-situation defines the human reality." ${ }^{17}$ However, it must be stressed that while the pour-soi expresses its existence in situation, the situation is not solely constituted by the pour-soi. The pour-soi is thrown into a world which consists of other pour-sois and their situations. The other pour-sois have established meanings in the world which then function as part of the reality which surrounds the individual pour-soi. ${ }^{18}$

Thus, to be free is "not to choose the historical world in which one arises-which would have no sense-but to choose oneself in the world, whatever it may be." 19 The realistic element in Sartre is apparent: the pour-soi does not create the world in any Fichtean sense. There is, rather, a given which the pour-soi grasps and, in grasping, renders uniquely meaningful to itself. "Freedom . . . recognizes and foresees implicitly in its original project the independent existence of the given on which it exercises itself." 20

${ }^{15} \mathrm{EN}, 569$.

${ }^{16}$ Ibid., 577-578. "Let us examine this paradox more closely: freedom being choice is change. It defines itself by the end which it projects, that is, by the future which it has to be. But precisely because the future is the-state-which-is-not-yet of that which is, it can be conceived only in a direct liaison to that which is. And it could not be that which is what clarifies that which is not yet: for that which is is lack and, consequently, cannot be known as such except from that which it lacks."

${ }^{17}$ Ibid., 634.

${ }^{18}$ Ibid., 603.

${ }^{19}$ Ibid., 604.

${ }^{20}$ lbid., 588. 
The complexus of choice-freedom-lack-nothingness-situation, which is the pour-soi as it "exists" itself, is ultimately reducible to two basic aspects: the given and the ends which the pour-soi imposes upon the given. "The arising of freedom is a crystallization of an end through a given, and discovery of a given in the light of an end: these two structures are simultaneous and inseparable." 21

\section{DEATH}

Sartre asserts that it is not possible for the pour-soi to be aware of its own possibility of dying. $M y$ death must in principle remain outside the orbit of my comprehension. "Death is not $m y$ possibility of no longer realizing a presence in the world, but an always possible nihilation of my possibles, which is outside of my possibility." 22

Sartre is quite willing to admit that the pour-soi can imagine $a$ death, but not its death. ${ }^{23}$ My death is a comprehensible notion only for the Other. "The fact of death ... gives final victory to the point of view of the Other." ${ }^{24}$ Sartre maintains that since, in principle, death, in so far as it is my death, is comprehended by the Other, my death can never be for me an ontological structure. It is unanalyzable and beyond me. ${ }^{25}$

It is now possible to see that there are two basic existential characteristics which qualify the pour-soi: "nothing is in the consciousness which is not consciousness of Being," and, secondly, "my Being is in question in my Being-which means that nothing comes to me which is not chosen." 26 These characteristics determine a pour-soi which, through the aspects of "lack," choice, Nothingness, etc., "exists" itself as freedom. This freedom is a strictly ontological concept. It is not to be confused with what is ordinarily meant by freedom. Sartre thus has given us a radically new concept of freedom: the pour-soi's situation or status as it "exists" itself ontologically. Freedom is the necessary condition of the pour-soi, and is evidenced in the pour-soi in so far as the pour-soi exists as "lack." Such is the freedom to which the pour-soi is condemned.

\footnotetext{
${ }^{21} \mathrm{EN}, 590$.

${ }^{22}$ Ibid., 621.

${ }^{28}$ Ibid., 624.

24 Ibid., 628.

${ }^{25}$ Ibid., 630.

${ }^{26}$ Ibid., 578.
} 


\section{Chapter IV}

\section{EXISTENTIAL PSYCHOANALYSIS}

\section{EXISTENTIAL VERSUS FREUDIAN PSYCHOANALYSIS}

Sartre defines existential psychoanalysis as a "special phenomenological method," 1 a "method designed to bring to light, under a rigorously objective form, the subjective choice by which each person makes himself a person, that is, makes himself announce to himself what he is." 2 The existential psychoanalyst rejects the Freudian psychoanalysis in so far as the latter describes certain general 'states' (complexes, attitudes, etc.) rather than individually determined projects and choices. The goal of existential psychoanalysis is to reveal the symbolization and rapports contained in the projects of the pour-soi and to find "through these empirical and concrete projects the original manner which each one has of choosing his being." 3

How does existential psychoanalysis differ from phenomenological ontology? The answer to this question will clarify the differences between orthodox and existential psychoanalyses. For Sartre, ontology has as its aim the analysis of the structure of Being in general. It cannot attempt a study of the detailed history of an individual pour-soi; it cannot make predictions concerning the outcome of any specific situation. These particularized questions are the concern of existential psychoanalysis.

The existential psychoanalysis interrogates particular human conducts, tendencies, inclinations, etc., and attempts to "decipher" their existential meaning. The principle of this kind of psychoanalysis is that man is comprehended as a totality, not as a collection of separate facts. Every act of man, however insignificant it may seem, reveals something of his nature. The goal of this psychoanalysis is to "decipher" the empirical behavior of man. It is primarily through a de-

${ }^{2} \mathrm{EN}, 559$.

Ibid., 662.

IIbid., 689. 
tailed and complete analysis of the acts of choice which a man makes that the existential psychoanalyst may hope to formulate a picture of the relationship between specific choices of an individual and the symbolic meanings which those choices represent.

The essential difference between the existential and the Freudian psychoanalyses is that the latter stresses the general complexes and attitudes determined unconsciously in the individual, while the former holds that all mental conditions are consciously disclosed and are to be comprehended through an analysis of the situation of the person. The two psychoanalyses are in closest agreement in regard to fundamental method and the desirability of reconstructing the total picture of the individual mind through an exhaustive investigation of the individual's personal history and behavior. ${ }^{4}$

\section{EXISTENTIAL PSYCHOANALYSIS AND ONTOLOGY}

Ontology lays the groundwork for general and abstract significations which analyze the nature of Being. Existential psychoanalysis is a method of applying the basic ontological principles to highly individualized projects, i.e., of analyzing the specific attitudes and actions of the individual in relation to his life-history. In this respect, ontology is basic to existential psychoanalysis: "The information which ontology may acquire about conducts and desire must serve as principles of existential psychoanalysis." 5 Thus, "What ontology may teach psychoanalysis is, in effect, first of all the true origin of the significations of things and their true relation to the human reality." 6

\section{VISCOSITY}

Sartre investigates the structure and basis of the existential psychoanalysis but is interested in describing the method rather than in using it. However, he does give us some illustrative examples of how he intends to apply the method. While Sartre's Baudelaire is a full length study in existential psychoanalysis, its consideration would involve us in too great a digression from the issues with which we have been dealing. We will therefore restrict ourselves to the analysis of "viscocity," which is the most extended illustration of existential psychoanalysis in EN.

${ }^{4} \mathrm{EN}, 656-658$.

${ }^{5}$ Ibid., 663.

${ }^{\circ}$ Ibid., 694. 
The analysis of viscosity is indebted to Bachelard's attempted psychoanalysis of things. ${ }^{7}$ Bachelard holds that one may psychoanalyze things, such as water, stones, fire, etc. Sartre is sympathetic toward this notion but holds that Bachelard's work lacked the method necessary to carry out a successful analysis of things. ${ }^{8}$

Sartre's analysis of viscosity is an application of the principles of existential psychoanalysis to things; but in the case of viscosity the things are of prime importance, since viscosity is symbolic of the ensoi, and to penetrate its nature is to know the nature of the en-soi.

The "viscous" is the sticky, glue-like, tar-like, soft quicksand-like stuff that was best described earlier in Sartre's novel Nausea. ${ }^{9}$ But the viscous is not simply matter: "a handshake is viscous, a smile is viscous, a thought, a sentiment is capable of being viscous." 10 We know the nature of the viscous when we consider it in its relation to the pour-soi. This relationship is dual: on the one hand, the viscous is molded by us, shaped by us; on the other hand, it "seizes" us and possesses us. ${ }^{11}$

The possibility of losing mastership over the viscous "haunts" the pour-soi, for "the viscous is the revenge of the en-soi." 12 The fear of the pour-soi that it will be absorbed by the $e n$-soi is the essence of the "flight" of the pour-soi previously described by Sartre. ${ }^{13}$

? $\mathrm{EN}, 694$.

${ }^{8}$ Ibid., "We would consider the study of Bachelard on water, which teems with ingenious and profound insights, as an ensemble of suggestions, as a precious collection of materials which would have to be utilized at present by a psycholoanalysis conscious of its principles."

- Vide supra 29-30.

${ }^{10} \mathrm{EN}, 695$.

${ }^{11}$ Ibid., 700. "The viscous is docile. Only, at the very moment when I believe to possess it, by a curious reversal, it is it which possesses me. It is there that appears its essential character: its softness makes a suction. If the object that $I$ hold in my hand is solid, I am able to let it slip when it pleases me; its inertia symbolizes for me my entire power: $I$ found it, but it never founds me . . . here it is that the viscous reverses the terms: the pour-soi is suddenly compromised. I remove my hands, I wish to let go of the viscous but it adheres to me, it sucks me, it clings to me; its mode of being is neither the reassuring inertia of a solid, nor a dynamism as that of water which wears itself out sliding away from me: it is a soft activity, frothy and feminine of suction, it lives obscurely under my fingers and $I$ sense it as a dizziness, it attracts me ... as the bottom of an abyss would be able to attract me. It is like a tactile fascination of the viscous. I am no longer the master of stopping the process of appropriation."

${ }^{12}$ Ibid., 701.

${ }^{13}$ Ibid., 702. 
The existential psychoanalysis of the viscous, Sartre claims, has revealed a sector of Being. We know en-soi through our experience of the viscous in nausea, and this experience suggests "a crowd of obscure significations and of sendings-back which pass beyond it." 14 In its most profound sense, the viscous "is a possible meaning of Being." 15

${ }^{14} \mathbf{E N}, 703$.

${ }^{15}$ Ibid. 


\section{Chapter V}

\section{GENERAL SUMMARY}

'For us, man is defined first of all as a being 'in a situation.' That means that he forms a synthetic whole with his situation -biological, economic, political, cultural, etc. He cannot be distinguished from his situation, for it forms him and decides his possibilities; but, inversely, it is he who gives it meaning by making his choices within it and by it. To be in a situation, as we see it, is to choose oneself in a situation, and men differ from one another in their situations and also in the choices they themselves make of themselves. What men have in common is not a "nature" but a condition, that is, an ensemble of limits and restrictions: The inevitablity of death, the necessity of working for a living, of living in a world already inhabited by other men. Fundamentally this condition is nothing more than the basic human situation, or, if you prefer, the ensemble of abstract characteristics common to all situations."

-Sartre

The topics to be discussed as general conclusions are Sartre's ideas regarding "situation," his explanation of how the dualism of Being (en-soi and pour-soi) is bridged, his statements regarding metaphysical questions, and, finally, his views on moral matters.

\section{APPROPRIATION}

Human reality for Sartre is understood only through situation. The pour-soi is not isolated in its existence; rather, it is engaged with the totality of things, Others, etc., which establishes the pour-soi as a being-in-the-midst-of-things. While $I$ am "absolutely free and responsible for my situation ... I am never free except in a situation." 1

\footnotetext{
${ }^{1}$ EN, 590.
} 
Since without the pour-soi there cannot be a situation, it is the pour-soi which constitutes its reality. By being-in-the-world the poursoi is responsible for legislating significance to the world in which it is. It is here, then, that the relationship between the situation and man's freedom is made clear:

"Man, being condemned to be free, carries the weight of the world on his shoulders: he is responsibile for the world and for himself considered as manner of being. . . The responsibility of the pour-soi is overwhelming, since it is that through which there is a world; and, since it is also that which makes itself be, whatever may be the situation in which it finds itself, the poursoi must assume this situation entirely ... with the proud consciousness of being the author of it. . . The situation is mine ... because it is the image of my free choice of myself and all that it presents to me is mine in that it represents me and symbolizes me." 2

However, the realistic element in Sartre's conception of situation must be stressed. The pour-soi does not of itself create its world; rather, in reacting to objective givens (objects, Others, significations created by Others, etc.), it makes of these givens the world of meanings it both "exists" and exists in. The brute given is nothing without the testimonies of Others and their significations. ${ }^{3}$

In the same manner, my past actions are never wholly completed and accomplished facts alone. In addition to the brute fact of their pastness, the meaning which they have is continually dependent on the significance which I continue to give them.4

${ }^{2} \mathrm{EN}, 639$.

I Ibid., 579.

${ }^{4}$ Ibid., 579. "The signification of the past is narrowly dependent on my present project. That signifies by no means that $I$ am able to vary at the mercy of my caprices the meaning of my anterior acts; but, much to the contrary, that the fundamental project that $I$ am decides absolutely the signification which the past that $I$ have to be can have for me and for others. $I$ alone in fact am able to decide at each moment the burden of the past: not in discussing, in deliberating, and in appreciating in each case the importance of such and such an anterior event, but in projecting myself toward my goals, I save the past with me and I decide by action its signification. Who shall decide if that mystic crisis of my fifteenth year 'was' pure accident of puberty or, on the contrary, first sign of a future conversion. I, according as I shall decide- at twenty, at thirty-to convert myself. The project of conversion confers at one sole stroke upon a crisis of adolescence the value of a premonition that I had not taken seriously." 
In regard to the facticity of pastness, the conclusion is that although "all my past is there, pressing, urgent, imperious," still "I choose its meaning." " 5 The past is never 'settled' once and for all, but the meaning of the past is perpetually in "suspension." 6 The meaning of the past is clarified only in the context of my present situation, and so Sartre terms this active, unstable past the "is-was" (est été). ${ }^{7}$

Despite the realistic element of the world (as expressed in the coefficient of adversity of things, the significations due to Others, the historical past, etc.), situation is primarily an expression of the active role of the pour-soi in fashioning the world which it "exists." The world is revealed to me, and, in this sense, I am its creator and possessor. ${ }^{8}$

The key concept which explains how situation is an expression of the pour-soi is what Sartre terms "appropriation." In appropriation the pour-soi gives meaning to its reality; it molds the significations for which it is responsible; the pour-soi "exists" its significations.

The concept of appropriation leads beyond constitution of meanings to an understanding of the special status of the pour-soi, for the pour-soi is the human reality. Its priority over facticity engenders the necessary interpretation that the existence of reality is a function of the pour-soi, and that it can be grasped only in the situation which the pour-soi "exists":

"To the degree to which I appear to myself as creating the objects through the sole rapport of appropriation, these objects are $I$. The pen and the pipe, the article of clothing, the desk, the house, it is $I$. The totality of my possessions reflects the totality of my being. I am what I have. It is $I$ that $I$ touch on this cup, on this trinket. This mountain which I climb, it is I to the degree to which I conquer it; and when I am at its summit, which I have 'acquired' at the price of some efforts, this large view over the valley and the surrounding mountains, it is $I$; the panorama, it is I expanded to the horizon, for it exists only through me, only for me." 9

${ }^{5} \mathrm{EN}, 580$.

- Ibid., 582.

7 "is-was" is another of Sartre's ungrammatical constructions. There seems to be no other way of successfully rendering the meaning of this term in English.

${ }^{8}$ Ibid, 666.

'Ibid., 680-681. 
Through the appropriation I "egotize" my reality. The mountain which is I is not "within" me in any sense; rather, it is I externalized. "Possession is a magic rapport; I am these objects which I possess, but outside of all subjectivity as an $e n$-so $i$ which escapes me at each instant and whose creation I perpetuate at each instant." 10

Appropriation is thus a paradoxical concept, for it seeks to explain both the realistic (objective) factor in experience and the idealistic (subjective) aspect which is the pour-soi. It amounts, in analytic reduction, to the problem of the en-soi-pour-soi-an ideal and unrealizable concept. ${ }^{11}$

In so far as appropriation leads ultimately to the problem of the en-soi-pour-soi, we are returned to the very question of EN: the problem of the nature of Being; for the en-soi-pour-soi is absolute Being. However, since the en-soi-pour-soi is an ideal and unrealizable structure, the question arises, How can appropriation be the project of the en-soi-pour-soi? The answer is that appropriation symbolizes the essential nature of the existant who, as pour-soi, can never be his own proper foundation, who, as Nothingness, is in flight toward an en-soi which he can never attain. ${ }^{12}$

\section{THE DUALISM OF EN-SOI AND POUR-SOI}

Since appropriation is symbolic of the ideal but impossible en-soipour-soi, the basic dualism of en-soi and pour-soi is still unresolved. In yearning to be its own foundation, the pour-soi seeks the status of en-soi-pour-soi: the Absolute. Another name for this Absolute is God. The ideal of en-soi-pour-soi is the ideal of "a consciousness which would be foundation of its own being-en-soi by the pure consciousness that it would take of itself. ${ }^{13}$ The pour-soi, if it could achieve this ideal status, would be God. "Thus," Sartre writes, "one can say that what renders the fundamental project of the human reality most conceivable is the fact that man is that being who projects himself to be God." 14

${ }^{10} \mathrm{EN}, 681$.

${ }^{11}$ Ibid., 682.

12 Ibid., 682.

${ }^{13}$ Ibid., 653.

14 lbid. 
Sartre concludes that "to be man is to stretch toward being God; or, if one prefers, man is fundamentally desire to be God." 15 That man is condemned to the desire to be Grod is his tragic condition. The dialectic of relationships between pour-soi and en-soi is the profound description of this failure to achieve the Absolute. Sartre states the conclusion of the en-soi-pour-soi dialectic: each human reality seeks to metamorphose its own pour-soi into en-soi-pour-soi, but in striving for this status, the pour-soi must lose itself if it makes itself $e n$-soi. The projection of the pour-soi to lose itself in order to found its own Being Sartre terms a "passion." But since the status of en-soi-pour-soi is impossible for the pour-soi to attain-since man cannot be God-the pour-soi loses itself in vain: "man is a useless passion." 16

Having spent the main part of $\mathbf{E N}$ in describing the nature of the two polarities of Being and in analyzing the flight of the pour-soi as well as the ideal but unrealizable en-soi-pour-soi, Sartre concludes his work by returning to the original question of whether the polarities of Being constitute an irrevocably separate and distinct dualism whose members can never be unified. He seeks to establish an ultimate resolution of the dualism: "the pour-soi and the en-soi are reunited by a synthetic liaison which is not other than the pour-soi itself." 17

The pour-soi, then, is considered as "synthetic liaison" which unites the $e n$-soi and the pour-soi. This union, however, is to be understood in regard to the genesis of the dualism. We mean simply that Sartre's answer to the dualism is really an answer to the question: How did the dualities arise? It is not an answer to the question: In what manner may the pour-soi unite itself with the en-soi? Sartre says that ontology cannot answer this latter question, for "we do not have grounds to interrogate ourselves about the manner in which the pour-soi may unite itself to the en-soi since the pour-soi is in no way an autonomous substance." 18 The only substance which the pour-soi has is its Nothingness.

\section{METAPHYSICAL QUESTIONS}

Further investigation of the problem of the dualism of Being leads to metaphysical considerations. Sartre says that the metaphysical

\footnotetext{
${ }^{15} \mathrm{EN}, 653-654$.

${ }^{18}$ Ibid., 708.

${ }^{17}$ Ibid., 711.

${ }^{18}$ Ibid., 712.
} 
problem might be formulated in this way: Why does the pour-soi arise from Being? ${ }^{19}$ Since, for Sartre, the ontological investigation is by definition a phenomenological study, we can analyze only givens; we cannot turn to questions of the ultimate origin of givens. It is the task of metaphysics to take up where, because of its method, ontology must leave off.

\section{ETHICAL QUESTIONS}

A final area of philosophic inquiry is taken up in the conclusion of EN: the question of ethical values. Sartre asserts that ontology is not concerned directly with formulating moral prescriptions. Ontology "concerns itself uniquely with that which is, and it is not possible to derive imperatives from indicatives." 20 It is possible to indicate, however, the general lines along which an existential ethic might be formulated. The existential ethic will begin its analysis by studying the human being as a pour-soi in a situation. Since, for Sartre, all values are determined through the choices that the pour-soi makes, it follows that the pour-soi will be understood as creating its moral values through its acts. The moral agent is "the being through whom values exist." 21 The existential analysis of values will be based upon the categories of Being, Nothingness, freedom, anguish, and so on, as these categories have been clarified through phenomenological ontology. The existential ethic will be founded upon a freedom which will "take consciousness of itself and will discover itself in anguish as the unique source of value." 22

The multiple questions and difficulties which face such an ethic are problems to be met in a special and separate work which Sartre promises in the closing line of EN. This work on existential ethics has not yet appeared.

\footnotetext{
${ }^{19} \mathrm{EN}, 713$.

${ }^{20}$ Ibid., 720.

${ }^{2 x}$ Ibid.', 722.

2s Ibid.
} 


\section{PART II \\ Evaluation}




\section{Chapter VI}

\section{SARTRE'S PHENOMENOLOGICAL METHOD}

In any analysis of L'Etre et le Néant, it is imperative that Sartre's use of phenomenological method be considered and evaluated. It is not a coincidence that phenomenology appears in Sartre's ontology, for we have been advised in the subtitle of EN, "Essay in Phenomenological Ontology," of his intention to make use of the phenomenological method. Since Sartre appears to mean by phenomenology the special discipline formulated by Husserl, it will be well to begin our discussion with a brief resumé of Husserl's position.

Husserl's early interests were in mathematics-more specifically, in so-called "foundations of mathematics." His first basic problem was one of "reconciling the objective validity of logic and mathematics with the subjective processes of experiencing." 1 Prior to Husserl's work on this problem there was a strong tradition which held that logic is intimately related to psychology, that logic is really a subbranch of psychology. Various writers argued that meaning and truth are dependent upon psychological processes, and that logical validity is possible only in so far as it is grounded in the thought-processes of individuals. According to Lipps, for example, "the rules of correct thought are identical with the natural laws of thought itself; and logic is either the physics of thought or nothing at all." 2 This "psychologism" Husserl examined; and to its refutation he devoted his first philosophical efforts.

The essence of Husserl's refutation of psychologism consists in his demonstration of the a priori validity of logical laws; i.e., it consists in demonstrating that the laws of logic are "established through apodictic evidence and not inductively." 3 As Husserl sees it, psychology, "because of its inability to yield more than empirical generalities, ...

\footnotetext{
${ }^{1}$ Farber, M., The Foundation of Phenomenology, 561.

2 Ibid., 110.

I Ibid., 112.
} 
cannot account for the apodictically evident, 'superempirical,' ab" solutely exact laws which make up the core of logic." 4 By pointing out the "ideal" nature of logical necessity, Husserl undermined the foundation of that psychologism according to which logical necessity is derived from "matters of fact." 5

The refutation of psychologism leads Husserl later in his career to the formulation of the distinctive philosophic method which is known as phenomenology. Husserl was able to "break through" to phenomenology largely because in his work on psychologism he had raised certain key questions for which, at that time, no method of philosophizing could provide an answer. These key questions were concerned with the attempt to relate subjectivity (not psychologistically understood) to those meanings, logical unities, and "ideal" elements in experience which Husserl had described in his attempt to rescue logic from psychology; they were questions concerning the possibility of exploring subjectivity in a non-psychologistic manner. In his prephenomenlogical period Husserl faced the problem of the " 'clarification' of the fundamental concepts of logic and mathematics, and of their relationship to thought processes." 6 In his phenomenological period, Husserl expanded this problem into a larger one: the search for a transcendental phenomenology which would provide a "universal . . . method for philosophy and a final foundation for science." 7

"The aim of phenomenological analysis," Farber writes, "is to bring the logical concepts and laws to epistemological clarity and distinctness. The logical concepts as valid thought-unities must originate in intuition, and must arise through ideating abstraction' on the basis of certain experiences. In repeated performances of this abstraction the logical concepts must be always confirmed anew, and must be grasped in their self-

4 Farber, M., op. cit., 112.

${ }^{5}$ Ibid., 114: "An analysis of the real meaning of logical laws shows that they are not laws of actual mental life. The psychologistic interpretation therefore does violence to the meaning of logical laws, which do not presuppose the facts of mental life, either in their content or in their establishment, any more than is the case in pure mathematics. The valid forms of inference refer generally to any terms or propositions, and do not involve the existence of any actual judgments or psychical phenomena."

'Farber, M., "Phenomenology," Twentieth Century Philosophy, 350.

"Ibid. 
identity. Expressed otherwise: Husserl is not content with 'mere words,' or with a merely symbolic understanding of words, such as we have to begin with in our reflections about the meaning of the laws set up in pure logic regarding 'concepts,' 'judgments,' 'truths,' etc. Meanings which are only animated by remote, confused, figurative intuitions-if by any at all-cannot satisfy him. He proposes to return to the 'things themselves.' By means of fully developed intuitions we are to see with evidence that what is given here in actually performed abstraction is really and truly that which word-meanings of the law mean." 8

The cry of "back to the things themselves" is the attempt to devise a philosophy which will take a new attitude toward the examination of the content of experience. This new attitude is at once the attempt to construct a "presuppositionless" method and a philosophy which will begin with that "root" experience or givenness which neither reflection nor dialectic nor scientific disciplines of any order can meaningfully deny.

"The 'phenomenology' represented by the Logical Investigations makes use of immanent intuition alone, and does not pass beyond the sphere of the intuitively given. That is the meaning of the precept 'Back to the things themselves'; it meant the appeal to intuitive givenness." 9

The question now is: What sort of attitude are we leaving when we turn to phenomenology, and what sort of attitude may we expect from phenomenology? The answers Husserl gives to these questions are clear. The phenomenological attitude is a radical departure from what Husserl termed the "natural" attitude-a term denoting the common-sense, uncritical view of the world which accepts as "obvious" the existence of things, of other persons, and of a structure of meanings which relate ourselves to the world we live in: In the phenomenological attitude nothing can be taken for granted. The presuppositions of the natural attitude are among the very elements to be explained by phenomenological philosophy.

Husserl's method is essentially a return in principle to the Cartesian point of view. Phenomenological knowledge must begin in subjectivity via the reflections of the meditating ego. Thus:

\footnotetext{
${ }^{8}$ Farber, M., The Foundation of Phenomenology, 213.
}

I Ibid., 218. 
"The choice of a subjective method is due to the aim for complete and radical understanding, which is of deciding importance for philosophy. Nothing may be naively assumed; there must be no pre-judgments. In the natural view of the world, the common-sense view, and in all the special sciences, a general thesis of existence is taken to be obvious. Its unconscious acceptance is well justified for purposes of natural existence, but not for theoretical understanding. A world existing continuously and independently of our experiencing is the natural basis for non-philosophic thinking. But because philosophy is guided by the ideal of completeness of understanding, it cannot allow even so obvious a belief to remain unquestioned. The 'natural' view of the world after all contains elements of theoretical interpretation to which we have become accustomed. In short, everything must be questioned, including the phenomenological procedure itself. Hence only a subjectivistic method which begins with the experiencing knower and his evidence will answer." 10

The first step in phenomenological investigation is a "reduction" of our common or "natural" experience into those special aspects of experience which are the objects of phenomenological investigation. As Farber points out, this "reduction"
"is really twofold, and consists of (1) eidetic reduction, which means that only essences, or essential structures, are of interest, and not particular facts; and (2) transcendental reduction, with its technique of 'elimination' and 'bracketing,' which leads one back to the 'pure' consciousness of an individual knower as the starting-point for philosophy." 11

In the transcendental reduction (termed "epoché") all judgments about existence, including material things, are suspended, placed in abeyance. The objects to which these judgments refer are bracketed, or put in quotation marks. What is left after this reduction are the perceiving, remembrances, and imaginings of the experiencing being. The bracketed world becomes a phenomenon for a transcendentally reduced consciousness. ${ }^{12}$ The reduction, which is the essence of the phenomenological attitude, thus enables the phenomenologist to go back to the "originary given."

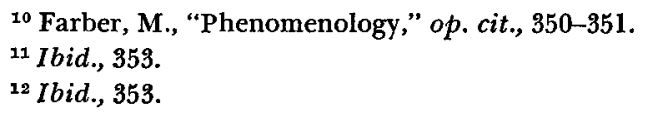


The nature of the starting point of phenomenology, the nature of the objects with which phenomenology is concerned-these indicate that Husserl's transcendental procedure is an attempt to examine the lowest categorial level of experience; and at this level the primary structure of subjectivity is, in Husserl's terminology, "intentionality." Consciousness, for Husserl, would not be consciousness were it not consciousness of something. Consciousness intends. Via its acts of intention it "endows" objects with meaning. Husserl's investigations of intentionality aim at a clarification of the complex relationships which prevail between the cogito and the meaning-intentions of the cogito, and open up a vast nexus of problems which, since they are basic to subjectivity, are basic to practically every area of human experience-basic to every discipline and to the structure of science. Phenomenology, therefore, as practiced by Husserl is but a prolegomenon to all branches of science and philosophy.

"The aim of phenomenology is said to be the achievement of an 'absolute knowledge of the world,' which it attempts to accomplish by going beyond all 'worldly' forms of explanation."13 Phenomenology "seeks to point out all presuppositions" and views everything factual as an exemplification of essential structures." It "is not concerned with matters of fact as such,"14 but with the "originarily given" in the "stream of pure experience." 15

Now Sartre, despite the fact that he speaks of his inquiry as "phenomenological," nowhere asserts that he is a "phenomenologist" following Husserl's method in detail. On the contrary, we shall show that Sartre departs radically from Husserl's method and that the term "phenomenological," when applied to Sartre's method, is ambiguous and, in certain respects, a misnomer.

The "phenomenological" basis of $\mathbf{E N}$ is contained in the first 37 pages of the book. It is in these pages that Sartre discusses the idea of phenomena, the phenomena of Being and the Being of phenomena, the pre-reflective cogito, and other relevant matters. He is attempting to do two things: (1) to concretize, locate, and, in general, indicate the problem of Being; (2) to show the initial differentiation of Being into two regions which are ultimately defined as the en-soi and the pour-soi.

\footnotetext{
${ }^{13}$ Farber, M., The Foundation of Phenomenology, 547.

14 Ibid., 568.

15 Ibid., 353.
} 
In attempting to develop the fundamental dualism which permeates the whole of his ontology, Sartre, early in EN, discusses the seemingly dualistic terms of the phenomena of Being and the Being of phenomena. ${ }^{16}$ Again, the primary consideration of the cogito and of consciousness as later contrasted with the treatment of being en-soi is another aspect of Sartre's technique of setting up the dualism of his ontology, since consciousness resides in the pour-soi. What is the phenomenological basis for the derivation and analysis of these structures?

Sartre tells us that "being is neither a quality of the object seizable among others, nor a sense of the object. The object does not reflect back to being as to a signification." 17 We learn, further, that "the object does not possess being, and its existence is not a participation in being, nor any other kind of relation. It is, that is the sole manner of defining its way of being." 18 The object can neither conceal nor reveal Being, since there is no hidden Being behind the appearance of the object. The object, rather than revealing itself to us, is there to-be-revealed. Sartre says: "Being is simply the condition of all revealing; it is being-in-order-to-reveal and not being revealed." 19 The Being of the phenomenon constitutes the transphenomenality of Being. We are able to have knowledge of this transphenomenality of Being since it is coextensive with the phenomenon of Being and makes itself known to us by an "overflowing." 20

Our basic criticism of this analysis of Being is that, whatever its merits or insights, it is not a phenomenological analysis. Quite to the contrary, the Husserlian method is put aside as inadequate. To begin with, no epoché or reduction has been performed. Sartre holds that the Husserlian reduction is not the proper method to begin the analysis of Being, since it is based on the concept of passing beyond particularity to the essence of that particularity. This, according to Sartre, ${ }^{21}$ is not a possible method for the analysis of Being, since Being has no meaning or essence 'beyond' its own particularity. Being is to-be-re-

\footnotetext{
${ }^{10}$ Later he will show that the former leads to the region of the pour-soi and the latter to the region of the en-soi.

17 EN 15.

${ }^{18}$ Ibid.

19 Ibid.

${ }^{20}$ Ibid., 16.

${ }^{21}$ Ibid., 15-16.
} 
vealed, but this revelation is not via any Husserlian phenomenological discipline. Instead, we have what might be termed a quasi-phenomenological sort of method, which may be further described through Sartre's analysis of the cogito.

Sartre commences his analysis of consciousness by asserting with Husserl that "all consciousness . . . is consciousness of something." 22 In being conscious of something, consciousness directs itself outward toward the object of which it is conscious. Thus, the intentional quality is the basic characteristic of the cogito. In order for there to be true intention, however, the cogito must be self-conscious: "the necessary and sufficient condition for a knowing consciousness to be knowledge of its object is that it be consciousness of itself as being this knowledge." ${ }^{23}$ Reflective consciousness in the cogito necessitates the precondition of a non-reflective consciousness; this is termed the pre-reflective cogito. "It is the non-reflective consciousness which renders the reflections possible: there is a pre-reflective cogito which is the condition of the Cartesian cogito." 24

There is no essence of consciousness prior to the intentions of consciousness: "Consciousness is not produced as singular exemplar of an abstract possibility, but ... in rising from the heart of being it creates and sustains its essence, that is, the synthetic arrangement of its possibilities." 25

Sartre has argued ${ }^{26}$ that Husserl's theory, according to which consciousness is consciousness of something, allows of two interpretations: "Either we understand by this that consciousness is constitutive of the being of its object, or else it signifies that consciousness in its most profound nature is in rapport with a transcendent being." 27 Sartre rejects the first interpretation and accepts the second. This is a key point of disagreement with Husserl, since Sartre holds that Husserl's theory of intentionality leads ultimately to a transcendental idealism which makes reality subjectively created and unreal.

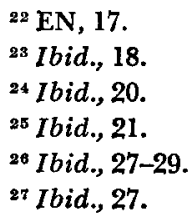


"It is in vain that one will attempt a hocus pocus, in basing the reality of the object on the subjective impressional plenitude and its objectivity on non-being: never will the objective come out of the subjective, nor the transcendent from the immanent, or being from non-being. But, one will say, Husserl precisely defines consciousness as a transcendence. In fact, it is this which he posits, and it is his essential discovery. But ... he is totally unfaithful to his principle" 28

In place of Husserlian phenomenology, Sartre uses a kind of ontological argument. Taking as his point of orientation Husserl's statement that consciousness implies consciousness of something, Sartre writes:

"Consciousness is consciousness of something: This signifies that transcendence is the constitutive structure of consciousness; i.e., consciousness originates carried in a being which is not it. It is this which we call the ontological proof." 29

Sartre's ontological argument is based on Husserl's theory of intentionality and constitutes an expansion of it:

"To say that consciousness is consciousness of something signifies that for consciousness there is no being outside of this precise obligation to be a revealing intuition of something, i.e., of a transcendent being; ... for a revealing intuition implies a revealed. Absolute subjectivity can only be constituted in the face of a revealed; immanence can be defined only in the seizure of a transcendent." 30

Whatever the validity of such ontological arguments, it is necessary to point out that such a form of argumentation is not phenomenological in Husserl's sense of the term. No reduction has been performed; the examined content of subjectivity is thus an unpurified content which bears the marks of the natural attitude. Sartre begins with Husserl's concept of intentionality and divorces it from Husserl's method, losing its methodological precision.

The discussion in the introduction of EN reviewed in the last pages forms Sartre's phenomenological framework for his ontological inquiry.

${ }^{28} \mathrm{EN}, 28$.

$20 \mathrm{Ibid}$.

${ }^{30}$ Ibid., 28-29. 
With minor exceptions, it is only in the first 37 pages of his 720 page work that he specifically considers any aspects of phenomenology as method for philosophizing, and, more specifically, as method for ontological philosophizing; and it is only in these first 37 pages that Sartre makes use of anything resembling Husserlian phenomenology.

We are advised of Sartre's departure from phenomenological techniques in his description of the Other. Since the existence of the Other cannot be determined ontologically, "Sartre ... renounces all efforts to derive ontologically the existence of the Other." 31 The Other is encountered but not constituted by the ego. We know that the Other exists because he looks at us. The importance of noting this inability to give an ontological proof for the existence of the Other is that non-ontological and, in Husserl's sense, non-phenomenological methods of analysis must be used. Thus, those extensive sections in EN dealing with the Other and with the relations to the Other all rest on nonontological grounds. "Ever since his Ego, in the Third Part of his book, had to acknowledge the existence of the Other as a plain 'nécessité de fait,' his philosophy had left the realm of pure ontology and moved within the onticempirical world." 32

The nature of Sartre's method may be characterized as quasiphenomenological and intuitive. The last term needs clarification. Sartre does not use the term "intuition" in the Kantian sense of Anschauung but rather in the sense of a felt necessity which accompanies an inspection of such experiences as "reveal" themselves as true ontological structures. It is this concept of "revealed" ontological truth which is the heart of Sartre's method. In contrast to hypotheticodeductive types of philosophies, revealed ontology is an exploration of the subject-pole of experience; in contrast to Husserlian phenomenology, ontological revelation does not begin with a formal epoché and does not have a precise methodology. If Sartre's ontology is to be characterized as phenomenological, this cannot be done in the sense of Husserl's usage of the term. However, another alternative is open to Sartre to justify his use of the term.

Sartre's only possible justification for describing his procedures as phenomenological is that his is that variety of phenomenology found in Hegel's Phenomenology of Mind. In this sense, we ally Sartre's onto-

${ }^{31}$ Marcuse, op. cit., 316; also Cf. EN, 307.

${ }^{32}$ Ibid., 319. 
logical investigation to the historical genesis of the field of ontology itself and are enabled to refer the problem of Being back to Hegel and to Aristotle before him. Another alliance which has been quite obvious to students of Sartre is his indebtedness to Heidegger, in whose philosophy the concept of "revelation" is used as the guide to phenomenological method..$^{33}$ According to Heidegger, revelation will come through certain modes of experiencing-through certain moods; and Sartre takes over much of this concept of "revealing." We can now understand the statement that EN "is in large parts a restatement of Hegel's Phenomenology of Mind and Heidegger's Sein und Zeit." ${ }^{4}$

Our basic criticism of Sartre's method, then, is that it deserves the name "phenomenological" only in so far as Hegel's phenomenology is intended, and that it is quasi-phenomenological if we are referring to Husserl's variety of phenomenology. Thus, the greatest part of EN is non-phenomenological (in Husserl's sense) and makes use of the intuitive method of "revelation." The specific forms of investigation which characterize the non-phenomenological parts of EN are closest to products of existential psychoanalysis which are on ontic-empirical rather than pure ontological grounds, and are marked by intuitions, projective guesses, literary insights, and psychological analyses. But such existential psychoanalysis is not an inquiry into Being and Nothingness via a phenomenological ontology.

What effect does departure from Husserlian method have on the validity of Sartre's ontology? The answer to this crucial question is reserved for a later time. Meanwhile, it is important to note that Sartre's failure to state clearly his methodological principles and to use Husserlian method, in addition to his failure to give an ontological proof for the existence of the Other and to remain on the grounds of pure ontology for the greater part of EN, results in internal confusions, basic ambiguities, and ultimate contradictions, and, as we hope to show, philosophic failure to resolve his initial problem. The following pages will have as their purpose the criticism of fundamental aspects of Sartre's ontology. We shall attempt to show in detail how the original failure to clarify phenomenological method and to remain within the scope of pure ontology invalidates Sartre's work.

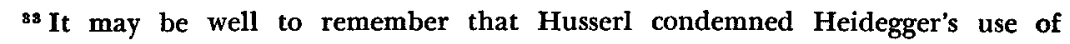
phenomenology as a distortion of Husserlian method.

34 Marcuse, op. cit., 311. 


\section{Chapter VII}

\section{THREE THESES OF L'ETRE ET LE NEANT CRITICIZED}

\section{FREEDOM}

Sartre's concept of freedom is unique: freedom is the condition of the pour-soi; and since the pour-soi exists as "lack," its freedom is the expression of its Nothingness. The pour-soi is what it is not, and is not what it is. This instability defines its freedom. Again, since this is the condition of the pour-soi, man is condemned to his freedom. Man is condemned to be free because man is freedom.

We consider first certain criticisms of Sartre's position.

Emmanuel Mounier argues that since freedom is confined to the circle of subjectivity-to the condition of the pour-soi-it never goes beyond its own subjectivity to meet any real objective obstacles, and that it is objectivity which truly defines freedom.

"Sartre's type of freedom ultimately eschews dramatic appeal, since, in the end, it never actually comes up against any restrictions. Actually, as far as outward observation which objectivates the path taken by freedom is concerned, there is restriction only to the extent to which it is observed. But freedom which is given expression never really comes up against the obstacle, because it creates the obstacle itself, and it never comes up against ultimate limits, not even death, because it has within itself no means of overstepping them. Its limitations are not placed upon it from outside, but by a sort of inherent flabbiness." 1

Mounier's second point is that Sartre's concept of freedom leads to a form of idealism which excludes any meaning from the pour-soi:

"It is impossible to avoid drawing attention to a subtle movement from Realism to ultimate Idealism. Such a drift seems to

${ }^{1}$ Mounier, E., Existentialist Philosophies, 103. 
be the result of a form of freedom which, like the whole of human being, does not ultimately represent superabundance of being but poverty of being. It is, in fact, not even being; like the 'for-oneself' with which it is identified, it represents lack of being; it is nothingness. 'It is because human reality is insufficient that it is free.' It is my constant overflow into the nothingness that $I$ am which gives me this nimbleness amongst things; it is my ontological scantiness which makes me so active; it is my aspiration to this gulf of being in me which puts the opportunity and the achievement before me. Freedom does not bring a state of perfection or any meaning into the world; it is nothing but a perpetual inwardization of contingency, nothing but a return to the primitive outburst of absurdity." 2

His final criticism is that Sartre's concept of freedom leads to a paradoxical theory of responsibility:

"There is . . . a fatal temptation to reduce subjectivity to a form of non-being which is isolated and which gushes forth into the world, which is paradoxically situated in the world and given shape by this fact, but which never actually comes up against the world; it is, in fact, the supreme paradox of a theory of absolute responsibility, a theory by which I am not responsible in the sight of anything." 3

The essence of Mounier's three criticisms is that Sartre is espousing a form of idealism which, in isolating the pour-soi from the world and making of it a Nothingness, results in the failure of the pour-soi to attain those meanings which come only from real contact with the world. Freedom, meaning, and responsibility are categories applicable to the pour-soi only to the degree to which they face objective existence.

These criticisms fail because they rest upon a partial and inadequate interpretation of Sartre's concept of situation. The pour-soi is an empty and abstract term without ontological significance unless it is understood, as Sartre intends it to be, in situation. Situation is the reality of the pour-soi; it is the intense and profound complex of the objective significations, meanings, coefficients of adversity, facticities, etc., determined strictly by Others or by history or by the socio-economic structure of society, and also the activity of the pour-soi which legislates its unique meaning and interpretation to these objective

2 Mounier, E., op. cit., 103-104.

s Ibid., 104. 
structures and relations. Thus, human reality is a combination of objectively existent givens which the pour-soi "exists" in the light of the ends and goals by which it defines itself.

In defining itself through choice, the pour-soi has a dual role: It meets certain coefficients of adversity ( the chains of the slave, for example, and the prison bars which hold him) which it must recognize and admit, but it legislates the meaning of those coefficients of adversity by considering them under certain goals or ideals which it freely chooses (the slave may interpret his chains as elements which limit his liberty or as things to be accepted as his 'just due'; he may interpret his chains as symbols to be revolted against or as symbols to be submitted to, etc.). In choosing the meaning of its coefficient of adversity, the pour-soi incorporates the meaning of the obstacle into its situation. In this sense, therefore, the pour-soi does meet the obstacles of reality.

The mistake Mounier makes is in asserting that the pour-soi does not face reality because it is bound in its subjectivity. But one cannot speak of 'reality' apart from the pour-soi, since reality is the pour-soi in the sense of being the situation of the pour-soi. To go beyond the pour-soi would be to do one of two things: either to penetrate to some noumenal realm of 'objectivity' or else to realize the status of en-soipour-soi. Both are impossible for Sartre; the first, because he has shown that there is no ding-an-sich 'behind' the phenomenon of Being (appearance is Being), and the second, because the whole meaning of the pour-soi is that it is what it is not, and is not what it is. Were the pour-soi to achieve the status of en-soi-pour-soi, the pour-soi would be what it is-would become substantialized-and the human reality, as Sartre has described it, would be shattered, for men would not be men but Gods.

The criticism developed by V. J. McGill is colored by the author's naturalist position and presents in clear language those understandable misinterpretations which result from a failure to comprehend the specifically ontological nature of Sartre's inquiry.

We can outline McGill's charges against Sartre's doctrine of freedom as follows:

1. Sartre's assertion that existence precedes essence results in his ignoring the psycho-biological essence of man. ${ }^{4}$

${ }^{4}$ McGill, V. J., op. cit., 329-330. 
2. The concept of the pour-soi as Nothingness is false, since it ignores the basic elements of continuity and stability in man's nature. ${ }^{5}$

3. McGill denies that "for the human-reality, to be is to choose" on the grounds that choice is not the only determinant in being human. ${ }^{6}$

4. In Sartre's assertion "to choose is to be free," choice is a necessary condition of freedom but not a sufficient condition. ${ }^{7}$

5. McGill denies that one becomes intuitively certain of his freedom in his experience of anguish. He analyzes two of Sartre's illustrations: the fear one has in high places that one might hurl himself down, and the anguish the soldier experiences in relation to his future behavior in an attack. Both instances, McGill says, offer feelings of anguish which are not reliable indicators of freedom. He explains the feelings held in such instances as varieties of psychological reactions (panic, auto-suggestibility, etc.) rather than true indicators of freedom. ${ }^{8}$

6. While Sartre's contention is that the "conscious project" rather than past or present events determines our actions, McGill favors the psycho-biological approach to human action and thinks that the work of such behaviorists as Clark Hull will lead to a surer, experimentallygrourded explanation of the problem. ${ }^{9}$

7. Arguing that objective obstacles truly limit man's freedom, McGill opposes what he takes to be Sartre's position on the question, namely, that "obstacles to freedom are only apparent." 10

8. The conclusion is that Sartre's doctrine of freedom is "too abstract and empty to ever win (sic.) general assent," 11 that it does not permit the setting up of criteria of freedom, and, finally, that since it "stipulates that freedom is already universal and inescapable," 12 it cannot give men directives for the extension of their freedom.

McGill's fundamental misinterpretation of Sartre is his failure to realize that Sartre means by the term "freedom" a radically new and

\footnotetext{
${ }^{5}$ McGill, V. J., op. cit., 330-331.

${ }^{B}$ Ibid., 331.

"Ibid., 332.

${ }^{8}$ Ibid., 333.

${ }^{9}$ Ibid., 335.

${ }^{10}$ Ibid.

${ }^{11}$ Ibid., 341.

12 Ibid.
} 
different doctrine which philosophic analysis has not hitherto revealed. Since Sartre is concerned purely with the ontological nature of freedom, all criticism of his doctrine, if it is to be meaningful, must be oriented with respect to this point of view. McGill, however, starts out with a naturalistic conception of Being and presupposes what Sartre endeavors to analyze.

There are two levels of human freedom: the first is the freedom of human Being which Sartre analyzes. This Being is prior to all psychological pronouncements. The second level of freedom is what naturalists such as McGill have in mind when they use the term. Here freedom refers to the existence of alternatives in human situations: the common sense understanding of freedom. By definition, the slave is the man who does not have freedom; otherwise, he would not be a slave. But the inescapable point is that this definition presupposes the nature of human reality and human consciousness by accepting psychological descriptions which are ontologically unexamined.

Sartre's task is ontological; and with this fact in mind we shall examine the specific charges made by McGill.

1. Sartre does not ignore the psycho-biological basis of man. $\mathrm{He}$ describes this basis under the category of "facticity." However, this facticity is not an "essence" of man, since its meaning is dependent upon the pour-soi for its interpretation. The pour-soi "exists" its facticity under the goals and ends it chooses for itself. Sartre does not deny essences to men: but he insists that all we can mean by essence is the resultant of the pour-soi's actions rather than any a priori and inescapable "human nature."

2. Continuity and stability are not denied the pour-soi; rather, the pour-soi is its memories, its past actions and choices, its physical, social, and cultural heritage in so far as it "exists" these aspects of its nature. The pour-soi is not an utter chaos but a dialectical continuity. The past actions, choices, attitudes, etc., of the pour-soi are forever in suspension in their Being; that is to say, the meaning of all of those aspects of the pour-soi is continually in question, since the new actions and choices of the pour-soi will alter or discard their importance and meaning. Although the pour-soi is what it is not and is not what it is, it is not an anarchic flux: its flux is dialectical. Its meaning and nature are continually being defined and redefined.

3. The meaning of choice is that the pour-soi is choice. It "exists" itself only by virtue of its choices. McGill has taken a typically 
naturalistic definition of choice and, upon the basis of this definition, attacks Sartre's concept of choice, which is on a different level. For Sartre, choice is never completed because the pour-soi is in flight and continually redefines itself. We are therefore human when we choose. Also, for Sartre, aesthetic enjoyment, love, humor, etc., are aspects of the human reality and of man's freedom, since the meaning which they have for the pour-soi is determined only to the degree to which the pour-soi chooses and appropriates those aspects of its experience.

4. To be consistent with Sartre's purpose in EN, we would have to say that the "test" of freedom which McGill mentions is revealed in the ontological analysis of the pour-soi, because freedom exists only by virtue of the pour-soi. McGill desires non-ontological criteria of freedom; and with these Sartre is not concerned.

5. We must distinguish between the intuition of anguish and the psychological states which may associate themselves with the intuition of anguish. The latter, but not the former, are the proper study of the psychologists. That the psychological experiences associated with the intuition of anguish may vary, Sartre can admit without endangering his position. The feeling of anguish is not the unavoidable accompaniment of the human condition, since we can escape by "bad faith." Anguish as an intuitable meaning of the human condition is inescapable. But McGill overlooks this difference.

6. Sartre is not attempting to ignore the importance of past and present events in human experience. $\mathrm{He}$ is trying to show only that such events are not fatalistic constants whose meaning, once stated, is forever frozen and static. The conscious project which determines our action is itself the expression of the pour-soi, which is in so far as it is the dialectical and dynamic unity of past, present, and future.

7. This criticism ignores Sartre's description of the coefficient of adversity which faces the pour-soi in its existence. The slave's chains are an obstacle to his freedom, but the latter is meaningful only in so far as the slave wishes to be free of his manacles. In other words, it is in the project of the pour-soi that freedom is expressed. The chains are only an apparent obstacle to the slave's freedom because the latter is only in so far as the slave has chosen the end of liberty. McGill has confused the concept of liberty-physical right to go about one's business-with the ontological concept of freedom. Sartre does not argue that the slave is at liberty to scale a fifty-foot wall or to break the steel bars of his prison with his fists; he argues, rather, that the meaning 
of the slavery of the individual is comprehensible only through an analysis of the situation of the pour-soi involved.

8. The popular appeal of a highly technical philosophic concept is no criterion for the validity of that concept. The criteria McGill wishes to set up deal with a common sense notion of freedom: one with which Sartre is not concerned here. Finally, the stipulation that man's freedom is inescapable, far from limiting the possible directives for human freedom, is the basis for asserting that such directives are unlimited. Since man is condemned to be free, everything is possible to his freedom.

Despite the answers given above to the criticisms of Mounier and McGill, we must admit that these critics of Sartre have hinted, however inadequately or mistakenly, at a certain core of truth in their analyses of freedom. This core might best be described through questions which we think Sartre fails to answer, and sometimes even fails to raise, in his ontology. These questions are: Although man "exists" his facticity, is not this facticity a sector of man's Being upon which only relative limits can be placed? Is it possible for the pour-soi to negate its own Nothingness via a violent flight from reality? ${ }^{13}$ In the case of the tortured man who chooses the instant he will "give into" his torturers, the question arises: Even if we agree that he chooses his torture by relenting at a certain point, what can we say of his freedom after that point? Finally, it is necessary to ask: How will existential analysis relate ontological freedom to those areas of freedom which comprise man's social, economic, and moral values? Thus far such correlation is lacking. Sartre's short work, Existentialism, is but a rough and, at points, vague attempt in this direction.

\section{NOTHINGNESS AND BAD FAITH}

The Nothingness of the pour-soi consists in the fact that the pour$s o i$ is what it is not and is not what it is. Consciousness is "nihilation" because it is in flight in its existence. It is perpetually remaking itself, redefining itself. The pour-soi is what it "is-was" (est été) in so far as its future projects reveal and interpret that "is-was"; the pour-soi is what it is not, because its situation is in flux. Thus, for Sartre, Wesen ist was gewesen ist.

${ }^{13}$ To illustrate: even if we may say that the catatonic schizophrenic chooses his disease, is there a true pour-soi extant after that choice? 
The anguish of man is his awareness of his responsibility, and this responsibility is man's burden because his existence is beset by the necessity of constant choice. Since the pour-soi is Nothingness, it cannot appeal to any a priori "human nature" for guidance to action in choice. The pour-soi is in so far as it is choice. For these reasons, anguish is the stamp of man's Nothingness.

Now if man is condemned to be free as Sartre says, is there any manner in which man may choose to yield his freedom or to hide from it? In his description of "mauvaise foi" (bad faith), Sartre has indicated that there is a mode of Being in which the pour-soi seeks to "un-free" itself-to take leave of its anguish, its responsibility. Our problem, then, is to attempt to discover the relationship between Nothingness and bad faith, and to determine whether it is possible for the pour-soi to negate its own Nothingness and shun its responsibility.

Bad faith is the attempt of the pour-soi to deny itself by trying to hide from its own anguish. The pour-soi tries to escape its anguish by fleeing from one aspect of its nature: its "is-was." Although the pour$s o i$ is not what it is, it does "exist" its "is-was" aspect (its past actions, choices, etc.). Two interpretations of this "is-was" of the pour-soi are possible: first, the attempt to substantialize the "is-was" into an essence. This might be illustrated by the description of man as being a coward because in the past he has committed certain cowardly acts. Such is the argument of those who hold for a "human nature," an essence of man which antecedes his acts and determines them. Obviously, this interpretation is the antithesis of Sartre's own position.

The second interpretation of the "is-was" is the conception of it as dialectically bound up with the existence of the pour-soi. The meaning of the "is-was" is continually in suspension, for man, by his actions, redefines and reinterprets his "is-was." Thus, Sartre maintains that the "is-was" of the pour-soi is that which the pour-soi is not. Now, to act in bad faith is to attempt to deny both of these interpretations. ${ }^{14}$

The individual who acts in bad faith seeks to negate the "is-was" of his pour-soi. This negation may be accomplished either by stopping at a certain period in one's life and refusing to take into consideration or even admit the changes that occur, or by clinging to the fact that

${ }^{14}$ EN, 103-104. 
changes are always taking place in one's situation, and refusing to be held accountable for what one has done in the past. ${ }^{15}$

However, all attempts to negate the "is-was" must result in failure, because every effort to flee from anguish and responsibility inevitably takes place under an unintended but unavoidable recognition of anguish and responsibility. "The flight from anguish is only a mode of being conscious of anguish. ... It cannot be concealed or avoided."16 Here is the paradox of bad faith: to be in bad faith is to attempt to flee from one's anguish, but such flight is accompanied necessarily by a recognition of anguish. Sartre states the paradox in the following way: "The first act of bad faith is to flee from what one cannot flee, to flee from what one is." 17 The condition of flight from Nothingness is Nothingness; and "the condition of the possibility of dishonesty is that the human reality in its most immediate being, in the intrastructure of the pre-reflective cogito, must be what it is not and not be what it is." 18

It might seem from this description that, since bad faith is a paradoxical condition, the pour-soi could never truly achieve the status of bad faith. To reason oneself into bad faith, to select or choose bad faith,-all such conscious actions could not lead one beyond the paradox; i.e., bad faith could not be realized, because its realization would depend on escaping from anguish, and active choice of escape from anguish means awareness of anguish. How, then, is bad faith possible?

Sartre's answer is that bad faith is not a "question of a reflectedupon and voluntary decision, but a spontaneous determination of our being." 19

"One is placed in bad faith as one sleeps and one is of bad faith as one dreams. Once this mode of being is realized, it is as difficult to go away from it as to wake up. Bad faith is a type of Being in the world, like insomnia or dreaming, which attempts by itself to perpetuate itself." 20

\footnotetext{
${ }^{15} \mathrm{EN}, 97$.

${ }^{10}$ Ibid., 82.

${ }^{17}$ Ibid., 111.

${ }^{18}$ Ibid., 108.

19 Ibid., 109.

${ }^{20}$ Ibid.
} 
With this "spontaneous determination of our being" goes a weak and uncritical acceptance of the world of bad faith, an initial decision not to make decisions, an initial decision to be indecisive. Bad faith does not maintain the criteria of truth as they are accepted by the critical thought of good faith. Bad faith is resigned in advance not to be transformed into good faith. ${ }^{21}$ Through the intitial determination of bad faith there will be obstinacy in the face of truth and a willingness to adhere to uncertain evidence.

The conclusion is that bad faith is a constant threat to consciousness: the unavoidable menace which accompanies the Nothingness of the pour-soi.

"If bad faith is possible, it is because it is the immediate and permanent menace of every project of the human being, it is because consciousness conceals in its being a permanent risk of bad faith. And the origin of this risk is that consciousness, at the same time and in its being, is what it is not and is not what it is." 22

With this exposition of bad faith in mind, we may turn to a criticism of the arguments Sartre has set forth regarding bad faith and its relationship to Nothingness.

Sartre has presented a highly ambiguous theory of bad faith. He argues, to begin with, that flight from Nothingness is a priori a failure, since admittance of Nothingness is presupposed in the attempted flight. Yet later he describes bad faith as a "type of being-in-the-world," and presumably this "being-in-the-world" is something more than a momen. tary structure. Sartre compares it to insomnia or dreaming and states that it is difficult to escape. If bad faith has this stability as a type of Being in the World, then how is it achieved? The failure to escape Nothingness would appear to render this stability inconsequential or illusory.

By holding that bad faith is not a reflective and voluntary decision "but a spontaneous determination of our being," Sartre presents a form of argument directly antithetical to what he is attempting to demonstrate. Sartre's point is that to be in bad faith is to fail to escape anguish, since choice of bad faith involves choice of anguish. Active choice is the key to the concept of bad faith. Yet when Sartre argues

21 EN, 109.

22 Ibid, 111. 
at the same time that active choice is not involved in the "spontaneous determination of our being," he has involved himself in a basic contradiction.

Sartre's main purpose in introducing the concept of bad faith was to show that, although man is condemned to be free, he is able to seek ways of avoiding that freedom. Bad faith is a meaningful concept only if it represents an anti-freedom value. Sartre has succeeded, however, in showing that bad faith is really only a peculiar aspect of freedom. Again, this is difficult to reconcile with the fact that he states that bad faith is the "menace" which accompanies every human project. Is the menace introduced by the pour-soi itself in the acts of choice of the pour-soi in its projects? Or is the menace of bad faith an a priori correlative of Nothingness which accompanies every pour-soi? When Sartre argues that bad faith is chosen, he is more consistent with his general position, but the meaning and force of the concept of bad faith are watered down. When Sartre argues that bad faith is some sort of spontaneous determination, he leaves the general line of his argument and make of bad faith an order of an a priori correlate of the pour-soi.

While it is clear that his general intention is to describe bad faith as the flight from anguish, from responsibility, from Nothingness, Sartre fails to make clear the nature of this flight and the import of its success or failure in its venture.

Involved in the entire concept of Nothingness and of bad faith is the problem of the facticity of the "is-was." Bad faith flees from its "is-was" because it is unwilling to accept the responsibility for the actions it has performed. But if the meaning of the acts and choices which comprise the "is-was" is always in transition, then a crucial problem arises: for what, precisely, is the pour-soi responsible? If I acted like a coward last year on fifteen occasions, then it would seem that these instances of cowardice comprise one sector of my "is-was." But now it is necessary to observe that these acts were acts of cowardice only in the light of certain criteria of cowardly action. Since these criteria are themselves in transition and are meaningful only in the light of my own projects, how can we say that the pour-soi is responsible for these cowardly acts? The meaning of cowardice is in suspension; therefore, the meaning of my past actions is also in suspension. In what sense are we responsible for them?

The point of the above criticism may be rephrased in the following way: if we are faithful to Sartre's argument, the actions which comprise 
the "is-was" can never be characterized as being acts of love, hate, violence, heroism, cowardice, deceit, etc. They may be characterized only as acts of a certain order and structure; e.g., to use love as an illustration, my "is-was" acts were acts of making certain vows, of performing certain actions, and so on, and these acts are called acts of love by definition and agreement. Thus, to be consistent, we should reduce the acts of the "is-was" to their basic structures. We cannot go beyond these basic structures and say that such and such an act was an act of love, because future experience may demonstrate that it was the opposite. The ardent filial love I bore my mother at the age of nine may turn out, ten years later, to have been part of an oedipus complex, which would then alter the meaning of that original love.

It is highly ambiguous to say that I am responsible for the actions of my "is-was." To follow the example just given, I am responsible for acts of kissing and hugging my mother at the age of nine, but does this mean that $\mathrm{I}$ am responsible for loving my mother at the age of nine? The latter could never be determined until the pour-soi is nonexistent.

The import of the criticism just made is that Sartre's concept of anguish must be extended. Since my responsibility for the acts of my "is-was" is a perpetually ambiguous one, my anguish is extended. The choices I make in the present and in the future not only define my pour-soi as a whole but redefine the facticity of my "is-was." By extending the concept of anguish we arrive at a more consistent interpretation of Nothingness, for it is now more clearly apparent that the pour-soi is that which it is not. The facticity of the pour-soi must be reduced to the bare structure of its past actions, whereas the Being of those actions is perpetually in question, because that Being is intimately associated with the meaning of the actions.

There is one final question concerning Sartre's conception of Nothingness: Is there any point where the human equation which is the pour-soi cancels out? We raised this question in the previous section by asking whether there is a true pour-soi extant in the catatonic schizophrenic after the choice of his disease (admitting the choice of the disease for the sake of the argument). Much of the criticism that has been raised against Sartre's concept of freedom is that this concept is false to reality, that it makes no sense, for example, to speak of the cremated prisoner of the concentration camp as having freely chosen his imprisonment and destruction. Sartre has said that either man is 
completely free or is not free at all. However, we may still raise the question of whether human freedom may undergo states of negation, leaving aside the question of whether those states have been initially chosen or not.

In our criticism of Sartre's theory of Nothingness and bad faith we have thus made the following points:

1. It is not clear whether bad faith is chosen by the pour-soi or is an a priori correlate of Nothingness.

2. It is unclear whether the pour-soi can truly achieve a status of bad faith.

3. The concept of anguish must be extended to accommodate the unsubstantiality of the "is-was."

4. It is doubtful whether there is ever a negation of the pour-soi.

\section{BEING}

In the introduction and early pages of EN, Sartre tells us that a fundamental problem he faces in his essay is to show that the two seemingly incommunicable realms of Being-the en-soi and the poursoi-do, in fact, ultimately achieve unification in his philosophy and that he is not left with an insurmountable dualism. It will be the burden of this section of our work to attempt to prove not only that Sartre fails to resolve the dualism but also that, by his own principles, any such attempt is destined to be a failure.

Sartre attacks a series of traditional dualisms. (1) He holds that the dualism of interior-exterior of the existant is fallacious, because there is no hidden aspect of Being - no Ding-an-sich. He says that "the being of an existant is precisely that which it appears" to be. ${ }^{23}$ (2) There is no dualism of appearance-essence, for appearance is essence (3) It is the Being of appearance which must be investigated. But upon inspection the Being of appearance reveals itself to be of two distinct varieties: the en-soi and the pour-soi. Here, then, is Sartre's problem: how can the two realms of Being be synthesized?

Sartre's first answer is the following:

"The pour-soi and the en-soi are reunited by a synthetic liaison which is no other than the pour-soi itself. The pour-soi, in effect, is nothing other than the pure nihilation of the en-soi; it is like a hole of being at the heart of being. ... The pour-soi has no

${ }^{23}$ EN, 11-14. 
other reality than that of being the nihilation of being. Its only qualification comes to it from the fact that it is nihilation of the individual and singular en-soi and not of being in general. The pour-soi is not nothingness in general but a singular privation; it constitutes itself as privation of this being." 24

While this description answers the question, "How did the dualities arise?" or, more precisely, "How does the pour-soi arise?," the real question regarding the synthesis of the two polarities of Being is not answered. The solution to this problem must also be the answer to the question: How does the pour-soi unite itself with the en-soi? And to this question Sartre paradoxically states that an answer is not possible:

"We do not have grounds to interrogate ourselves about the manner in which the pour-soi may unite itself to the en-soi because the pour-soi is in no way an autonomous substance." 25

Were the pour-soi an autonomous substance, it would be what it is, but we know already that for Sartre the pour-soi is not what it is and can never be what it is-this status is reserved for the en-soi alone. Since the pour-soi is what it is not and is not what it is, it is impossible to describe the manner in which this "lack," this Nothingness, can unite itself with that which is what it is: the en-soi. We must conclude, therefore, that the synthetic liaison established by the pour-soi between the en-soi and the pour-soi is not the structure which can solve the original problem of how the two polarities of Being are synthesized. At best, the synthetic liaison is an explanatory relation which tells something about the genesis of the realms of Being.

But we cannot yet assert that Sartre has completely failed to solve his problem, for he makes a second attempt. He points out that prior analysis has shown that one cannot understand the pour-soi without immediately taking the en-soi into consideration, and vice versa. Unless the intimate relationship between the two realms of Being is kept in view, they are both reduced to empty abstractions:

"The en-soi and the pour-soi are not juxtaposed. Quite to the contrary, the pour-soi without the en-soi is something like an abstraction. It could no more exist than a color without form or

${ }^{24} \mathrm{EN}, 711-712$.

${ }^{25}$ Ibid., 712. 
than a sound without highness and without timbre; a consciousness which would be consciousness of nothing would be an absolute nothing." 26

Since consciousness is consciousness of the en-soi, the two are in internal relationship which is the essence of the bond unifying en-soi and pour-soi.

"If consciousness is linked to the en-soi by an internal relation, does that not signify that it is articulated with it in order to constitute a totality and is it not to this totality that the name of being or of reality refers? Undoubtedly, the pour-soi is nihilation, but, by virtue of nihilation, it is; and it is in a priori unity with the en-soi." 27

But, Sartre argues, even if this internal relationship does give us a concept of Being which is a synthetic totality, we are left with the dualism as it appears in the existant, who is still a pour-soi in relation to an en-soi.

"If we have to consider the total being as constituted by the synthetic organization of the en-soi and the pour-soi, are we not going to find again the difficulty which we wished to avoid? Are we not going to encounter again in the existant itself the hiatus which we discerned in the concept of being?" 28

Sartre says that in order to be able to consider an existant as a totality, "it is necessary that the diversity of its structures be retained in a unitary synthesis, in such a way that each structure, envisaged apart, is only an abstraction." 29 One part of the equation fulfllis this criterion: the pour-soi envisaged by itself is an abstraction. The other half of the equation, however, does not fulfill the requirement, because "the en-soi has no need of the pour-soi in order to be." 30 The Being of the pure en-soi without consciousness is not an abstraction. Sartre describes the way out of the difficulty in these words:

${ }^{26} \mathrm{EN}, 715-716$.

${ }^{27}$ Ibid., 716.

28 Ibid.

${ }^{20}$ lbid

${ }^{30}$ Ibid. 
"If we should wish to conceive of a synthetic organization such that the pour-soi is inseparable from the en-soi and that, reciprocally, the en-soi is indissolubly linked to the pour-soi, it would be necessary to conceive of it in such a way that the ensoi receives its existence from the nihilation which makes the $e n$-soi take consciousness of that nihilation. What does this mean if not that the indissoluble totality of en-soi and pour-soi is conceivable only under the form of being "cause of self." "31

We may understand the nature of the form of Being which is "cause of self":

"The real is a miscarried effort to attain to the dignity of causeof-self. Every thing happens as if the world, man, and man-inthe-world succeeded in realizing only a God who is lacking (un Dieu manqué). Everything happens as if the en-soi and the pour-soi were presented in a state of disintegration in regard to an ideal synthesis. Not that the integration has ever taken place, but precisely on the contrary, because it is always indicated and always impossible. It is the perpetual defeat which explains at once the indissolubility of the en-soi and the pour-soi, and their relative independence." 32

The conclusion is that the ideal synthesis of Being is an impossible and self-contradictory structure, although if it should exist, we should know also in what manner it existed: we should know its structure.

It is disconcerting to note that if this is a correct interpretation of what Sartre is arguing, then he contradicts himself basically and has not solved his original problem. The contradiction is the following: Sartre is able to posit the possibility of an ideal synthesis of Being by a "pre-ontological comprehension of the self-caused being." 33 The comprehension is pre-ontological because it is of an ideal and not a real structure. Ontological analysis can be made of real (i.e., existant) structures only. Yet Sartre states that ontological analysis includes analysis of the region of "cause of self." He writes: "For ontology, the only regions of being which can be elucidated are those of the en-soi, the pour-soi, and the ideal region of the 'cause of self'."34 Apart from the fact that ontology cannot analyze $i d e a l$ regions, it remains a con-

\footnotetext{
${ }^{31}$ EN, 716-717.

32 Ibid., 717.

${ }^{3 a}$ Ibid.

s4 Ibid., 719 .
} 
tradiction to hold, in view of what Sartre said earlier, that the ideal region of "cause of self" can be comprehended both pre-ontologically and ontologically.

Thus, in his analysis of "cause of self," Sartre has not solved his original problem of the synthesis of the polarities of Being. If "the real is a miscarried effort to attain to the dignity of cause-of-self," if "everything happens ... as if the en-soi and the pour-soi were presented in a state of disintegration," then it must follow that the ultimate integration of en-soi and pour-soi must remain an incomplete and unrealizable ideal. The dualism is not resolved, and the two realms of Being find no true integration. Surprisingly, this is what Sartre himself points out when he says that the integration of en-soi and pour-soi is "always impossible." 35

Sartre's conclusion to the argument concerning the resolution of the dualism of Being is this: "If it is impossible to pass from the notion of being-en-soi to that of being-pour-soi and to reunite them in a common genre, then the passage in fact from one to the other and their reunion cannot be brought about." 36 But it is not possible to reconcile this statement with his earlier claim that his analysis of Being will not end in a dualism of two incommunicable realms of Being.

The only consistent conclusion that may be drawn from Sartre's ontological analysis of Being is the one which he hints at in certain places but does not make explicit, and which he later contradicts. The logical conclusion of his argument is that a self-caused Being "is impossible and that its concept ... contains a contradiction." 37 The contradiction is that man is the creature who aspires to be the en-soi-poursoi. This aspiration must end in failure in principle, for the pour-soi cannot be its own proper foundation, since it is what it is not-since it is Nothingness.

A further aspect of the logical conclusion to Sartre's problem is that if the ideal whole can be imagined or posited, it is only imaginable or positable-never realizable. This is the paradox of the en-soi-pour-soi. The paradox of Being, therefore, is Sartre's proper conclusion. However, if this conclusion is accepted, Sartre must give up the claims made in his introduction to EN, in which he berated the traditional philosophic positions for their unsolvable dualisms.

${ }^{35} \mathrm{EN}, 717$.

se Ibid.

${ }^{37}$ Ibid. 
The logical conclusion to Sartre's own ontology is an unbridgeable dualism. Only within this dualism can all the structures of Being which Sartre describes retain their meaning and consistency. The crucial relations of freedom, choice, situation, etc., all receive consistent interpretation if we understand Sartre's concept of Being as essentially dualistic. The relation of freedom may serve as an example of what is intended here.

The pour-soi is free because it exists as "lack"; i.e., it has no stable or permanent structure which it is. Rather, the pour-soi must continually define and redefine itself. It must make itself as it goes along. Now, the pour-soi is free because it is not the foundation of its Being. Were it en-soi-pour-soi, it would be a permanent and substantial structure: it would be God. However, if we assume now that the pour-soi and the en-soi are united in such a manner that the pour-soi causes the en-soi to be, then the concept of the freedom of the pour-soi is distorted, and the pour-soi itself no longer exists in the way Sartre has previously described. The same applies to the concepts of choice and situation, because they, too, are profoundly bound up with the structure of the pour-soi.

If his ontology were revised so that the en-soi and the pour-soi were made attributes of Being after the fashion of Spinoza, then every structure of Being Sartre has described would lose its unique meaning and he would have accomplished no more than a reformulation of traditional ontologies. The validity, consistency, and significance of Sartre's ontology require the unresolvable dualism of en-soi and pour-soi. 


\section{Chapter VIII}

\section{SARTRE'S "COPERNICAN REVOLUTION": AN INTERPRETATION}

Sartre's "Copernican revolution" is essentially the attempt to formulate at the ontological level what Kant attempted to show at the epistemological level: that the phenomenal world we experience is the resultant of the activity of the forms of cognition upon a primordial "given." The basic similarity between Sartre and Kant which must be kept in mind is that for Sartre the 'molding' of phenomenal reality is at the ontological level derivative of and dependent upon the activity of the pour-soi, which both "exists" reality and exists in reality. There are important dissimilarities, however, between the two Copernican revolutions. Kant describes the action of the forms of sensibility and of cognition which ultimately constitute the synthetic unity identified as the phenomenal object. Sartre, on the other hand, is not concerned with deducing the categories or determining how synthetic a priori propositions are possible and valid for experience; rather, he wishes to find out in what way the human reality is a function of two polarities: the en-soi and the pour-soi. By introducing his Copernican revolution and asserting the priority of the pour-soi, Sartre attempts to demonstrate how the dialectic of relationships which hold between the $e n$-soi and the pour-soi is ultimately comprehensible. It should be added, of course, that Sartre nowhere uses the term "Copernican revolution" to describe this approach to Being; it is implicit rather than explicit in his writing. What follows here is, therefore, an interpretation and not an exposition of what Sartre himself has said.

In our expository section we stressed the fact that there is a strong realistic element in Sartre. The pour-soi "exists" its reality, but also it exists in its reality. By this we understand the following: to "exist" reality is to constitute the reality about us--to appropriate the object. To exist in reality is to be a pour-soi among other pour-sois in a world whose significations are not all $m y$ significations but contain the signifi- 
cations of Others; it is to admit the objective existence of the object through the idea of the coefficient of adversity. For Sartre, reality is the complex: "existed" and existed-in. The polarities of Being are reality, i.e., that which is "existed" is the function of the pour-soi, and that which exists in is the function of the en-soi. But at this point a crucial difficulty arises.

It is one thing to assert that the meaning of experience is dependent on the meaning-giver: the pour-soi; it is quite another thing to hold that the object itself is constituted by the pour-soi. The Kantian Copernican revolution can be interpreted in two ways: either as a working hypothesis in the attempt to explicate the knowing process, or as a metaphysical interpretation which holds that the constitution of the object is directly dependent upon the categories of the understanding in such a manner that, without the synthetic operation of the categories, the constituted object would be impossible and there would be no phenomenal reality. It is here that we find the variation in the interpretation of Kant: the realistic interpretation which considers the activity of mind in the knowing process as fulfilling a strictly logical role of synthesis of meaning, and the subjectivistic interpretation which holds that the phenomenal object is the resultant of the activity of mind as it molds or shapes what is given to it.

Should Sartre's Copernican revolution be given a realistic or a subjectivistic interpretation? Under the headings of signification by Others, coefficient of adversity, etc., we have already dealt with the realistic basis in Sartre's philosophy. We cannot accept the realistic interpretation completely because of contrary evidence: Sartre's intense stress on the appropriative techniques of the pour-soi. Sartre has told us that "the known object is my thought as thing" ${ }^{1}$ and that "to have is to create" 2 and that "the original and radical rapport of creation is a rapport of emanation. ... That which I create ... is myself ... To the degree to which I appear to myself as creating the objects by the sole rapport of appropriation, these objects are me." 3 Sartre repeatedly stresses the importance of both subjectivist and objectivist approaches. Phenomenological ontology is to cut across the positions of both idealism and realism.

1 EN, 668.

${ }^{2}$ Ibid., 680.

${ }^{3}$ Ibid., 680-681. 
Complete appropriation is an ideal and not a realizable structure of experience. "It is impossible to realize the relation symbolized by appropriation," 4 since realization would mean an impossible synthesis-the synthesis, namely, of the en-soi-pour-soi. If, as Sartre maintains, appropriation is a symbolic relation, then any true Copernican revolution in the metaphysical sense is ruled out. Sartre, however, has not accepted a strictly non-metaphysiacl interpretation.

Whether we accept a subjectivist or realist interpretation of Kant, it is still true that for him the sensibility and the understanding are stable structures. As necessary preconditions of the possibility of experience they are constants. If they did change somehow, the experience we might imagine ourselves to have would not be what we could understand as human experience. For Sartre, however, such constant and unchanging categories cannot be introduced into the nature of the pour-soi, for the latter is that which it is not and is not that which it is. The pour-soi, then, is in a constant state of unfulfilment-in a state of "lack." At the ontological level no categorial constants can be ascribed to it. Hence, if the pour-soi molds experience or legislates the nature of its situation, that molding or legislation takes place within a framework of flux and transition of meanings. But if now the nature of the pour-soi is such that a hypothetical interpretation of the Copernican revolution is ruled out (since appropriation is a projective but unaccomplished relation), what is left?

Sartre's Copernican revolution at the ontological level places the pour-soi at the core of existence. The pour-soi has priority because it is its situation. However, since the pour-soi is in perpetual flux, the significations which it creates change with it. In short, the constancy or regularity of the phenomenal world of Kant has been denied, and in its place is put a dialectical reality. The essence of Sartre's Copernican revolution, therefore, is that the manifestation of the pour-soi is dialectical reality. Reality exists through situation, and situation is a function of the pour-soi. To be sure, the en-soi does have a facticity which is independent of and prior to the individual pour-soi, but the meaning of the en-soi is determinable only through the pour-soi. Thus, Sartre's Copernican revolution establishes two points: 1) that reality is a function of the pour-soi although it is not the phenomenal world of Kant; it is the dialectical reality which the pour-soi "exists";

${ }^{4} \mathrm{EN}, 683$. 
2) that the facticity of things has realistic status, but that the meaning of this status depends on the interpretation it receives from the poursoi. In a certain sense, therefore, the Copernican revolution intended by Sartre has never been and never can be completed. It is a perpetual and on-going process. Its meaning is continually in suspension.

Is it of value to introduce this interpretation of the Copernican revolution into Sartre's work? We said earlier that Sartre has performed his revolution on the ontological rather than the epistemological plane. His revolution gives an explanation of how Being is determined by human Being, or, to put it in another way, how the en-soi is determined by the pour-soi. But if our interpretation of Sartre's Copernican revolution is correct, the resultant of the revolution is a non-stable reality, is Being in flux. The importance of having introduced the concept of the Copernican revolution into this discussion lies in the fact that we may now use it as an interpretive category in furthering our understanding of Sartre's ontology, in particular, the nature of appropriation.

The appropriative relation is, in principle, incomplete and must, therefore, remain an ideal. Appropriation for the pour-soi is appropriation only of certain segments of the objects of experience, of those segments, namely, which the pour-soi holds in its situation. The ensoi of some unchartered peak in the Himalayan Mountains is not "existed" by me. I do not appropriate it; it is not I. However, the mountain I climb with great difficulty is I. I appropriate it in conquering it.

"The totality of my possessions reflects the totality of my being. I am what I have. It is I that I touch on this cup, on this trinket. This mountain which I climb, it is $I$ to the degree to which I conquer it; and when I am at its summit, which I have 'acquired' at the price of some efforts, I am this large view over the valley and the surrounding mountains; the panorama is I expanded to the horizon, for its exists only because of me and for me." 5

And further:

"Possession is a magic rapport. I am these objects which I possess, but outside of me. That which I posses is me outside of

${ }^{5} \mathrm{EN}, 680-681$. 
me, outside of all subjectivity as an en-soi which escapes me at each instant and whose creation I perpetuate at each instant." 6

The conquered mountain is I as en-soi. But this $e n$-soi is, as it were, an externalized internality-a projection of my pour-soi which has momentarily become en-soi. This $e n$-so $i$ is impermanent. It has no stability of its own, it fades. It necessitates constant renewing for survival and is a "creation I perpetuate at each instant." Such en-soi is impermanent, because the pour-soi is organically incapable of founding its own Being.

Thus, Sartre has shown that the pour-soi can create a certain type of $e n$-soi, but that such en-soi is impermanent because its existence is constantly in suspension; it is like a paralytic who depends upon a machine to keep him breathing and whose life would be terminated the moment the machine stopped working. It seems, then, that the one form of the true metaphysical creation of which the pour-soi is capable is, in principle, doomed to failure. Upon ascending the mountain, $I$ am the mountain, but the en-soi which is the I that is the mountain is an en-soi that can never be realized in true permanence and stability.

Making use of the Copernican revolution as an interpretive category, we may attempt one more and final analysis of a certain existential problem: Sartre's idea of situation. The pour-soi, in order to be pour-soi, must be engaged. It must choose itself in a situation. The pour-soi "exists" the situation. All of the significations, the meanings of projects, the interpretation of rapports, the grasping of the facticity of objects, and so on-all of these, making up the reality of the poursoi, are the pour-soi and define its existence. Now, if we admit that through the thesis of the Copernican revolution the pour-soi constitutes its dialectical reality ("exists" its situation), then it must follow that the pour-soi is responsible for its situation. Further, since the situation of the pour-soi includes other pour-sois, it also follows that the pourso $i$ is responsible for Others as well. If, as Sartre says, situation is possible only through choices of the pour-soi, then these choices involve a grave responsibility, for they affect completely and profoundly the status of Others. In Existentialism we learn that, when we choose, we choose all mankind and involve thereby all mankind. Thus we choose in anguish.

- EN, 681. 
Since Sartre has not pursued the value question in EN, it is unnecessary for us to continue further with this analysis. We see, however, that, as an interpretive category, the thesis of Sartre's Copernican revolution goes far toward explaining many aspects of his philosophy which otherwise would remain unconnected or obscure. For example, the frequently recurring statement that Being haunts the pour-soi now becomes intelligible. The pour-soi is haunted by the en-soi which it can never absorb or with which it can never become one; it is haunted by its passion to make itself the Absolute: God. It is haunted also by the fact that, while it "exists" its reality, it can never stabilize that reality; it must re-create it at every moment. The responsibility for this re-creation is the anguish of the pour-soi. It is anguish that haunts the pour-soi, the anguish of Being. 


\section{Chapter IX}

\section{FINAL EVALUATION}

"Metaphysics is not a sterile discussion about abstract notions which have nothing to do with experience. It is a living effort to embrace from within the human condition in its totality."

$$
\text { -Sartre }
$$

In our introduction we described the general area of existential thought, both literary and philosophic, and we attempted to show in this connection that Sartre's technical philosophy cannot be understood from his popular novels or plays or public lectures, but that he is a serious philosopher attempting to investigate the problem of Being via a phenomenological ontology, and that it is only by an examination of his EN that a real comprehension of his philosophic thought can be attained. We indicated further that certain fundamental questions face Sartre's projected ontology: Does phenomenology have the inner capacity to expand into a critical theory of knowledge and into an ontology? Is phenomenology a generalized Kantianism? And, finally, in what sense is Sartre's variety of phenomenology indebted to Husserl and Hegel? We shall return to these questions in order to indicate our final conclusions regarding Sartre's answers to them.

After an exposition of the structure and content of $\mathrm{EN}$, we turned to our criticisms of the work. In the discussion of phenomenological method we described Husserl's phenomenology and attempted to show that Sartre's method is distinctly non-Husserlian and that the only valid sense in which it can be termed "phenomenological" is in the Hegelian sense of the term. In this respect EN is in many ways a restatement of the Phenomenology of Mind. The significance of Sartre's failure to adopt Husserl's method we shall discuss later.

Next, we examined three central theses of EN: Freedom, Nothingness and Bad Faith, and Being. In the first thesis, we examined the Sartrean concept of freedom and defended it against the attacks of several critics who, we claimed, had misinterpreted its meaning. We 
reserved our own criticisms of Sartre's doctrine of freedom for the second thesis on Nothingness and Bad Faith, because this thesis is intimately tied to the concept of freedom. Our major point of criticism of Sartre's concept of Nothingness was that the idea of human responsibility, which is the core of the concept of Nothingness, is presented in a paradoxical light: it is not clear from the discussions in EN whether Bad Faith (flight from responsibility) is a "possible" of the pour-soi. Associated with this criticism is our discovery of the uncertain status of the facticity (the "is-was") of the pour-soi and the role it plays in human freedom.

In the third thesis on Being we investigated the fundamental dualism of the en-soi and the pour-soi in Sartre's ontology. After showing that the essence of Sartre's contribution to ontology lies in the $a$ priori incapacity of the pour-soi to become its own foundation: to become en-soi-pour-soi (the Absolute or God), we demonstrated that Sartre's attempt to resolve the dualism through some sort of synthetic liaison or idea of "detotalized totality" must prove a failure for two main reasons: first, because the structure of the argument in EN requires the dualism, and, second, because the ideal synthesis of the polarities of Being would transcend the reach of ontological analysis.

The final critical section is concerned with what we have termed Sartre's Copernican revolution. The criticism raised there is that in Sartre's description of the dialectic of relationships which holds between the $e n$-soi and the pour-soi, there is contained implicitly an attempt to formulate at the ontological level something analagous to Kant's revolution in epistemology. Rather than its being introduced as a working hypothesis, Sartre's revolution, we held, is the outcome of his kind of phenomenological inspection of what is given in experience. The importance of raising the question of an ontological revolution is that, having formulated the idea of a Copernican revolution, we may then use it as an interpretive category in the analysis of other areas in Sartre's thought which might otherwise remain obscure. Thus, via the Copernican revolution, we re-examined such vital Sartrean concepts as "appropriation" and "situation" and were able to secure a more complete understanding of Sartre. Finally, we showed that through clarification of the concepts of appropriation and situation, we were able to achieve greater insight into his doctrine of human responsibility: the profound relationship between the pour-soi, human freedom, human responsibility, and existential anguish. 
With this summary of our work in mind, we turn now to questions raised in the introduction.

(1) Does phenomenology have the inner capacity to expand into a critical theory of knowledge and into an ontology? Despite the fact that writers such as Farber have attempted to present Husserl's phenomenology as strictly philosophic method, it nevertheless remains true that Husserl himself, in later years, developed a position in many respects close to the transcendental idealism of the Kantians. In accepting Husserl's method in the extremely limited and partial sense we have previously indicated, Sartre cannot be said to be part of the movement of the followers of Husserl, who are attempting to carry his work forward in various special fields. It is not, therefore, Sartre's intention to attempt the expansion of Husserl's phenomenology into an ontology. We shall return later to the question of whether or not such an expansion is possible.

(2) Is phenomenology a generalized Kantianism? This question remains a general problem confronting Husserlian phenomenology rather than a specific question for Sartre. We have tried to show in the section on Sartre's Copernican revolution that on the ontological level, he faces some questions basically similar to the questions Kant faced. The answer to the question of whether phenomenology is a generalized Kantianism should come from Husserl rather than from Sartre.

Perhaps the basic similarity between Husserl and Kant is that both are profoundly concerned with a non-psychological exploration of the categorial structure and content of subjectivity in general and of consciousness in particular. As for Kant the problem of knowledge is referred back to cognition and is analyzed there transcendentally, so for Husserl "Phenomenology refers the being of the world back to the transcendental subjectivity in whose life the world is "valid'." 1 One way of referring to Husserl's concern with subjectivity is to view it in the light of the Kantian problem of the a priori. Thus, according to Farber, "Husserl has formulated the method which is implicit in all attempts, from Kant to Lewis, to determine the a priori aspect of experience." 2 What is pursued by Husserl is the typically Kantian

\footnotetext{
${ }^{1}$ Farber, M., The Foundation of Phenomenology, 553.

${ }^{2}$ Ibid., 562.
} 
quest for that comprehension obtainable "only by an analysis which gives an account of the part played by mind (or subjectivity) in its relationship with that which is 'given' in experience." 3

Although we can give no final answer to Husserl's own ideas regarding the inner capacity of phenomenology to be expanded into a generalized Kantianism, we do know that phenomenology deals with basically Kantian questions, that Husserl, in his later philosophizing, turned more and more to a sympathetic interpretation of Kant and, finally, that some of his writings indicate that, had he lived to complete his projected work, he would have taken up many of the questions we have considered in the course of this work, and especially the basic questions we have now raised regarding the relationships between phenomenology, Kantianism, and ontology. The demonstration of Husserl's concern with these areas is revealed convincingly when Farber writes:

"It was Husserl's aim through the years to determine the genuine concept of the analytic, as distinguished from Kant's unclear concept of it, and to distinguish the genuine analytic ontology from the essentially different material (synthetic-a priori) ontology. After the appearance of the Logical Investigations he planned a systematic theory of categories, or of the possible regions of being; and he was careful to distinguish the phenomenological a priori from the ontological a priori." 4

We might conclude our answer to the question of the relationship between Husserl's phenomenology and Kantianism by pointing out that there was an agreeable and close kinship between the Marburg school of Neo-Kantianism and Husserl's phenomenology. In the opinion of Husserl, Natorp was one of the very few critics who understood his work as it appeared in Logical Investigations. This thread of communal interest and mutual respect which runs through the relationship of phenomenology and Neo-Kantianism continues to the present day. ${ }^{5}$

${ }^{3}$ Farber, M., The Foundation of Phenomenology, 562.

4 lbid., 206.

${ }^{5}$ It can be observed in the interest of Cassirer in phenomenology and in the interest of such representatives of the phenomenological school as Fritz Kaufman in Neo-Kantianism. The intended "dialogue" between Cassirer and Kaufman which was to take up these very problems was made impossible by the death of Cassirer. See Kaufman, F., "Neo-Kantianism and Phenomenlogy." 
(3) In what sense is Sartre's variety of phenomenology indebted to Husserl and Hegel? We have largely answered this question in our section on phenomenological method by showing in detail what the Husserlian method of phenomenology is and how Sartre departs radically from it. We concluded in that section that the only true sense in which Sartre can call his ontology "phenomenological" is the Hegelian sense of that term. Accordingly we wrote that EN is in large part a restatement of Hegel's Phenomenology of Mind. But the real question that arises in this connection is: What is the significance of Sartre's abandonment of Husserlian phenomenological method? What effect does this abandonment have on his ontological inquiry?

In the final analysis, Sartres "radical' ontology rests upon the claim to a new method of dealing with the questions of ontology. Unless he does use a new method, his work can be considered only as a repetition of the old. If we realize that it has been the burden of much contemporary philosophy-the positivistic movement, in particular-to rid philosophy of the traditional morasses and forests of empty verbiage which have resulted from metaphysical systems, it would be only a poor excuse for Sartre's claim to originality to have merely restated Hegelian philosophy.

From the very start of EN, Sartre attacks prior ontologies and philosophic positions as having led to unresolvable dualisms and impasses; phenomenological ontology is created for the very purpose of overcoming the difficulties of this situation. Thus, Sartre's work, judged by his own claims and intentions, can be considered a meaningfully new approach to ancient problems only if his method is new and distinctive. He leads us to believe that it is Husserl's method he will employ, but then proceeds to abandon that method and, without overt statement, returns to Hegelian phenomenology. Because of this abandonment, he gives up the one hope he offered for precise and clear methodology. Let us see if we can get to the heart of Sartre's reason for departing from Husserlian method.

In accepting Husserl's idea that all consciousness is consciousness of something, Sartre places his ontology on the terrain of Husserl's starting point: subjectivity. With Husserl, Sartre agrees that the Cartesian point of orientation is the only true starting point in philosophic inquiry. However, where Husserl develops strict methods for the inspection of intentionality, Sartre does not. In giving up the theory of intentionality, Sartre departs drastically from Husserlian phenomenology. His quarrel with Husserlian intentionality is, fundamentally, that 
it results in that variety of idealism which fails to found transcendent Being.

"During his whole philosophical career, Husserl was haunted by the idea of transcendance and passing-beyond. But the philosophic instruments which he used, in particular his idealist conception of existence, deprived him of this transcendance. His intentionality is only the carricature of it. The Husserlian consciousness can, in reality, transcend itself neither toward the world nor toward the future, nor toward the past." 6

The difficulty in understanding Sartre's use of phenomenology arises because he does not completely give up the Husserlian phenomenology. He retains its starting point in intentionality, but this retention of the starting point is not a retention of the meaning, nature, or use of Husserlian intentionality. All of these are given up. What does Sartre put in their place?

We observed in an earlier section that Sartre makes considerable use of a kind of "ontological argument." It is his use of the ontological form of arguing that replaces the distinctive method of intentionality as developed by Husserl. Sartre's ontological proof of transphenomenal Being begins with the idea of intentionality, with the idea, that is, that consciousness is consciousness of something. However, he does not continue the argument as the tradition of Anselm would have it, i.e., he does not argue that there must be Being because we have an idea of it. Rather, Sartre argues that subjectivity itself is possible only on the condition that what it is conscious of is a real and transphenomenal existant. Consciousness of Being, he contends, is a revealing intuition which implies a revealed.7 Thus, "to say that consciousness is consciousness of something, is to say that it must be produced as revelation-revealed of a being which is not it and which is given as existant already at the time it reveals it." 8 Sartre concludes that "there is an ontological proof valid for the whole domain of consciousness." 9

The "revealing" of Being returns us to our earlier criticism in the section on phenomenological method in which we stated that the concept of proof or demonstration in Sartre resolves itself into an

\footnotetext{
- EN, 152-153.

'Ibid., 28-29.

s Ibid.

- Ibid., 30.
} 
order of "revealing" of the status of ontological affairs. It is now possible to see that the ontological proof is not a proof in the traditional scholastic sense but an ontologically "revealed" condition of Being.

What has Sartre gained and lost by this substitution of ontological proof for Husserlian method? According to his own views, he has gained that transcendance of Being which, he claims, "haunted" Husserl's philosophizing; unfortunately, he has gained it (granting, at present and for the sake of the argument, its validity) at the cost of replacing any rationally comprehensible form of proof with a psychological, nearly-mystical, and ontic sort of demonstrability. This form of demonstration is quasi-phenomenological in so far as it stems from the Husserlian theory of intentionality, but it is non-phenomenological in so far as it takes advantage of the "natural attitude" as its principle of verification.

This Sartean method is consistently used only in the opening pages of EN. After Sartre, admittedly, fails to accomplish an ontological proof for the existence of the Other, he uses the phenomenological method sporadically and inconsistently. Throughout the sections on the concrete relations between selves, he leaves all forms or degrees of phenomenology and gives us a psychologistic account of sadism, masochism, sexuality, etc. In existential psychoanalysis he abandons phenomenological philosophizing. Only in the last third of EN, when he returns to the problem of human freedom, does he seek to reestablish his phenomenological lines; but by this time his analyses are largely based on what has gone before, and this prior content, to a great degree, reduces his analysis to existential psychoanalysis. Now, for Sartre, existential psychoanalysis is valid because it rests upon previously established ontological foundations, but since those supposed ontological foundations are shot through with psychologism, as well as with genuine intutitions and keen insights-none of which being the instruments Sartre purports to be using-the arguments based upon these foundations cannot be validated, not even on Sartre's own grounds.

Summarizing our criticism of Sartre's method, we may therefore say that, through the abandonment of true Husserlian phenomenology, Sartre invalidates his inquiry and the resultant ontology, because of the lack of a clear and consistent method. Sartre is drawn from ontological to psychological analysis and thus fails to present a clear theory of proof. Without such a theory of proof Sartre's ontology is left wide open to the attacks of positivism: the general charge being 
that Sartrean terminology is meaningless and Sartre's problem a "pseudo-problem." The nerve of the positivist attack lies in the claim that the propositions of ontology-as of metaphysics-are nonsensical and that, accordingly, the time has come to purge contemporary philosophizing of such meaningless and useless hindrances to clear thinking.

Ayer gives a concise statement of the positivistic rejection of metaphysics when he writes:

"We may ... define a metaphysical sentence as a sentence which purports to express a genuine proposition, but does, in fact, express neither a tautology nor an empirical hypothesis. And as tautologies and empirical hypotheses form the entire class of significant propositions, we are justified in concluding that all metaphysical assertions are nonsensical." 10

With metaphysics eliminated, the concept of philosophy which remains is described as follows:

"The propositions of philosophy are not factual, but linguistic in character-that is, they do not describe the behavior of physical, or even mental, objects; they express definitions, or the formal consequences of definitions. Accordingly, we may say that philosophy is a department of logic." 11

In a recent work on analytic philosophy, Arthur Pap tells us that "a metaphysical statement is not just at the time unverified but unverifiable in principle." 12 Also, "according to positivist usage ... a metaphysical statement is one which it is logically impossible to verify." 13 Examples of metaphysical statements for positivist writers are: "There was a time when matter was created" and "There is a cause which itself is uncaused, that is, a first mover." 14 It is obvious to any reader of EN that the complex, often obscure, figurative, and elusive language of Sartre yields statements which are much worse instances of what the positivists term "nonsense." It is enough to call to mind such a key statement as Sartre's characterization of the pour-

\footnotetext{
${ }^{10}$ Ayer, A. J., Language, Truth and Logic, 41.

${ }^{11}$ Ibid., 57.

12 Pap, A., Elements of Analytic Philosophy, 9.

${ }^{13}$ Ibid., 10.

14 Ibid., 12.
} 
soi (as that which is what it not and is not what it is) in order to realize that positivists would term the great majority of sentences in EN nonsensical. And this, in fact, is the case in Ayer's review of EN. He berates "the attempt to endow Nothing with an activity, the fruit of which is found in such statements as Heidegger's 'das Nichts nichtet' or Sartre's 'le Néant est néantisé" "15 "Whatever may be the effective value of these statements," Ayer writes, "I cannot but think that they are literally nonsensical." 16 His conclusion is: "What is called existentialist philosophy has become very largely an exercise in the art of misusing the verb "to be'." 17

How can Sartre meet such criticism? Can EN be justified as philosophy after the onslaught of positivism? In defense of Sartre one might attempt the following replies to the general positivistic criticism. First, the analysis of Being is prior to any epistemological considerations. Whereas the positivist wishes to set up criteria for verifiability of propositions, the ontologist is interested in analyzing the primal given from which all analyses ultimately derive. The epistemologist assumes the Being of his area of investigation in the sense that any attempt to define Being via logical constructs removes the investigation one step from the "originary givens" of our experience and so departs from pure Being.

Second, Sartre might claim that his "phenomenological" method offers the possibility of verifying the propositions concerning Being and Nothingness which he formulates. In some sense, this method does center about the formulation of arguments on the basis of individual and direct insights into and inspections of the given. The idea that truths regarding the given will be revealed to the phenomenologist is then a basic departure from the main line of contemporary philosophic analysis. This departure is what makes Sartre's, at least in part, a "radical" ontology. Since the positivist rules out by definition verification through "revelation," he can never hope to comprehend Sartre's method or results.

Third, the difficulty which the positivist has in understanding Sartre's work is one partially of philosophic orientation, temperament, and sympathy. Although in the course of this work we have not

\footnotetext{
${ }^{15}$ Ayer, A. J., "Novelist-philosophers, V, Jean-Paul Sartre," Horizon, July, Vol. XII, No. 67, 1945, 16.

${ }^{10}$ Ibid., 19.

${ }^{17}$ Ibid., 25.
} 
stressed the "irrational" aspect of Sartre's philosophy, it must be recalled that existential philosophy has such a quality. ${ }^{18}$ We understand the irrationalism of EN when we realize that the pour-soi is Nothingness and that, as Nothingness, it cannot support itself with the traditional categories of thought. Sartre, therefore, forsakes all theories which hold for an essence of man, and brings forth instead his categories of anguish and nihilation. Sartre's countercharge against the positivists might be that they are a part of the tradition of philosophy which clings to the rationalist categories and which holds for an essence of man-a human nature. The implicit presupposition of thinkers like Ayer is that the world is of such a nature that logical analysis may reveal its structure. But Sartre might argue that without ontological analysis such a position is unwarranted.

Fourth, the considerations stated above regarding the radical categoriology of existentialism lead to an important difference between Sartrean and positivistic analysis. The existentialist claims that he is exploring areas of human reality which are closed to positivistic approaches. It is certainly clear that, apart from the validity of Sartre's work, he has attempted to analyze the concepts of human freedom, choice, and so on. Positivists have excluded such concepts from their work for various reasons: that they are the proper object of study for different disciplines- psychology or social theory; that empirical verification of propositions concerning human freedom (in the way that Sartre deals with the problem) is impossible in principle. Sartre, however, might answer these arguments by asserting that the ontological investigation of man's "situation" cannot be the work of special disciplines, because they all begin by presupposing the very object of ontological inquiry: the Being of man. Further, existentialism is reacting against the system of traditional and fixed categories of the special sciences. Man's existential fear, dread, suffering, aloneness, and anguish are incomprehensible when viewed as psychological or psychiatric disturbances to be cured by proper clinical therapy. Similarly, the existential category of responsibility of the pour-soi is meaningless if it is understood in terms of the "responsibility" of the business executive, the civic "responsibility" of the citizen, or the religious "responsibility" of the Christian. The positivists, on the other hand, deny validity to the existential area of inquiry by fiat: they assert that

${ }^{18}$ See Introduction. 
all areas not the objects of positivistic inquiry are necessarily referred to the special sciences.

Fifth, Sartre may claim that his ontology is in the tradition of "perennial philosophy." This statement is more than an argument ad vericundum. Jaspers writes of the spirit of perennial philosophy:

"Today as at all times we must do the work of the philosophical craft: develop the categories and methods that constitute the structure of our basic knowledge, orient ourselves in the cosmos of the sciences, assimilate the history of philosophy, practice speculative thinking in metaphysics, and apply the elucidating methods of existential philosophy.

The aim of philosophy is at all times to achieve the independence of man as an individual. This he gains by establishing a relation to authentic being. He gains independence of everything that happens in the world by the depth of his attachment to transcendance. What Lao Tse found in the Tao, Socrates in the divine mission and in knowledge, Jeremiah in Yahweh who revealed himself to him, what Boethius, Bruno, Spinoza knew: that was what made them independent." 19

Perennial philosophy has as its quest what Plato called "the healing of our unwisdom." But, more precisely, the meaning of perennial philosophy centers about a rich appreciation of the great questions and answers of the history of philosophy, and is a passionate concern with the problems raised by the dominant figures of philosophic inquiry. We must be careful to state here that agreement with the core of perennial philosophy does not compel the contemporary thinker to accept any special philosophic position nor to hold that every utterance ever made by an important philosopher is in some degree true. Rather, perennial philosophy is desirous of keeping intact the dialectic of history of philosophy so that what has been gained in insight over the past centuries will not be either overlooked or purposely ignored in the rush of certain contemporary thinkers to ostracize from philosophy everything which dates earlier than the work of Frege. It is agreed that the idea of perennial philosophy is a "loose" and undemanding one, but its importance is to be observed, ironically, more in those who revolt against it with a great show of indignation than in those who accept it as a worthy guide and a meaningful directive.

${ }^{12}$ Jaspers, K., The Perennial Scope of Philosophy, 166. 
Sartre's place in perennial philosophy is assured in the sense that he raises again the great metaphysical question of Being. Thus, he is in that line of philosophizing which begins with Aristotle and contains in its ranks the names of Aquinas, Spinoza, Leibnitz, Descartes, Kant, Hegel, Husserl, and Heidegger. The "unwisdom" of many of the positivists lies in their rejecting, by ex cathedra pronouncement, this history of problems related to theory of Being, basing their action on the assertion that the problem of Being is unresolvable. The advice of perennial philosophy is that "unresolvable" problems are no less the province of philosophic study than are "resolvable" ones, and that the worth of philosophy lies as much in questions that are raised as in the solutions to those questions, as much in clarifying the "unresolvable" as in solving the resolvable. "Science and philosophy," Santayana writes, "cast a net of words into the sea of being, happy in the end if they draw anything out besides the net itself, with some holes in it."

Last, in responding with Sartre to the accusations of positivism, we must be careful to admit some of the similarities between these seemingly completely contradictory and disparate positions. The basic similarity we shall stress is one of historical genesis. Both positions are seriously concerned with the Cartesian-Husserlian problem of the proper starting point in philosophizing. Both positions are in some sense thrown back upon the cogito as the only certain point of orientation. Both positions are in approximate agreement in the usage of methodological solipsism as the key to correct philosophical procedure. Sartre might claim that from this point on the dissimilarities multiply because ontology analyzes the primordial level of the human reality and positivism goes 'forward' to the analysis of language, formal methods, and the complexus of problems associated with these. Whereas Sartre desires a phenomenological explication of the subject-pole of experience, positivism turns to an analysis of the object-pole by use of hypothetico-deductive methods. These comparisons must not be misconstrued to imply that Sartrean existentialism and modern positivism are basically alike or that they may be synthesized: such an assertion would be completely false. We have attempted only to point out, in the vast welter of obvious differences between the two positions, a basic similarity which derives from the historico-genetic aspects of both existentialism and positivism.

It must be remembered that, for the main part, the above replies to positivistic criticisms of Sartre are attempts to formulate those 
answers which Sartre himself might give to his critics. However, we are not in agreement with all of these answers and do not think that they fully exonerate Sartre's inadequacies and weaknesses. Our basic criticism throughout this work has been that Sartre's failure to make use of true Husserlain phenomenology deprives his work of the method necessary to a successful ontological investigation. We have gone so far as to assert that this methodological failure basically invalidates Sartre's ontology. We have not attempted to answer the question which has been raised by the positivists: Is ontology a valid area of philosophic inquiry?, for an answer to this question, were it to be done adequately, would require a separate study. But in order to give some indication of what our answer might be, we may once again turn to Husserl's phenomenology and may try to see what possibilities it contains intrinsically which might qualify it as the proper instrument for ontological inquiry. Let us first see what Husserl himself has contributed to the general question of the relationship between phenomenology and metaphysics.

At first glance it might appear that Husserl's phenomenology is incommensurable with metaphysics. Since Husserl's phenomenological program is to develop a method which will make philosophy a "rigorous science," it seems that the dark tangles and confusions of metaphysics would be the first things to be eliminated from this program. Husserl says:

"Profundity is the symptom of a chaos which true science must
strive to resolve into a cosmos, i.e., into a simple, unequivocal,
pellucid order. True science, insofar as it has become definable
doctrine, knows no profundity. Every science, or part of a
science, which has attained finality, is a coherent system of
reasoning operations each of which is immediately intelligible;
thus, not profound at all. Profundity is the concern of wisdom;
that of methodical theory is conceptual clarity and distinctness.
To reshape and transform the dark gropings of profundity into
unequivocal, rational propositions: that is the essential act in
methodically constituting a new science." 20

However, our problem is the interpretation of Husserl's philosophy and its internal relationships with metaphysics. The quotation just

${ }^{20}$ Husserl, E., "Philosophie als strenge Wissenschaft,"; quoted and translated in "Phenomenology and Metaphysics," by Landgrebe, Philosophy and Phenomenological Research, Vol. X, No. 2 (December, 1949), 197. 
given sets the stage for the inquiry and does not give us any sort of final answer. We must remember that phenomenological method is a propaedeutic to all disciplines and branches of philosophy, and that, therefore, it bears some distinct relationship to metaphysics. The first indication of what this relationship might be is given by Farber when he writes:

"The characteristic concepts of metaphysics, such as being, reality, object, etc., are clarified in a preliminary way by being referred back to the rudimentary level of experience from which they first derive their sense." 21

The "rudimentary level" is the level of pure consciousness divorced from the "natural attitude." It is here that the first distinction vital to comprehending the relation between phenomenology and metaphysics must be found: phenomenology is concerned with a priori grounds of Being as they may be grasped in the intuitions of the pure ego. Phenomenology is not concerned with metaphysics as the a priori analysis of Being in general; i.e., with an investigation of the structures of Being apart from their foundation in the content of consciousness as intuited elements.

"Phenomenology is anti-metaphysical only with respect to the tradition. It attempts the construction of a priori sciences on the basis of concrete intuition-such sciences as pure grammar, p'xre logic, pure law, the eidetic science of the world intutitively apprehended, etc., and the elaboration of a general ontology of the objective world which embraces everything. This is metaphysics, says Husserl, if it is true that the ultimate knowledge of being may be called metaphysics. Rejecting the traditional metaphysics because of its speculative excesses, he sets up his own 'apodictic' theory. Eidetic descriptions of constitutive experiences take the place of physical reality." 22

Thus, while metaphysics is admissible in so far as its foundations are phenomenologically grounded in the intuitions of consciousness, the traditional speculative metaphysics is rejected and "the problem of an a priori ontology of the real world, which is intended to make

21 Farber, M., "Phenomenology," op. cit., 363.

${ }^{22}$ Farber, M., The Foundation of Phenomenology, 533. 
clear its universal structure as conforming to intuitively given essential laws, is not truly philosophical in Husserl's sense." 23

Let us look more carefully into Husserl's rejection of speculative metaphysics. The "quest for Being" which characterizes traditional metaphysics is really a quest for the origin of Being. It was the contribution of Kant to show that "the origin of the whole of Being cannot be anything actually to be met with ... a as a part of the existing universe." 24 The reaction of idealism to this insight was the attempt to locate the Absolute in human subjectivity. "But the relation of the absolute, Mind, as subjectivity, to mind as human consciousness, was never fully clarified and this lack of clarity brought about the shipwreck of idealism." ${ }^{25}$ It is at this point that phenomenology takes up the problem of Being and offers a solution by redefining the idealist principle of the dependence of experience upon the subjectivity into the phenomenological principle of the dependence of the structure of experience upon the meaning-endowing acts of consciousness.

"The world, the totality of all Being, into whose 'origin' metaphysics inquires, is not a sum or collection of objects known and fixed from the outset, but that articulated into objects as it presents itself to us, it is but the result or function of the performances (Leistungen) of subjectivity, in which it constitutes itself as a world. Already Kant's 'categories,' no less than the Leibnizian idea of the vis apperceptiva of the monad, had been the first stirrings of the discovery of this functional dependence of the world on subjectivity." 26

Speculative metaphysics gives way to phenomenological metaphysics, and the abstractness of speculative thought gives way to the concreteness of phenomenological intuition. In this radical sense, "metaphysics is an answer to the question of Being, of its meaning and origin, of the origin of the universe, and the absolute Being-not by puzzling out a dimly suspected behind-the-world, beyond all possible knowledge, but by analyzing 'performances' and functions of con. sciousness." 27

${ }^{23}$ Farber, M., The Foundation of Phenomenology, 532.

${ }^{24}$ Landgrebe, op. cit., 202.

${ }^{25}$ Ibid.

s6 Ibid., 203.

${ }^{97}$ Ibid., 204. 
We are thus on the true terrain of Husserlian phenomenology, which offers to us the distinctive method for the analysis of consciousness. To pursue our problem any further would require a detailed study of phenomenology and Husserl's life-work, a task which is beyond the scope of this study. Our sole purpose in raising the question of the relationship between metaphysics and phenomenology was to show in a general way how Husserl's phenomenological method might be used in an ontological investigation. Since we brought up the problem of the relationship between metaphysics and phenomenology in regard to the positivistic attack against ontology, it is valuable to note that whatever the accomplishments and validity of the positivistic criticism of metaphysics, the positivists have not investigated the possibility of a true phenomenological ontology, and their criticisms of speculative metaphysics, therefore, have not been shown to be valid also against the Husserlian approach.

Our study of Sartre's EN leads us to conclude that the problem of Being which he investigates is a genuine philosophical problem but that his solution of this problem is fundamentally inadequate because of his failure to develop and make use of an appropriate phenomenological method. While we cannot accept Sartre's main conclusions, we must commend his efforts in raising once again vitally important philosophic issues which much of contemporary philosophy has tended to ignore or defame. Sartre's work is intimately connected with "perennial philosophy," and the questions he raises concerning man's Being, freedom, anguish, and responsibility are crucial problems which philosophy must attempt to clarify and answer. Sartre's shortcomings have thus prepared the way for an advance beyond quasi-phenomenological ontology. Whether or not this advance, making use of Husserl's method, will succeed, we leave an open question. Sartre's greatest achievement is to have returned us to the nexus of philosophic problems concerned with the ultimate isomorphism between human subjectivity and human reality. We are returned, then, to the profound core of Kant's Copernican revolution and to the question: Can phenomenological ontology complete or advance beyond the Copernican revolution? 
APPENDIX 


\section{Appendix}

All quotations from L'Etre et le Néant have been translated from the original French by the author of this work. To date, there has been no translation of L'Être et le Néant into English. All other quotations from foreign languages have been translated from the original source by the author of this work with the exception of a few instances which are clearly noted in the footnotes involved.

The following French quotations are the originals from which the main quotations in this work have been taken. Each quotation is identified by the number of the page in this work on which the translation appears, and the footnote on that page which gives the reference to the original work.

Page 14, footnote 22 (Varet, G., L'Ontologie de Sartre, 17)

"L'échec de la critique kantienne commence avec l'idée que la théorie de la connaissance peut se faire de façon indépendante, sans une ontologie."

Page 14, footnote 23 (Varet, G., L'Ontologie de Sartre, 15)

“Dans l'idée critique, toute question sur l'être appelle l'examen des conditions pour le connaître . . . Ainsi, chez Heidegger et chez Sartre, toute question philosophique a pour propriété-c'est l'essence même d'une question philosophique-de renvoyer aux possibles de cette question. Dans ce sens précis, tout existentialiste conscient, phénoménologue ou non, Sartre en particulier, est largement tributaire de la 'Révolution' Kantienne, qui est bien une des acquisitions fondamentales de la philosophie moderne: ce doit être désormais le caractère distinctif de toute philosophie que d'inclure dans sa propre problématique l'entreprise philosophique dans son ensemble, et partant le philosophie lui-même."

Page 32, footnote 10 (EN, 299)

"la vérité est vérité du Tout. Et il se place du point de la verité, c'est-à-dire du Tout pour envisager le problème de l'autre. Ainsi, lorsque le monisme hégélien considère la relation des consciences, il ne se place en aucune conscience particulière. Bien que le Tout soit à réaliser, il est déjà comme la vérité de tout ce qui est vrai; aussi, lorsque Hegel écrit que toute conscience étant identique avec 
elle-même est autre que l'autre, il s'est établi dans le tout, en dehors des consciences et les considère du point de vue de l'Absolu."

Page 33, footnote 11 (EN, 299)

"l'optimisme de Hegel aboutit à un échec: entre l'objet-autrui et moi-sujet, il n'y a aucune commune mesure, pas plus qu'entre la conscience (de) soi et la conscience de l'autre. Je ne puis pas me connaître en autrui si autrui est d'abord objet pour moi et je ne peux pas non plus saisir autrui dans son être vrai, c'est-à-dire dans sa subjectivité. Aucune connaissance universelle ne peut être tirée de la relation des consciences. C'est ce que nous appellerons leur séparation ontologique."

Page 39, footnote 51 (EN, 389-390)

"Nous avons renoncé à nous doter d'abord d'un corps pour étudier ensuite la façon dont nous saisissons ou modifions le monde à travers lui. Mais, au contraire, nous avons donné pour fondement au dévoilement du corps comme tel, notre relation originelle au monde, c'est-à-dire notre surgissement même au milieu de l'être. Loin que le corps soit pour nous premier et qu'il nous dévoile les choses, ce sont les choses-ustensiles qui, dans leur apparition originelle, nous indiquent notre corps."

Page 41, footnote 60 (EN, 413)

"ces froncements de sourcils, cette rougeur ... qui semblent ... menaçants n'expriment pas la colère, ils sont la colère. Mais il faut bien l'entendre: en soi-même un poing serré n'est rien et ne signifie rien. Mais aussi ne percevons-nous jamais un poing serré: nous percevons un homme qui, dans une certaine situation, serre le poing. Cet acte signifiant considéré en liaison avec le passé et les possibles, compris à partir de la totalité synthétique 'corps en situation,' est la colère."

Page 41, footnote 61 (EN, 418)

"Le corps pour autrui est l'objet magique par excellence. Ainsi, le corps d'autrui est-il toujours 'corps-plus-que-corps,' parce qu'autrui m'est donné sans intermediaire et totalement dans le dépassement perpétuel de sa facticité."

Page 42, footnote 62 (EN, 418-419)

"J'existe mon corps: telle est sa première dimension d'être. Mon corps est utilisé et connu par autrui: telle est sa seconde dimension. 
Mais en tant que je suis pour autrui, autrui se dévoile à moi comme le sujet pour lequel je suis objet. Il s'agit même là, nous l'avons $\mathrm{vu}$, de ma relation fondamentale avec autrui. J'existe donc pour moi comme connu par autrui-en particulier dans ma facticité même. J'existe pour moi comme connu par autrui à titre de corps. Telle est la troisième dimension ontologique de mon corps."

Page 49, footnote 9 (EN, 515)

"Être, pour le pour-soi, c'est néantiser l'en-soi qu'il est. Dans ces conditions, la liberté ne saurait être rien autre que cette néantisation. C'est par elle que le pour-soi échappe à son être comme a son essence, c'est par elle qu'il est toujours autre chose que ce qu'on peut dire de lui, car... [le pour-soi] est déjà par delà le nom qu'on lui donne, la propriété qu'on lui reconnaît. Dire que le pour-soi a à être ce qu'il est, dire qu'il est ce qu'il n'est pas en n'étant pas ce qu'il est, dire qu'en lui l'existence précède et conditionne l'essence ou ... que pour lui 'Wesen ist was gewesen ist,' c'est dire une seule et même chose, à savoir que l'homme est libre."

Page 50, footnote 14 (EN, 569)

"A désir égal d'escalade, le rocher sera aisé à gravir pour tel ascensionniste athlétique, difficile pour tel autre, novice, mal entraîné et au corps malingre. Mais le corps ne se révèle à son tour comme bien ou mal entraîné que par rapport à un choix libre. C'est parce que je suis là et que j'ai fait de moi ce que je suis que le rocher développe par rapport à mon corps un coefficient d'adversité. Pour l'avocat demeuré à la ville et qui plaide, le corps dissimulé sous sa robe d'avocat, le rocher n'est ni difficile ni aisé à gravir: il est fondu dans la totalité 'monde' sans en émerger aucunement."

Page 51, footnote 16 (EN, 577-578)

"Examinons de plus près ce paradoxe: la liberté étant choix est changement. Elle se définit par la fin qu'elle pro-jette, c'est-a-dire par le futur qu'elle a à être. Mais, précisément parce que le futur est l'état-qui n'est-pas-encore de ce qui est, il ne peut se concevoir que dans une étroite liaison à ce qui est. Et ce ne saurait être ce qui est qui éclaire ce qui n'est pas encore: car ce qui est manque et, par suite, ne peut être connu comme tel qu'à partir de ce dont il manque." 
Page 55, footnote 8 (EN, 694)

“considérerions-nous l'étude de M. Bachelard sur l'eau, qui fourmille d'aperçus ingénieux et profonds, comme un ensemble de suggestions, comme une collection précieuse de matériaux qui defraient être utilisés, à présent, par une psychanalyse consciente de ses principes."

Page 55, footnote 11 (EN, 700)

"Le visqueux est docile. Seulement, au moment même où je crois le posseder, voilà que, par un curieux renversement, c'est lui qui me possede. C'est là qu'apparaît son caractère essentiel: sa mollesse fait ventouse. L'objet que je tiens dans ma main, s'il est solide, je peux le lâcher quand il me plaît; son inertie symbolise pour moi mon entière puissance: je le fonde, mais il ne me fonde point ... voici que le visqueux renverse les termes: le Pour-soi est soudain compromis. J'écarte les mains, je veux lâcher le visqueux et il adhère à moi, il me pompe, il m'aspire; son mode d'être n'est ni l'inertie reassurante du solide, ni un dynamisme comme celui de l'eau qui s'épuise à me fuir: c'est une activité molle, baveuse et féminine d'aspiration, il vit obscurément sous mes doigts et je sense comme un vertige, il m'attire . . comme le fond d'un précipice pourrait m'attirer. Il y a comme une fascination tactile du visqueux. Je ne suis plus le maître d'arrêter le processus d'appropriation."

Page 58, footnote 2 (EN, 639)

"l'homme, étant condamné à être libre, porte le poids du monde tout entier sur ses epaules: il est responsable du monde et de luimême en tant que manière d'être . . . la responsabilité du pour-soi est accablante, puisqu'il est celui par qui il se fait qu'il $y$ ait un monde; et, puisqu'il est aussi celui qui se fait être, quelle que soit donc la situation où il se trouve, le pour-soi doit assumer entièrement cette situation . . . avec la conscience orgueilleuse d'en être l'auteur ... la situation est mienne ... parce qu'elle est l'image de mon libre choix de moi-même et tout ce qu'elle me présente est mien en ce que cela me représente et me symbolise."

Page 58, footnote 4 (EN, 579)

"Ia signification du passé est étroitement dépendante de mon projet présent. Cela ne signifie nullement que je puis faire varier au gré de mes caprices le sens de mes actes antérieurs; mais, bien au 
contraire, que le projet fondamental que je suis décide absolument de la signification que peut avoir pour moi et pour les autres, le passé que j'ai à être. Moi-seul en effet peut decider à chaque moment de la portée du passé: non pas en discutant, en délibérant et en appréciant en chaque cas l'importance de tel ou tel événement antérieur, mais en me pro-jetant vers mes buts, je sauve le passé avec moi et je décide par l'action de sa signification. Cette crise mystique de ma quinzième année, qui décidera si elle 'a été' pur accident de puberté ou au contraire premier signe d'une conversion future? Moi, selon que je deciderai-à vingt ans, à trente ans-de me convertir. Le projet de conversion confère d'un seul coup à une crise d'adolescence la valeur d'une prémonition que je n'avais pas prise au sérieux."

Page 59, footnote 9 (EN, 680-681)

"dans la mesure où je m'apparais comme créant les objets par le seul rapport d'appropriation, ces objets sont moi. Le stylo et la pipe, le vêtement, le bureau, la maison, c'est moi. La totalité de mes possessions réfléchit la totalité de mon être. Je suis ce que j'ai. C'est moi que je touche sur cette tasse, sur ce bibelot. Cette montagne que je gravis, c'est moi dans la mesure où je la vaincs; et lorsque je suis à son sommet, que j'ai 'acquis,' au prix de mêmes efforts, ce large point de vue sur la vallée et sur les cimes environnates, je suis le point de vue; le panorama, c'est moi dilaté jusqu'à l'horizon, car il n'existe que par moi, que pour moi."

Page 72, footnote 28 (EN, 28)

"C'est en vain qu'on tentera un tour de passe-passe, en fondant la réalité de l'objet sur la plénitude subjective impressionnelle et son objectivité sur le non-être: jamais l'objectif ne sortira du subjectif, ni le transcendant de l'immanence, ni l'être du non-être. Mais, dira-t-on, Husserl définit précisément la conscience comme une transcendance. En effet: c'est là ce qu'il pose; et c'est sa découverte essentielle. Mais ... il est totalement infidèle à son principe."

Page 72, footnote 29 (EN, 28)

"La conscience est conscience de quelque chose: cela signifie que la transcendance est structure constitutive de la conscience; c'està-dire que la conscience naît portée sur un être qui n'est pas elle. C'est ce que nous appelons la preuve ontologique." 
Page 72, footnote 30 (EN, 28-29)

"Dire que la conscience est conscience de quelque chose cela signifie qu'il n'y a pas d'être pour la conscience en dehors de cette obligation précise d'être intuition révélante de quelque chose, c'est-à-dire d'un être transcendant . . . Or, une intuition révélante implique un révélé. La subjectivité absolue ne peut se constituer qu'en face d'un révélé, l'immanence ne peut se definir que dans la saisie d'un transcendant."

Page 83, footnote 20 (EN, 109)

"On se met de mauvaise foi comme on s'endort et on est de mauvaise foi comme on rêve. Une fois ce mode d'être réalisé, il est aussi difficile d'en sortir que de se réveiller: c'est que la mauvaise foi est un type d'être dans le monde, comme la veille ou le rêve, qui tend par lui-même à se perpétuer."

Page 84, footnote 22 (EN, 111)

"Si la mauvaise foi est possible, c'est qu'elle est la menace immédiate et permanente de tout projet de l'être humain, c'est que la conscience recèle en son être un risque permanent de mauvaise foi. Et l'origine de ce risque, c'est que la conscience, à la fois et dans son être, est ce qu'elle n'est pas et n'est pas ce qu'elle est."

Pages 87-88, footnote 24 (EN, 711-712)

"le Pour-soi et l'En-soi sont réunis par une liaison synthétique qui n'est autre que le Pour-soi lui-même. Le Pour-soi, en effet, n'est pas autre chose que la pure néantisation de l'En-soi; il est comme un trou d'être au sein de l'Etre ... Le Pour-soi n'a d'autre réalité que d'être la néantisation de l'être. Sa seule qualification lui vient de ce qu'il est néantisation de l'En-soi individuel et singulier et non d'un être en général. Le Pour-soi n'cest pas le néant en général mais une privation singulière; il se constitue en privation de cet être-ci."

Page 88, footnote 25 (EN, 712)

"Nous n'avons donc pas lieu de nous interroger sur la manière dont le pour-soi peut s'unir à l'en-soi puisque le pour-soi n'est aucunement une substance autonome."

Pages 88-89, footnote 26 (EN, 715-716)

"I'en-soi et le pour-soi ne sont pas juxtaposés. Bien au contraire, le pour-soi sans l'en-soi est quelque chose comme un abstrait: il ne 
saurait pas plus exister qu'une couleur sans forme ou qu'un son sans hauteur et sans timbre; une conscience qui ne serait conscience de rien serait un rien absolu."

Page 89, footnote 27 (EN, 716)

"si la conscience est liée à l'en-soi par une relation interne, cela ne signifie-t-il pas qu'elle s'articule avec lui pour constituer une totalité et n'est-ce pas à cette totalité que revient la dénomination d'être ou de réalité? Sans doute, le pour-soi est néantisation, mais, à titre de néantisation, il est; et il est en unité a priori avec l'ensoi."

Page 89, footnote 28 (EN, 716)

"si nous devions considérer l'être total comme constitué par l'organisation synthétique de l'en-soi et du pour-soi, n'allons-nous pas retrouver la difficulté que nous voulions éviter? Ce hiatus que nous décelions dans le concept d'être, n'allons-nous pas le rencontrer à présent dans l'existant lui-même?"

Page 90, footnote 31 (EN, 716-717)

"Si nous voulions concevoir une organisation synthétique telle que le pour-soi soit inséparable de l'en-soi et que, réciproquement, l'en-soi soit indissolublement liée au pour-soi, il faudrait la concevoir de telle sorte que l'en-soi reçoive son existence de la néantisation qui en fait prendre conscience. Qu'est-ce à dire sinon que la totalité indissoluble d'en-soi et de pour-soi n'est concevable que sous la forme de l'être 'cause de soi.' "

Page 90, footnote 32 (EN, 717)

"le réel est un effort avorté pour atteindre à la dignité de cause-desoi. Tout se passe comme si le monde, l'homme et l'homme-dansle-monde n'arrivaient à réaliser qu'un Dieu manqué. Tout se passe donc comme si l'en-soi et le pour-soi se presentaient en état de désintégration par rapport à une synthèse idéale. Non que l'intégration ait jamais $e u$ lieu, mais précisément au contraire parce qu'elle est toujours indiquée et toujours impossible. C'est le perpétuel échec qui explique à la fois l'indissolubilité de l'en-soi et du pour-soi et leur relative indépendance."

Page 96, footnote 5 (EN, 680-681)

"La totalité de mes possessions réfléchit la totalité de mon être. Je suis ce que jai. C'est moi que je touche sur cette tasse, sur ce 
bibelot. Cette montagne que je gravis, $c^{\prime} e s t$ moi dans la mesure où je la vaincs; et lorsque je suis à son sommet, que j'ai 'acquis,' au prix de mêmes efforts, ce large point de vue sur la vallée et sur les cimes environnantes, je suis le point de vue; le panorama, c'est moi dilaté jusqu'à l'horizon, car il n'existe que par moi, que pour moi."

Pages 96-97, footnote 6 (EN, 681)

"La possession est un rapport magique; je suis ces objets que je possède, mais dehors, face à moi; je les crée comme indépendants de moi; ce que je possède, c'est moi hors de moi, hors de toute subjectivité, comme un en-soi qui m'échappe à chaque instant et dont je perpétue à chaque instant la création."

Page 104, footnote 6 (EN, 152-153)

"Husserl a été, tout au long de sa carrière philosophique, hanté par l'idée de la transcendance et du dépassement. Mais les instruments philosophiques dont il disposait, en particulier sa conception idéaliste de l'existence, lui ôtaient les moyens de rendre compte de cette transcendance: son intentionnalité n'en est que la caricature. La conscience husserlienne ne peut en réalité se transcender ni vers le monde, ni vers l'avenir, ni vers le passé." 


\section{BIBLIOGRAPHY}




\section{Bibliography}

\section{PRIMARY SOURCES}

A. Jean-Paul Sartre: Philosophical Works (in chronological order)

"Légende de la vérité," Bifur, 8 jun., 1931.

"La transcendance de l'ego, esquisse d'une description phénoménolgique," Recherches Philosophiques, 6: 1936-1937.

L'imagination, Paris, 1936.

"La structure intentionelle de l'image," Revue de Métaphysique et de Morale, 45: 4, Oct., 1938.

"Une idée fondamentale de la 'Phénoménoligie' de Husserl," Nouvelle Revue

Française, 52: 304, Jan., 1939.

Esquisse d'une theorie des émotions, Paris, 1939. (English translation: The Emotions, Outline of a Theory, N. Y., 1948).

"M. Jean Giraudoux et la philosophie d'Aristote. A propos de 'Choix des élues'," Nouvelle Revue Française, 54: 318, March, 1940.

L'imaginaire, psychologie phénoménologique de l'imagination, Paris, 1940.

(English translation: The Psychology of Imagination, N. Y., 1948).

L'Etre et le Néant, essai d'ontologie phénoménologique, Paris, 1943.

"Materialisme et révolution," Les Temps Modernes, 1:9 June, 1946.

Descartes, (Introduction to Descartes' Work, ed. by Sartre), Paris, 1946.

$L^{\prime}$ existentialisme est un humanisme, Paris, 1946.

(English translation: Existentialism, N.Y., 1947).

Réflexions sur la question juive, Paris, 1946.

(English translation: Anti-Semite and Jew, N. Y., 1948) .

Baudelaire, precédeé d'une note de Michel Leiris, Paris, 1947.

(English translation: Baudelaire, London, 1949).

Situations I, Paris, 1947.

Situations II, Paris, 1948.

(“Qu'est-ce que la litterature?," a part of Situations II, has been translated into English as What is Literature?, N. Y., 1949) .

Situation III, Paris, 1949.

B. Jean-Paul Sartre: Novels and Plays (in chronological order)

La nausée, Paris, 1938.

(English translation: Nausea, N. Y., 1949. "The Root of the Chestnut Tree," a chapter of La nausée, was especially translated for publication in Partisan Review, Winter, 1946).

Le mur, Paris, 1939.

(English translation: The Wall and other stories, N. Y., 1948).

Les mouches, Paris, 1943.

(English translation: The flies (together with No exit (Huis clos)), N. Y., 1947. 
Huis clos, piece en un acte, Paris, 1945.

(English translation given above).

Les Chemins de la liberté. I L'age de raison, Paris, 1945.

("Les Chemin de la liberté" is the title for a projected teralogy of which three volumes have been published in France) (English translation: The roads to freedom. I The age of reason, N.Y., 1947)

Les Chemins de la liberté. II Le sursis, Paris, 1945.

(English translation: The Reprieve, N. Y., 1947).

Theatre I, Paris, 1947.

(Contains Sartre's first four plays: Les Mouches, Huis clos, Morts sans sépulture, La Putain respecteuse). (English translations of last two plays appear in Three Plays, N. Y., 1949).

Les jeux sont faits, Paris, 1947.

(English translation: The Chips are Down, N.Y., 1948).

Les mains sales, Paris, 1948.

(English translation: Dirty Hands, in Three Plays, op. cit.).

Les Chemins de la Liberté. III La mort dans l'âme, Paris, 1949.

(English translation: Troubled Sleep, N. Y., 1951).

Les Chemins de la Liberté. IV La dernière chance (in preparation).

\section{BIBLIOGRAPHIES ON SARTRE}

Douglas, Kenneth, A Critical Bibliography of Existentialism (The Paris School), Yale French Studies Special Monograph No. I, New Haven, Connecticut, 1950. Included in this bibliography is a complete listing of all of Sartre's writings, from his unpublished juvenalia to his latest interview with the press. In addition to the complete listing of all books, articles, reviews, interviews, broadcasts, etc., there is a thorough account of all books and articles which have criticized all aspects of Sartre's thought, philosophic and non-philosophic. This work represents, then, a complete bibliography of Sartre's writings and of the criticisms of Sartre's writings.

Jolivet, Régis, Französische Existenzphilosophie, Bern, 1948.

Yanitelli, Victor R., "A Bibliographical Introduction to Existentialism," The Modern Schoolman, Vol. XXVI, No. 4, May, 1949.

"Bibliographie," Revue Internationale de Philosophie, Troisième année, Juillet, 1939.

\section{SECONDARY SOURCES}

A. Books

Audry, Collette (ed.), Pour et Contre L'existentialisme: grand débat avec J. B. Pontalis, J. Pouillon, F. Jeanson, Julien Benda, Emm. Mounier, R. Vailland. Un texte de Jean-Paul Sartre, Paris, 1948.

Barrett, William, What is Existentialism?, N. Y., 1947.

Beigbeder, Marc, L'homme Sartre: Essai de devoilement préexistentiel, Bordas, 1947.

Benda, Julien, Tradition de L'existentialisme, Paris, 1947. 
Bobbio, Norberto, The Philosophy of Decadentism: A Study in Existentialism, Oxford, 1948.

Boutang, Pierre, and Pingaud, Bernard, Sartre, est-il un possedé?, Paris, 1946.

Campbell, Robert, Jean-Paul Sartre: ou une Littérature Philosophique, Paris, 1945.

Farber, Marvin, (ed.), Philosophic Thought in France and the United States, Buffalo, N. Y., 1950.

Farber, Marvin, The Foundation of Phenomenology, Cambridge, Mass., 1943.

Foulquié, Paul, Existentialism, London, 1948.

Grene, Marjorie, Dreadful Freedom, Chicago, 1948.

Harper, Ralph, Existentialism: A Theory of Man, Cambridge, Mass., 1948.

Hessen, G., Existenzphilosophie, Basel, 1948.

Hoffman, Kurt, Existential Philosophy: A Study of its Past and Present Forms, Harvard University Ph.D. dissertation, March, 1949.

Husserl, Edmund, Ideas: General Introduction to Pure Phenomenology, London, 1931.

Husserl, Edmund, Logische Untersuchungen, 2 vols., 4th ed., Halle, 1928.

Husserl, Edmund, Méditations Cartésiennes, Paris, 1947.

Jeanson, F., Le Problème moral et la Pensée de Sartre, (Introduction by Sartre), Paris, 1946.

Jolivet, R., Les Doctrines existentialistes, de Kierkegaard a J.-P. Sartre, Paris, 1948.

Kuhn, Helmut, Encounter With Nothingness, An Essay on Existentialism, Hinsdale, Illinois, 1949.

Lefebvre, Henri, L'existentialisme, Paris, 1946.

Lukacs, Georges, Existentialisme ou Marxisme?, Paris, 1948.

Mounier, Emmanuel, Existentialist Philosophies, An Introduction, London, 1948.

Ruggiero, Guido de, Existentialism: Disintegration of Man's Soul, N. Y., 1948. Troisfontaines, Roger, Le Choix de J.-P. Sartre, exposé et critique de l'être et le néant, Paris, 1945.

Truc, Gonzague, De J.-P. Sartre à L. Lavella ou Desagregation et Reintegration, Paris, 1946.

Varet, Gilbert, L'Ontologie de Sartre, Paris, 1948.

Wahl, Jean, $A$ Short History of Existentialism, N. Y., 1949.

B. Articles

Alquié, F., "L'Être et le Néant, par J.-P. Sartre," Cahiers du sud, No. 273-274, 1945.

Arendt, Hannah, "What is Existenz Philosophy?," Partisan Review, Winter, 1946.

Ayer, A. J., "Novelist-Philosophers V, Jean-Paul Sartre," Horizon, Vol. XII, Nos. 67-68, July-August, 1945. 
Beck, Maximillian, "Existentialism versus Naturalism and Idealism," The South Atlantic Quarterly, April, 1948, Vol. 47, No. 2.

Blondel, Maurice, "The Inconsistency of Jean-Paul Sartre's Logic," The Thomist, X, 1947.

Boorsch, Jean, "Sartre's View of Cartesian Liberty," Yale French Studies, Vol. 1, No. 1, Spring-Summer, 1948.

Campbell, Robert, "Existentialism in France since the Liberation," Philosophic Thought in France and the United States, (ed. by Marvin Farber), Buffalo, N. Y., 1950.

Castelli, Enrico, "L'existentialisme: philosophie de la crise," Revue Internationale de Philosophie, Troisième année, No. 9, Juillet, 1949.

Chenu, J., "J.-P. Sartre et L'existentialisme," Le Monde Français, 1946.

Cohn, Robert G., "Sartre's First Novel: La nausée," Yale French Studies, Vol. 1, No. 1, Spring-Summer, 1948.

Collins, James, "The Existentialism of Jean-Paul Sartre," Thought, Vol. XXIII, No. 88, March, 1948.

Cuenot, Claude, "Litterature et philosophie chez J.-P. Sartre," Renaissances, 1946, No. 21.

Descoqs, P., "L'atheisme de J.-P. Sartre," Revue Philosophique, 1946.

De Waelhens, Alphonse, "Heidegger et Sartre," Deucalion, 1946.

De Waelhens, Alphonse, "J.-P. Sartre, L'être et le néant," Erasmus, 1: 9-10, May, 1947.

De Waelhens, Alphonse, "Les constantes de l'existentialisme," Revue Internationale de Philosophie, Troisième année, No. 9, Juillet, 1949.

De Waelhens, Alphonse, "L'existentialisme de Sartre est-il un humanisme?" Revue Philosophique de Louvain, 44, 1946.

Doublas, K. N., “The Nature of Sartre's Existentialism," The Virginia Quarterly Review, April, 1947.

Fabre, Lucien, "Essentialisme et existentialisme. Le Néant de M. Sartre," Revue de Paris, 54:4, April, 1947.

Farber, Marvin, "Phenomenlogy," Twentieth Century Philosophy (edited by Dagobert D. Runes), N.Y., 1943.

Fowlie, Wallace, "Existentialist Hero: a Study of L'Age de Raison," Yale French Studies, Vol. 1, No. 1, Spring-Summer, 1948.

Geiger, Moritz, "An Introduction to Existential Philosophy" (edited by Herbert Spiegelberg), Philosophy and Phenomenological Research, Vol. III, No. 3, March, 1943.

Godet, Pierre, "Note sur L'être et le néant, de J.-P. Sartre," Jahrbuch des Schweizerischen Philosophischen Gesellschaft, V, 1945.

Grene, Marjorie, "Sartre's Theory of the Emotions," Yale French Studies, Vol. 1, No. 1, Spring-Summer, 1948.

Heinemann, F. H., "What is Alive and What is Dead in Existentialism?," Revue Internationale de Philosophie, Troisième année, No. 9, Juillet, 1949. 
Hering, Jean, "Phenomenology in France," Philosophic Thought in France and the United States (edited by Marvin Farber), Buffalo, N. X., 1950.

Husserl, Edmund, "Phenomenology," Encyclopaedia Britannica, 1927, 14th edition, Vol. XVII.

Jeanson, Francis, "L'existentialisme: Philosophie du sujet humain," Pour et Contre L'Existentialisme, Paris, 1948.

Landgrebe, Ludwig, "Phenomenology and Metaphysics," Philosophy and Phenomenological Research, Vol. X, No. 2, December, 1949.

Leavitt, Walter, "Sartre's Theatre," Yale French Studies, Vol. 1, No. 1, SpringSummer, 1948.

Lukacs, Georg, "Existentialism," Philosophy for the Future (edited by Sellars, McGill, and Farber), N. Y., 1949.

McGill, V. J., "Sartre's Doctrine of Freedom," Revue Internationale de Philosophie, Troisième année, No. 9, Juillet, 1949.

Magny, C.-E., "Sartre ou la duplicité de l'être, Ascese et mythomanie," Les scandales d'Empédocle, Neuchâtel, 1945.

Magny, C.-E., "Système de Sartre," Esprit, 13:4, March, 1945.

Marcuse, Herbert, "Existentialism: Remarks on Jean-Paul Sartre's L'Etre et le Néant," Philosophy and Phenomenological Research, Vol. VIII, No. 3, March, 1948.

Merleau-Ponty, Maurice, "Jean-Paul Sartre ou un Auteur scandaleux," Figaro littéraire, 3. Jan., 1948.

Peyre, Henri, "Existentialism-A Literature of Despair?," Yale French Studies, Vol. 1, No. 1, Spring-Summer, 1948.

Picard, Gabiel, "L'Existentialisme de Jean-Paul Sartre," Melanges de science religieuse, III, 1946.

Polin, Raymond, "Introduction à la philosophie de J.-P. Sartre," Revue de Paris, LIII, 1946.

Rau, Katherine, "The Ethical Theory of Jean-Paul Sartre," The Journal of Philosophy, Vol. XLVI, No. 17, August 18, 1949.

Schuetz, Alfred, "Sartre's Theory of the Alter Ego," Philosophy and Phenomenological Research, Vol. 9, No. 2, December, 1948.

Wahl, Jean, "Essai sur le Néant d'un Problème," Deucalion, 1946.

Wahl, Jean, "La liberté chez Sartre," Deucalion, I, 1946.

Wahl, Jean, "The Present Situation and the Present Future of French Philosophy," Philosophic Thought in France and the United States (edited by Marvin Farber), Buffalo, N. Y., 1950.

\section{RELATED WORKS}

A. Bibliographies and Works Containing Bibliographies

\section{Martin Heidegger}

"Bibliographie," Revue Internationale de Philosophie, Troisième année, Juillet, 1949. 
De Waelhens, A., La Philosophie de Martin Heidegger, Louvain, 1942.

Hoffman, Kurt, Existential Philosophy: A Study of its Past and Present Forms, Harvard University Ph.D. dissertation, March, 1949.

Yanetelli, Victor R., "A Bibliographical Introduction to Existentialism," The

Modern Schoolman, Vol. XXVI, No. 4, May, 1949.

\section{Edmund Husserl}

Welch, E. Parl, The Philsosophy of Edmund Husserl, N. Y., 1941.

\section{Karl Jaspers}

"Bibliographie," Revue Internationale de Philosophie, Troisième année, Juillet, 1949.

Hoffman, Kurt, Existential Philosophy: A Study of its Past and Present Forms, Harvard University Ph.D. dissertation, March 1949.

Yanetelli, Victor R., "A Bibliographical Introduction to Existentialism," The Modern Schoolman, Vol. XXVI, No. 4, May, 1949.

\section{Sфren Kierkegaard}

Jolivet, Régis, Kierkegaard, Bibliographische Einführungen in das Studium der Philosophie, Bern, 1948.

Mesnard, Pierre, Le Vrai Visage de Kierkegaard, Bibliotheque des Archives de Philosophie, Paris, 1948.

Yanetelli, Victor R., "A Bibliographical Introduction to Existentialism," The Modern Schoolman, Vol. XXVI, No. 4, May, 1949.

\section{Gabriel Marcel}

“Bibliographie," Revue Internationale de Philosophie, Troisième année, Juillet, 1949.

Jolivet, Régis, Franzöische Existenzphilosophie, Bern, 1948.

Yanetelli, Victor R., "A Bibliographical Introduction to Existentialism," The Modern Schoolman, Vol. XXVI, no. 4, May, 1949.

Lesser Known Existentialists: Georges Bataille, Nicolas Berdiaeff, Albert Camus, Simone de Beauvoir, and Maurice Merleau-Ponty.

Douglas, Kenneth, A Critical Bibliography of Existentialism (The Paris School), Yale French Studies Special Monograph No. 1, New Haven, Connecticut, 1950.

Jolivet, Régis, Französische Existenzphilosophie, Bern, 1948.

\section{Italian Existentialism}

"Bibliographie," Revue Internationale de Philosophie, Troisième année, Juillet, 1949.

L'Archivio di Filosofia, (Organo del R. Istituto di Studi Filosofici), Roma, anno B. Books XV, vol. I e II, 1946.

Ayer, A. J., Language, Truth and Logic, London, 1949.

Berdiaeff, Nicolas, Cinq Méditations sur L'Existence, Paris, 1936. 
Bocheński, I. M., Europäische Philosophie der Gegenwart, Bern, 1947.

Brock, Werner, An Introduction to Contemporary German Philosophy, Cam. bridge, England, 1935.

Brunner, Auguste, La Personne Incarnée: étude sur la phénoménologie et la philsophie existentialiste, Paris, 1947.

Buber, Martin, Between Man and Man, N. Y., 1948.

Camus, Albert, The Plague, N.Y., 1948.

de Beauvoir, Simone, L'Existentialisme et la Sagesse des Nations, Paris, 1948.

de Beauvoir, Simone, The Ethics of Ambiguity, N. Y., 1948.

De Waelhens, A., La Philosophie de Martin Heidegger, Louvain, 1942.

Dufrenne, Mikel and Ricoeur, Paul, Karl Jaspers et la Philosophie de l'existence, Paris, 1947.

Farber, Marvin (ed.), Philosophical Essays in Memory of Edmund Husserl, Cambridge, Mass., 1940.

Gurvitch, Georges, Les Tendances Actuelles de la Philosophie Allemande, Paris, 1949.

Hegel, G. W. F., The Phenomenlogy of Mind, London, 1931.

Heidegger, Martin, De L'Essence de la Verité, Paris, 1948.

Heidegger, Martin, Existence and Being, London, 1949.

Heidegger, Martin, Sein und Zeit, Halle, 1927.

Jaspers, Karl, The Perennial Scope of Philosophy, N. Y., 1949.

Kafka, Franz, The Trial, N. Y., 1945.

Kierkegaard, Søren, Fear and Trembling, Princeton, 1941.

Laird, John, Recent Philosophy, London, 1945.

Levinas, Emmanuel, Le Choix, le Monde, L'Existence, Paris, 1948.

Levinas, Emmanuel, De L'existence à l'existant, Paris, 1947.

Levinas, Emmanuel, En découvrant l'existence avec Husserl et Heidegger, Paris, 1949.

Marcel, Gabriel, Being and Having, Westminster, England, 1949.

Marcel, Gabriel, Homo Viator, Aubier, Editions Montaigne, 1944.

Marcel, Gabriel, The Philosophy of Existence, N. Y., 1949.

Maritain, Jacques, Existence and the Existant, N. Y., 1948.

Pap, Arthur, Elements of Analytic Philosophy, N. Y., 1949.

Pascal, Blaise, Pensées, N. Y., 1941.

Tonquedec, Joseph de, L'Existence d'après Karl Jaspers, Paris, 1945.

Unamuno, Miguel, Perplexities and Paradoxes, N. Y., 1945.

Van Molle, Germaine, La Connaissance dialectique et l'Experience existentielle,

Bibliotheque Scientifique Belge, Georges Thone (ed.), Liege, (no date).

Villaseñor, José Sánchez, Ortega y Gasset, Existentialist, Hinsdale, Illinois, 1949.

Wahl, Jean, Existence Humaine et Transcendance, Éditions de la Baconnière, Neuchatel, 1944.

Wahl, Jean, Etudes Kierkegardiennes, Paris, 1938. 
Welch, E. Parl, The Philosophy of Edmund Husserl: The Origin and Development of His Phenomenlogy, N. Y., 1941.

C. Articles

Abbagnano, Nicola, "Outline of a Philosophy of Existence," Philosophy and Phenomenological Research, Vol. IX, No. 2, December, 1949.

Berger, Gaston, "Experience and Transcendance," Philosophic Thought in France and the United States (edited by Marvin Farber), Buffalo, N. Y., 1950.

Blackham, H. J., "Karl Jaspers' Philosophy of Existence," The Plain View, No. 3, Vol. IV, Winter, 1949.

Blanchard, P., "L'existentialisme athée et la Morale," Chronique sociale de France, 1946.

Bollnow, O. Fr., "Deutsche Existenzphilosophie und französischer Existentialismus," Zeitschrift f. phil. Forschung, 2, 1948.

Brock, Werner, "An Account of 'Being and Time'" in Existence and Being by Martin Heidegger, London, 1949.

Brown, J. L., "Chief Prophet of the Existentialists," The New York Times Magazine, Feb. 2, 1947.

Bruneau, Jean, "Existentialism and the American Novel," Yale French Studies, Vol. 1, No. 1, Spring-Summer, 1948.

Brunner, A., "Zur Freiheit verurteilt," Stimmen der Zeit, Vol. 140, 1947.

Cassirer, Ernst, "Kant und das Problem der Metaphysik," Kantstudien, 1931.

Copleston, Frederick, "Existentialism and Religion," The Dublin Review, Spring, 1947.

Copleston, Frederick, "The Philosophy of the Absurd," The Month, CLXXXIV, 1947.

Copleston, Frederick, "What is Existentialism?," The Month, CLXXXIII, 1947.

Cornu, Auguste, "Bergsonianism and Existentialism," Philosophic Thought in France and the United States (edited by Marvin Farber), Buffalo, N. Y., 1950.

De Corte, M., "Réflexions sur G. Marcel et J.-P. Sartre," Revue Philosophique, 1946.

Dieckmann, Herbert, "French Existentialism before Sartre," Yale French Studies, Vol. 1, No. 1, Spring-Summer, 1948.

Dumery, Henry, "Catholic Philosophy in France," Philosophic Thought in France and the United States (edited by Marvin Farber), Buffalo, N.Y., 1950.

Farber, Marvin, "Descriptive Philosophy and the Nature of Human Existence," Philosophic Thought in France and the United States (edited by Marvin Farber), Buffalo, N. Y., 1950.

Farber, Marvin, "Experience and Subjectivism," Philosophy for the Future (edited by Sellars, McGill, and Farber), N. Y., 1949.

Farber, Marvin, "Professor Reulet on 'Being, Value, and Existence'," Philosophy and Phenomenlogical Research, Vol. X, No. 1, September, 1949.

Gascoyne, David, "Leon Chestov," Horizon, Vol. XX, No. 118, October, 1949. 
Gérard, Jacques, "Existence et position," Revue Internationale de Philosophie, Troisième année, No. 9, Juillet, 1949.

Glicksman, Marjorie, "A Note on the Philosophy of Heidegger," The Journal of Philosophy, Vol. XXXV, No. 4, February 17, 1938.

Hartmann, Nicolai, "German Philosophy in the last Ten Years," Mind, Vol. LVIII, No. 232.

Havet, Jacques, "French Philosophical Tradition Between the Two Wars," Philosophic Thought in France and the United States (edited by Marvin Farber), Buffalo, N. Y., 1950.

Hill, E. F. F., "The Philosophy of Martin Heidegger," World Review, November, 1949.

Kaufman, Fritz, "Cassirer, Neo-Kantianism, and Phenomenology," The Philosophy of Ernst Cassirer (edited by Paul Arthur Schilpp), Evanston, Illinois, 1949.

Kecskemeti, Paul, "Existentialism: a new trend in philosophy," New Directions 10, N. Y., 1948.

Lavelle, Louis, "The Three Stages of Metaphysics," Philosophic Thought in France and the United States (edited by Marvin Farber), Buffalo, N.Y., 1950.

Lefebvre, Henri, "Knowledge and Social Criticism," Philosophic Thought in France and the United States (edited by Marvin Farber), Buffalo, N. Y., 1950.

Le Senne, René, "La Philosophie de L'Esprit," Philosophic Thought in France and the United States (edited by Marvin Farber), Buffalo, N. Y., 1950.

Magny, C.-E., "Les Chemins de la liberté," Poesie 45, 1945.

McKeon, Richard, "An American Reaction to the Present Situation in French Philosophy," Philosophic Thought in France and the United States (edited by Marvin Farber), Buffalo, N. Y., 1950.

Mehl, Roger, "The Situation of Religious Philosophy in France," Philosophic Thought in France and the United States (edited by Marvin Farber), Buffalo, N. Y., 1950.

Nadler, K., "Die französische Existenzphilosophie der Gegenwart," Die Tatwelt, Sept., 1936.

Natanson, Maurice, "H. B. Alexander's Projection of a Categoriology," Philosophy and Phenomenological Research, Vol. X, No. 2, December, 1949.

Natanson, Maurice, “The Prison of Being," Prairie Schooner, Fall, 1949.

Patrie, A., "Sur une nouvelle doctrine de la liberté," Deucalion, I, 1946.

Pessis, B., "In the Cesspool of Existentialism," Soviet Literature, Moscow, 1949.

Petrement, Simone, "La Liberté selon Descartes et selon Sartre," Critique, I, 1946.

Peyre, Henri, "Literature and Philosophy in Contemporary France," Ideological Differences and World Order (edited by F. S. C. Northrop), New Haven, Conn., 1949.

Polin, Raymond, "The Philosophy of Values in France," Philosophic Thought in France and the United States (edited by Marvin Farber), Buffalo, N. Y., 1950. 
Pos, H. J., "L'existentialisme dans la perspective de l'historie," Revue Internationale de Philosophie, Troisième année, No. 9, Juillet, 1949.

Reulet, Aníbal Sánchez, "Being, Value, and Existence," Philosophy and Phenomenological Research, Vol. IX, No. 3, March, 1949.

Reulet, Aníbal Sánchez, "Reply to Marvin Farber," Philosophy and Phenomenological Research, Vol. X, No. I, September, 1949.

Ritchie, A. M., "Language, Logic, and Existentialism," Philosophy and Phenomenological Research, Vol. X, No. 3, March, 1950.

Robert, J. D., "La Vie de L'Existentialisme en France," Tijdschrift voor Philosophie, IX, 1947.

Segond, J., "Réflexions critique sur L'existentialisme et le monde des valeurs," Revue Internationale de Philosophie, Troisième année, No. 9, Juillet, 1949.

Slochower, Harry, "The Function of Myth in Existentialism," Yale French Studies, Vol. 1, No. 1, Spring-Summer, 1948.

Smith, Vincent Edward, "Philosopher of the Absurd," The Shield, XXVI, 1946.

Vial, Fernand, "Existentialism and Humanism," Thought, XXIII, 1948.

Wahl, Jean, "Freedom and Existence in Some Recent Philosophies," Philosophy and Phenomenological Research, Vol. VIII, No. 4, June, 1948.

Waters, Bruce, "Existentialism in Contemporary Literature," Prairie Schooner, Spring, 1950.

Weiss, Paul, "Existenz and Hegel," Philosophy and Phenomenological Research, Vol. VIII, No. 2, December, 1947.

Werkmeister, W. H., "An Introduction to Heidegger's Existential Philosophy," Philosophy and Phenomenological Research, Vol. II, No. 1, September, 1941. 